. CEIVED

JABI 791997

\section{OSTI}

\section{Multidimensional Computational Fluid Dynamics Modeling of the Dispersion of White Oak Creek Contaminants in the Clinch River}

J.H. Platfoot
M.W. Wendel
P.T. Williams

NSTFIPTIIS OF THS DOSUMAENT IS UNLMMTED

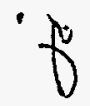

MANAGED AND OPERATED BY

LOCKHEED MARTIN ENERGY RESEARCH CORPORATION FOR THE UNTED STATES

DEPARTHENT OF ENERGY

ORNL-27 (3-96) 
This report has been reproduced directly from the best available copy.

Available to DOE and DOE contractors from the Office of Scientific and Technical Information, P. O. Box 62, Oak Ridge, TN 37831; prices available from (423) 576-8401, FTS 626-8401.

Available to the public from the National Technical Information Service, U.S. Department of Commerce, 5285 Port Royal Road, Springfield. VA 22161.

This report was prepared as an account of work sponsored by an agency of the United States Government. Neither the United States Government nor any agency thereof, nor any of their employees, makes any warranty, express or implied, or assumes any legal liability or responsibility for the accuracy, completeness, or usefulness of any information, apparatus, product, or process disclosed, or represents that its use would not infringe privately owned righis. Reference herein to any specific commercial product, process, or service by trade name, trademark, manufacturer, or otherwise, does not necessarily constitute or imply its endorsement, recommendation, or favoring by the United States Government or any agency thereof. The views and opinions of authors expressed herein do not necessarily state or reflect those of the United States Government of any agenicy thereof. 


\title{
MULTIDIMENSIONAL COMPUTATIONAL FLUD DYNAMICS MODELING OF THE DISPERSION OF WHITE OAK CREEK CONTAMINANTS IN THE CLINCH RIVER
}

\author{
M. W. Wendel \\ P. T. Williams \\ Computational Engineering and Physics Division \\ J. H. Platfoot \\ Ėngineering Division \\ October 1996

Prepared by the

OAK RIDGE NATIONAL LABORATORY

Oak Ridge, Tennessee 37831

managed by

LOCKHEED MARTIN ENERGY RESEARCH CORP.

for the

U.S. DEPARTMENT OF ENERGY

under contract DE-AC05-96OR22464 
and 


\section{DISCLAMMER}

Portions of this document may be illegible in electronic image products. Images are produced from the best available original document. 


\section{CONTENTS}

Page

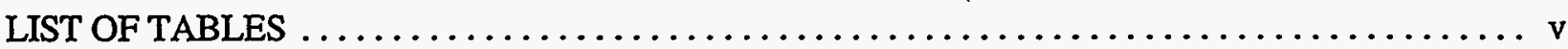

LIST OF FIGURES $\ldots \ldots \ldots \ldots \ldots \ldots \ldots \ldots \ldots \ldots \ldots \ldots \ldots \ldots \ldots \ldots \ldots \ldots \ldots \ldots \ldots \ldots \ldots \ldots$

ACRONYMS $\ldots \ldots \ldots \ldots \ldots \ldots \ldots \ldots \ldots \ldots \ldots \ldots \ldots \ldots \ldots \ldots \ldots \ldots \ldots \ldots \ldots \ldots \ldots \ldots \ldots \ldots \ldots$

NOMENCLATURE $\ldots \ldots \ldots \ldots \ldots \ldots \ldots \ldots \ldots \ldots \ldots \ldots \ldots \ldots \ldots \ldots \ldots \ldots \ldots \ldots \ldots$

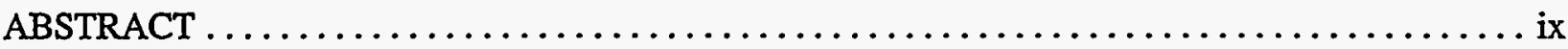

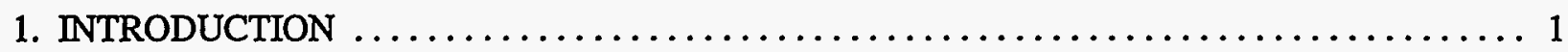

2. HYDRODYNAMIC MODELING OF RIVERS $\ldots \ldots \ldots \ldots \ldots \ldots \ldots \ldots \ldots \ldots \ldots \ldots \ldots$

2.1 CONSERVATION LAW SYSTEM $\ldots \ldots \ldots \ldots \ldots \ldots \ldots \ldots \ldots \ldots \ldots \ldots \ldots \ldots \ldots \ldots$

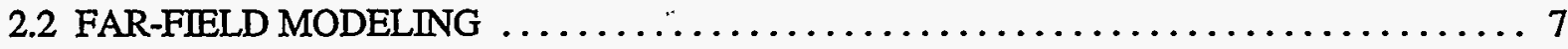

2.3 NEAR-FIELD MODELING $\ldots \ldots \ldots \ldots \ldots \ldots \ldots \ldots \ldots \ldots \ldots \ldots \ldots \ldots \ldots$

2.4 TURBULENCE MODELS AVAILABLE IN CFDS-FLOW3D $\ldots \ldots \ldots \ldots \ldots \ldots \ldots \ldots$

2.5 PREVIOUS CLINCH RIVER HYDRODYNAMIC MODELING $\ldots \ldots \ldots \ldots \ldots \ldots \ldots \ldots 10$

2.6 CLINCH RIVER MEASURED DATA $\ldots \ldots \ldots \ldots \ldots \ldots \ldots \ldots \ldots \ldots \ldots \ldots \ldots \ldots \ldots$

3. MULTIDIMENSIONAL CFD REPRESENTATION $\ldots \ldots \ldots \ldots \ldots \ldots \ldots \ldots \ldots \ldots \ldots$

3.1 TWO-DIMENSIONAL REPRESENTATION $\ldots \ldots \ldots \ldots \ldots \ldots \ldots \ldots \ldots \ldots \ldots \ldots \ldots \ldots \ldots$

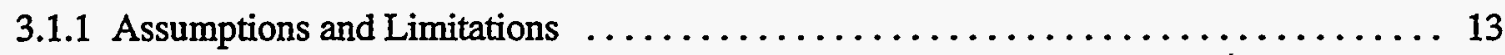

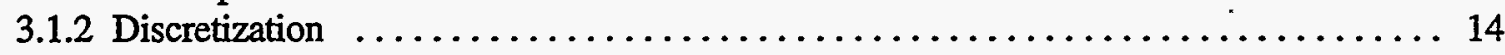

3.2 THREE-DIMENSIONAL REPRESENTATION $\ldots \ldots \ldots \ldots \ldots \ldots \ldots \ldots \ldots \ldots \ldots \ldots$

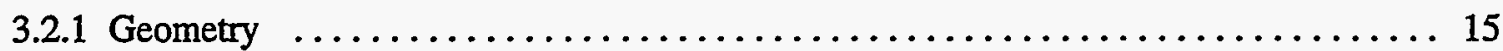

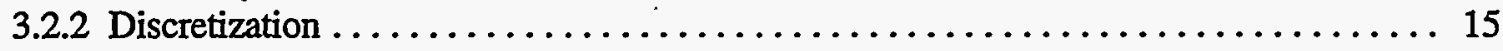

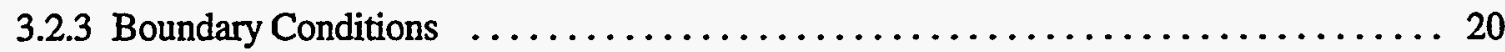

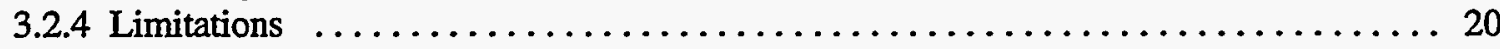

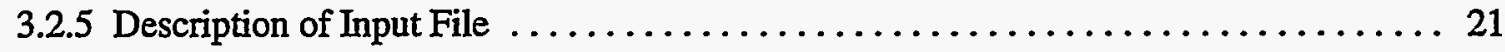

4. VALIDATION OF THREE-DIMENSIONAL CFD APPLICATION $\ldots \ldots \ldots \ldots \ldots \ldots \ldots \ldots 25$

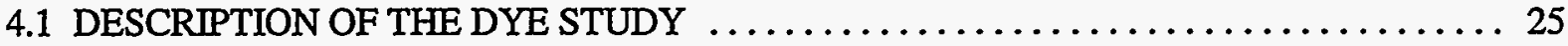

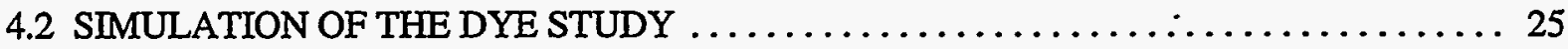

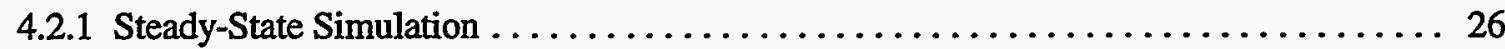

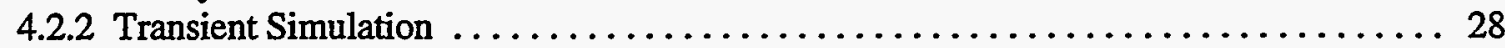

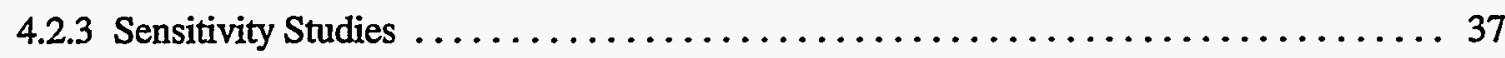

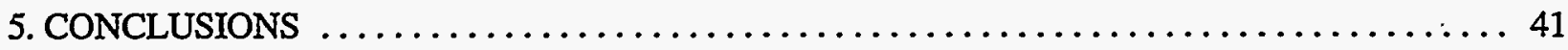

ACKNOWLEDGMENTS $\ldots \ldots \ldots \ldots \ldots \ldots \ldots \ldots \ldots \ldots \ldots \ldots \ldots \ldots \ldots \ldots \ldots \ldots$

iii 


\section{LIST OF TABLES}

Table

Page

1. Important flow rates during the Clinch River dye study of May $7,1987 \ldots \ldots \ldots \ldots \ldots \ldots \ldots$

2. Maximum concentrations of dye for all dye study simulation cases 


\section{LIST OF FIGURES}

Figure

Page

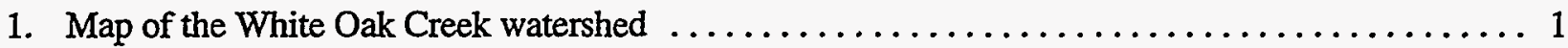

2. Portion of the Clinch River of primary interest to the present analysis $\ldots \ldots \ldots \ldots \ldots \ldots \ldots 2$

3. Depth contours measured near the mouth of White Oak Creek in December 1990 as part of the

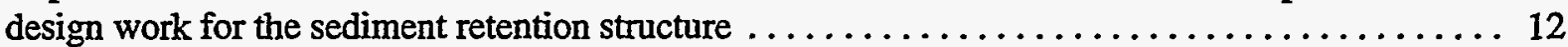

4. Transects of the Clinch River between Melton Hill Dam and the mouth $\ldots \ldots \ldots \ldots \ldots \ldots \ldots 12$

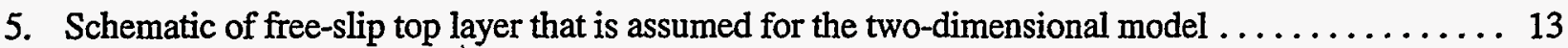

6. Two-dimensional discretization developed for the Clinch River CFD simulation ........... 14

7. Block structure used to define the surface of the Clinch River used in the three-dimensional model 15

8. River bottom topology used in the three-dimensional model $\ldots \ldots \ldots \ldots \ldots \ldots \ldots \ldots \ldots \ldots$

9. Geometry of the three-dimensional $C R$ river boundary near wOC $\ldots \ldots \ldots \ldots \ldots \ldots \ldots \ldots$

10. Baseline discretization of river surface for the three-dimensional model near White Oak Creek

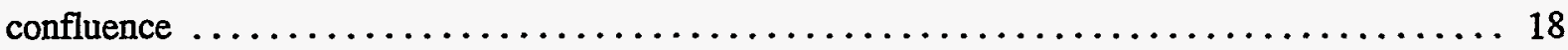

11. Baseline discretization of river surface for the three-dimensional model between Jones and

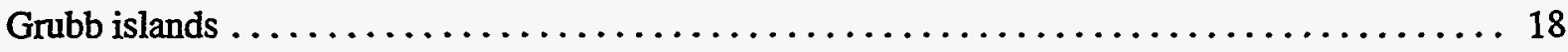

12. Baseline discretization of river surface for the three-dimensional model between Grubb Islands

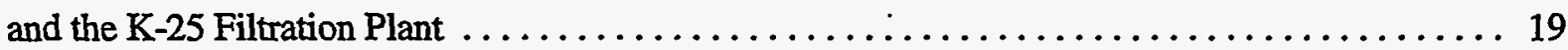

13. Baseline discretization of river surface for the three-dimensional model near Grubb Islands . . . . 20

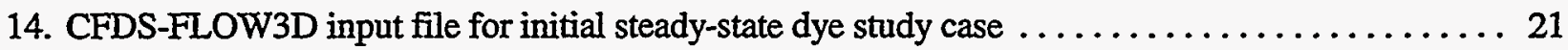

15. Dye concentration measurements taken on May 7,1987 , at CRM $19.6 \ldots \ldots \ldots \ldots \ldots \ldots \ldots$

16. Dye concentration measurements taken on May 7, 1987, at CRM $18.0 \ldots \ldots \ldots \ldots \ldots \ldots \ldots$

17. Dye concentration measurements taken on May 7,1987 , at CRM $16.5 \ldots \ldots \ldots \ldots \ldots \ldots$

18. Dye concentration measurements taken on May 7,1987 , at CRM $14.5 \ldots \ldots \ldots \ldots \ldots \ldots \ldots$

19. Speed on the surface of the Clinch River computed with the three-dimensional model for

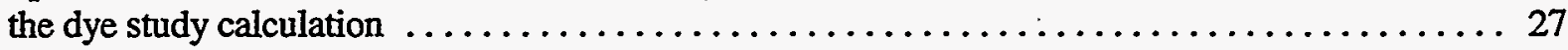

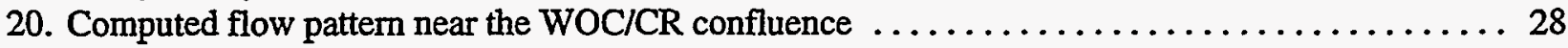

21. Isometric of computational domain near WOC SRS showing computed steady-state surface velocities and control volumes used for simulating dye injection $\ldots \ldots \ldots \ldots \ldots \ldots \ldots \ldots$

22. Clinch River dye concentration at 11:22 a.m. when maximum concentration is calculated at

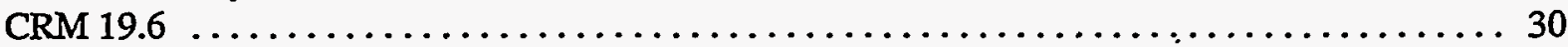

23. Clinch River dye concentration at 1:38 p.m. when maximum concentration is calculated at

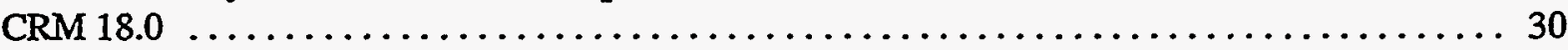

24. Clinch River dye concentration at 3:18 p.m. when maximum concentration is calculated at

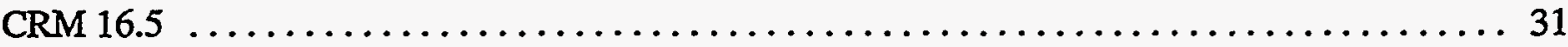

25. Clinch River dye concentration at 6:02 p.m. when maximum concentration is calculated at

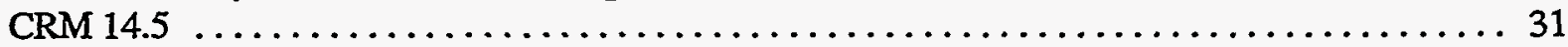

26. Comparison of computed and measured dye concentration at CRM 19.6 for baseline case ..... 33

27. Comparison of computed and measured dye concentration at CRM 18.0 for baseline case ..... 34

28. Comparison of computed and measured dye concentration at CRM 16.5 for baseline case .... 35

29. Comparison of computed and measured dye concentration at CRM 14.5 for baseline case $\ldots \ldots \ldots 36$

30. Comparison of maximum dye concentration for time-step sensitivity study $\ldots \ldots \ldots \ldots \ldots \ldots 38$

31. Comparison of maximum dye concentrations for grid resolution sensitivity study . ........ 39 


\section{ACRONYMS}

ASM

CFD

CR

CRM

DFM

DSM

ORNL

RNG

SRS

3D

2D

TVA

WOC algebraic stress model

computational fluid dynamics

Clinch River

Clinch River mile

differential flux model

differential stress model

Oak Ridge National Laboratory

renormalization group

sediment retention structure

three-dimensional

two-dimensional

Tennessee Valley Authority

White Oak Creek

\section{NOMENCLATURE}

$B$ time-averaged body forces per unit volume

$D_{\Phi} \quad$ molecular diffusivity of contaminant within water

$h$ instantaneous static enthalpy

$H \quad$ time-averaged static enthalpy

$p$ motion pressure

$S_{H} \quad$ distributed volumetric heat sources

$S_{\Phi} \quad$ source term for the contaminant

$t$ time

$u \quad$ instantaneous velocity vector field

$U$ time-averaged velocity vector resolution of mean flow field

$V$ time-averaged uniform flow speed
$\mathrm{N} / \mathrm{m}^{3}$

$\mathrm{kg}^{2} / \mathrm{s}$

$\mathrm{J} / \mathrm{kg}$

$\mathrm{J} / \mathrm{kg}$

$\mathrm{Pa}$

$\mathrm{W} / \mathrm{m}^{3}$

$\mathrm{kg} / \mathrm{s}-\mathrm{m}^{3}$

$\mathrm{s}$

$\mathrm{m} / \mathrm{s}$

$\mathrm{m} / \mathrm{s}$

$\mathrm{m} / \mathrm{s}$

\section{Greeks}

$\alpha \quad$ molecular thermal diffusivity

$\Gamma_{\phi} \quad$ eddy diffusivity for contaminant

$\Gamma_{H} \quad$ eddy diffusivity for enthalpy

$\delta \quad$ Kronecker delta

$\epsilon \quad$ isotropic dissipation rate of turbulent kinetic energy

$\kappa \quad$ turbulent kinetic energy

$\mu \quad$ molecular dynamic viscosity

$\mu_{T} \quad$ eddy viscosity

$\rho$ density

$\sigma_{\Phi} \quad$ turbulent Schmidt number

$\sigma_{H} \quad$ turbulent Prandtl number

$\phi \quad$ instantaneous fluctuating contaminant concentration

$\Phi$ time-averaged contaminant concentration

$\mathrm{m}^{2} / \mathrm{s}$

$\mathrm{kg} / \mathrm{s}-\mathrm{m}$

$\mathrm{kg} / \mathrm{s}-\mathrm{m}$

$\mathrm{m}^{2} / \mathrm{s}^{3}$

$\mathrm{m}^{2} / \mathrm{s}^{2}$

$\mathrm{kg} / \mathrm{s}-\mathrm{m}$

$\mathrm{kg} / \mathrm{s}-\mathrm{m}$

$\mathrm{kg} / \mathrm{m}^{3}$ 



\begin{abstract}
This report describes the simulation of the dispersion and dilution of dissolved or finely suspended contaminants entering the Clinch River from White Oak Creek. The work is accomplished through the application of a commercial computational fluid dynamics (CFD) solver. This study assumes that contaminants originating in the White Oak Creek watershed, which drains Oak Ridge National Laboratory, will eventually reach the mouth of White Oak Creek and be discharged into the Clinch River. The numerical model was developed to support the analysis of the off-site consequences of releases from the ORNL liquid low-level waste system. The system contains storage tanks and transfer lines in Bethel Valley and Melton Valley. Under certain failure modes, liquid low-level waste could be released to White Oak Creek or Melton Branch to White Oak Creek and eventually be discharged to the Clinch River. Since the Clinch River has unrestricted access by the public and water usage from the Clinch River is not controlled by the Department of Energy, such a liquid low-level waste spill would create the possibility of public exposure to the contaminant. This study is limited to the dispersion of the contaminants downstream of the confluence of White Oak Creek.
\end{abstract}

Assessing the impact of an accidental spill requires the prediction of contaminant dispersion and dilution at various downstream locations along the Clinch River. One-dimensional aquatic spill models have been developed to provide estimates for the spread of radioactively decaying contaminants in these waters. These one-dimensional plume models are valid only for sufficiently large downstream distances where the spill has become well-mixed across the active areal river cross section. Within the "entrance region," complex multidimensional mechanisms must be addressed to predict the mixing process of the contaminant as it enters " the river.

The purpose of this work is to build a multidimensional, transient CFD model to the entrance region of the confluence of White Oak Creek and the Clinch River that will simulate the time-dependent conservation of mass, momentum, energy, and species concentration of an accidental spill of a liquid low-level waste into the White Oak Creek watershed. The objective of the study is to provide estimates of contaminant concentration distributions in the Clinch River downstream of the confluence.

The commercial program CFDS-FLOW3D, developed and supported by AEA Technology, in the United Kingdom, was employed to build a detailed three-dimensional discretization of the Clinch River. Validation against dye-study data obtained for the Clinch River in May, 1987 shows that the three-dimensional CFD model can predict within a factor of 2 the maximum concentration of a White Oak Creek contaminant after it has traveled five miles downstream in the Clinch River. 


\section{INTRODUCTION}

The Oak Ridge National Laboratory (ORNL) is a U.S. Department of Energy (DOE) facility located in Oak Ridge, Tennessee. ORNL carries out research in a wide range of energy-related areas and operates a number of facilities that generate hazardous low-level liquid wastes. The possibility exists for an accidental spill of one or more of these contaminants into the environment. Serving as the main Clinch River (CR) subbasin that drains ORNL, the White Oak Creek (WOC) watershed (Fig. 1) consists of a series of small creeks that combine to form White Oak Lake, with its discharge passing over White Oak Dam into an embayment. Water from the WOC embayment flows through or over a sediment retention structure (SRS) into the CR, which empties into the Tennessee River near Kingston, Tennessee. Water is withdrawn from the CR at the Clinch River mile (CRM) 14.5 raw water pumping station and is used for potable and process purposes at the Oak Ridge K-25 Plant. The pumping station also supplies the water to the small industrial park south of Bear Creek Road. The intake is about $10.1 \mathrm{~km}$ (6.3 miles) downstream of the WOC outfall to the CR. The intake for the city of Kingston is located at Tennessee River mile 568.2 , about $0.6 \mathrm{~km}$ ( $0.4 \mathrm{mile})$ above the confluence of the Clinch and Tennessee rivers and 34.1 river $\mathrm{km}$ (21.2 river miles) below the WOC outfall.

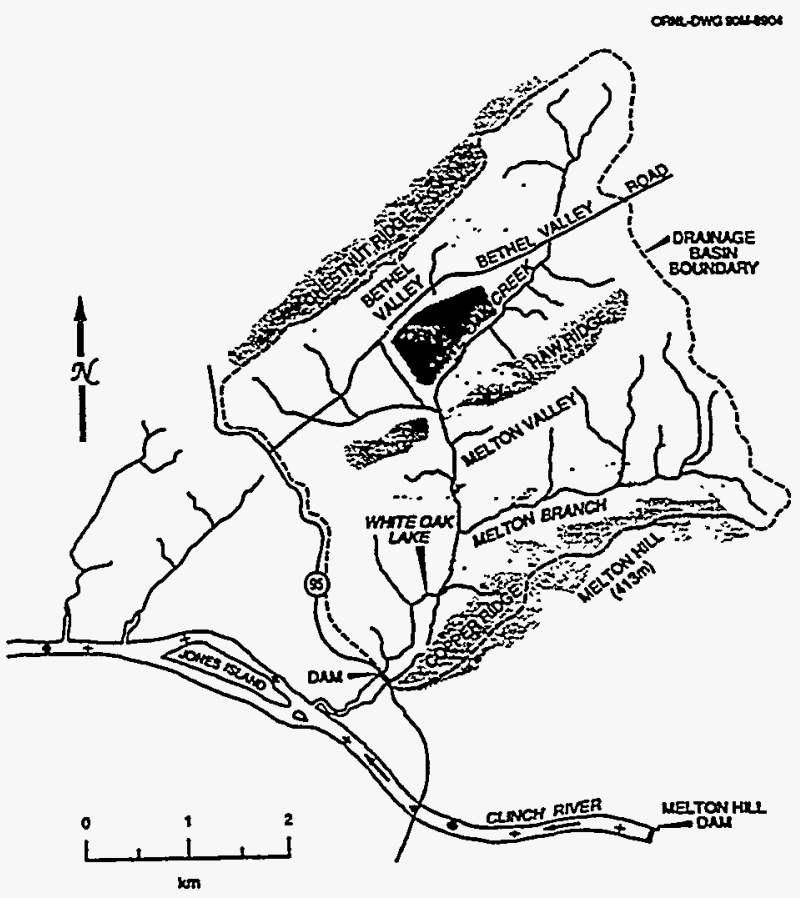

Fig. 1. Map of the White Oak Creek watershed.

The portion of the CR important to the present analysis lies within the Watts Bar Reservoir, which includes $116 \mathrm{~km}(72.4 \mathrm{mi})$ of the Tennessee River upstream from Watts Bar Dam to Fort Loudon Dam and $37.2 \mathrm{~km}(23.1 \mathrm{mi})$ of the CR upstream from the Tennessee River to Melton Hill Dam. Figure 2 shows the surface water boundary for the CR near the WOC confluence at CRM 20.8. 


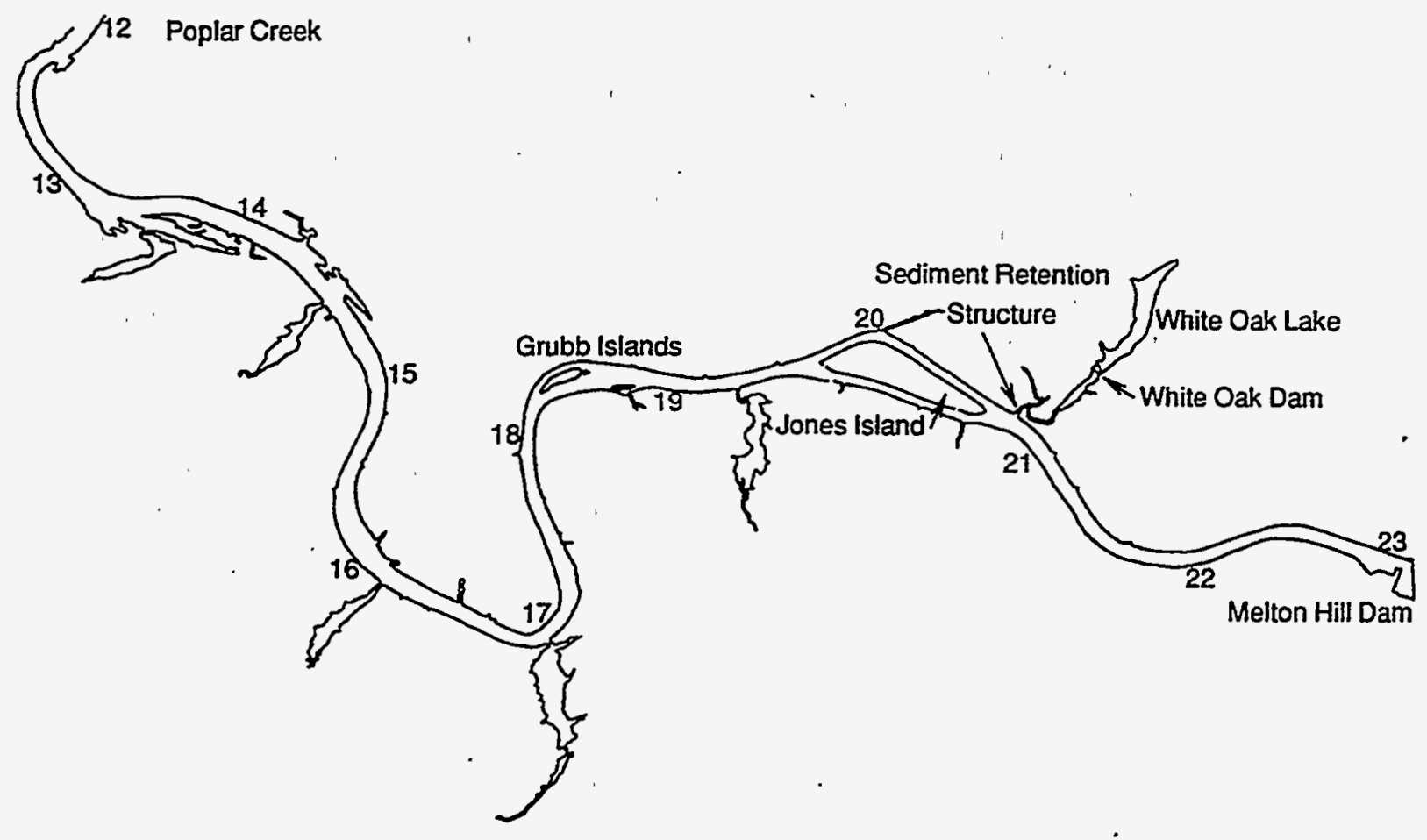

Fig. 2. Portion of the Clinch River of primary interest to the present analysis.

The purpose of this work is to develop a multidimensional, transient computational fluid dynamics (CFD) model for the "entrance region" of the confluence of WOC and the CR that will produce accurate predictions for dispersion of contaminants within a segment of the river. A study by Morton ${ }^{1}$ has indicated that under normal flow conditions (without reverse flow) a contaminant plume originating in WOC will be fully mixed across the river within the first $8 \mathrm{~km}$ ( 5 miles) of travel (by CRM 14.5). To simulate the mixing process in the entrance region, an appropriate model requires the capability to satisfy the time-dependent, multidimensional conservation equations for mass, momentum, energy, and species concentration of the liquid low-level waste originating in the WOC watershed. Only the short-term consequences of the spill are considered. Radioactive decay, sedimentation, and resuspension of the contaminant are neglected, although in future work models for these phenomena could be included. The dilution of contaminant in WOC upstream of the WOC SRS is not considered in the present analysis. Rather, it is assumed that the water flowing into the CR through the rock-filled SRS is well mixed with contaminant, and the concentration of contaminant as it enters the CR is known from other analysis. ${ }^{2}$ The objective is to develop the capability to predict the multidimensional distribution of contaminant concentration in the $\mathrm{CR}$.

The numerical model was defined using the commercial CFD computer program CFDS-FLOW3D, developed at Harwell Laboratories in the United Kingdom and marketed by AEA Technology in the United States. Later releases of this code are named CFX. The program solves the Navier-Stokes energy and speciestransport equations with the SIMPLEC finite-volume method. A scalar advection-diffusion equation was defined to represent transport of the contaminant within the flow field. CFDS-FLOW3D has a "multiblock" capability that allows an accurate representation of the true river geometry. Several state-of-the-art turbulence models are available, including the standard high Reynolds number $k-\in$ model, a Reynolds differential stress model (DSM), and a renormalization group (RNG) $k-\epsilon$ model. Since the predominant near-field mechanism for horizontal and vertical dispersion of the contaminant is turbulent mixing, the accuracy of the turbulence 
model is very important. The present study represents the first application of a general-purpose turbulence model to the CR dispersion problem. Previous spill models of the $C R$ have typically utilized longitudinal and possibly transverse "dispersion coefficients," calibrated to a set of experimental data. This approximation, although proven useful for far-field analysis of long-term sedimentation phenomena, effectively amounts to assuming a constant eddy diffusivity throughout a substantial portion, if not all, of the river, and is therefore insufficient to predict cross-stream and depthwise variations in the entrance region.

A two-dimensional (2D) (horizontal) representation of the CR extending from Melton Hill Dam to the junction of the CR with Poplar Creek (CRM 12) was initially developed as an intermediate step to a more complete three-dimensional (3D) representation that accounts for vertical dispersion. One purpose of the 2D application was to run parametric studies that help define the 3D input; however, it has very limited use for addressing real problems and primarily served as an intermediate step to the more elaborate 3D analysis. For 2D simulations, it is assumed that all of the contaminant remains within a surface layer thin enough that depthwise gradients in the flow field are very small. The idea is to conservatively ignore vertical mixing but to realistically predict dispersion of the contaminant in the cross-stream (transverse) direction.

Ultimately, a fully 3D application of the model was completed that allows for horizontal and vertical mixing of the contaminant. Buoyancy effects included in the 3D model may be important if the temperature difference between the CR and WOC water is significant and the CR flow rate is low. If the CR flow rate is high (e.g., when Melton Hill Dam is producing electricity), buoyancy effects may not be important because so much CR water is mixed with very little WOC water. Initially, the available CR transects giving depth information were extrapolated to give a smooth river bed, and preliminary results were obtained; however, more recent data ${ }^{3}$ have been made available that represent the river bottom in much more detail. The model has been improved to incorporate these recent data, and it is this improved model that is described in this report.

In Chap. 2, a description of the physics important to numerical modeling of river flows is presented, as well as a survey of the literature on CFD modeling of large bodies of water. The specific approach taken through the use of the commercial CFD program CFDS-FLOW3D is also discussed. Finally, previous hydrodynamic modeling of the CR is reviewed. Chapter 3 contains a description of the development of the 2D and $3 \mathrm{D}$ applications. The assumptions are discussed and justified, and the available topological CR data are summarized. The limitations of the present application are also discussed in Chap. 3. For purposes of validation, comparisons (presented in Chap. 4) have been made against a $1987 \mathrm{CR}$ dye study ${ }^{4}$ performed by the Tennessee Valley Authority (TVA) Engineering Laboratory in Norris, Tennessee. This study was carried out to quantify dispersion coefficients used in the one-dimensional hydrodynamic models of the CR; however, because time-dependent and multidimensional data were taken, it lends itself nicely to comparison against results from the present $3 \mathrm{D}$ application. A detailed presentation and discussion of the results is included in Chap. 4. Conclusions and guidelines for application of the model are presented in Chap. 5. 



\section{HYDRODYNAMTC MODELING OF RIVERS}

\subsection{CONSERVATION LAW SYSTEM}

The hydrodynamics of water flowing in a river are governed by the physical principles of conservation of mass, momentum, and energy. Since river flow is almost always turbulent, an appropriate mathematical form for this conservation law system is the coupled set of partial differential equations called the Reynoldsaveraged Navier-Stokes equations for an incompressible (constant-density) fluid. ${ }^{5}$ The conservation of mass, momentum, and energy are described by the continuity equation

$$
\nabla \cdot U=0
$$

the momentum equation,

$$
\frac{\partial \rho \boldsymbol{U}}{\partial t}+\dot{\nabla} \cdot\left\{\rho \boldsymbol{U} \otimes \boldsymbol{U}-\mu\left[\nabla \boldsymbol{U}+(\nabla \boldsymbol{U})^{\boldsymbol{T}}\right]+\rho \overline{u \otimes u}\right\}+\nabla p-\boldsymbol{B}=\mathbf{0}
$$

and the energy equation,

$$
\frac{\partial \rho H}{\partial t}+\nabla \cdot(\rho U H-\rho \alpha \nabla H+\rho \overline{u h})-S_{H}=0
$$

where $\rho, \mu$, and $\alpha$ are the density, molecular dynamic viscosity, and molecular thermal diffusivity, respectively, of the fluid; $U$ is the time-averaged velocity vector resolution of the mean flow field; $H$ is the time-averaged static enthalpy; $p$ is the motion pressure (equal to the thermostatic pressure minus the hydrostatic pressure); $B$ is any time-averaged body forces per unit volume (e.g., buoyancy forces) acting on the fluid; and $S_{H}$ represents any distributed volumetric heat sources. The transport of an arbitrary contaminant by the river flow can be modeled with a scalar species advection-diffusion equation of the form

$$
\frac{\partial \rho \Phi}{\partial t}+\nabla \cdot\left(\rho U \Phi-\rho D_{\Phi} \nabla \Phi+\rho \bar{u} \Phi\right)-S_{\Phi}=0
$$

where $\Phi$ is the contaminant concentration, $D_{\phi}$ is the molecular diffusivity of the contaminant within the fluid, and $S_{\phi}$ is a general source term for the contaminant.

Arising from the time- or ensemble-averaging of the convection terms in the original instantaneous conservation law system, several statistical double correlations appear in Eqs. (2)-(4) that characterize the effects of turbulence on the transport of momentum (Reynolds stresses, $p \bar{u} \otimes u$ ), thermal energy (turbulent heat fluxes, $\rho \overline{u h}$ ), and contaminant concentration (Reynolds fluxes, $\rho \overline{u \phi}$ ) in the mean flow field. Transport equations for each of these double correlations can be derived that contain additional unknown higher-order correlations; therefore, Eqs. (1)-(4) do not represent a closed set. An exact closure for these correlations does not exist, thus producing the classic turbulence closure problem. Approximate closure is the task of turbulence models. 
For engineering calculations, the most commonly used turbulence models are based upon the Boussinesq eddy viscosity approximation, where the Reynolds stresses are modeled by a constitutive relation having a form similar to the Stokes viscosity law for Newtonian fluids,

$$
-\rho \overline{u \otimes u}=-\frac{2}{3} \rho k \delta+\mu_{T}\left[\nabla U+(\nabla U)^{T}\right]
$$

where $k$ is the turbulent kinetic energy $\left(\equiv 1 / 2 u^{2}\right)$ and $\mu_{T}$ is the eddy viscosity. Similar eddy diffusivity hypotheses, coupled with Reynolds-analogy approximations, result in constitutive relations for the turbulent heat flux

$$
-\rho \overline{u h}=\Gamma_{H} \nabla H=\frac{\mu_{T}}{\sigma_{H}} \nabla H
$$

and Reynolds flux of the contaminant concentration,

$$
-\rho \overline{u \Phi}=\Gamma_{\Phi} \nabla \Phi=\frac{\mu_{T}}{\sigma_{\Phi}} \nabla \Phi,
$$

where $\Gamma_{H}$ and $\Gamma_{\Phi}$ are eddy diffusivities, and $\sigma_{H}$ and $\sigma_{\Phi}$ are turbulent Prandtl and Schmidt numbers, respectively. Equations (5)-(7) represent defining relations for the eddy viscosity and eddy diffusivities. A method for calculating these quantities remains to be identified to obtain closure.

Another approach to calculating approximations for the Reynolds stresses and fluxes that does not involve the eddy viscosity concept is to derive transport differential equations for the individual components of the Reynolds stresses. The unknown higher-order correlations that appear in these equations require special modeling to obtain closure. These Reynolds stress and Reynolds flux models involve a significant increase in computational effort relative to typical eddy viscosity-based models; however, they are able to simulate certain turbulence-induced secondary flow features that cannot be resolved by the simpler models.

When applying Eqs. (1)-(4) to a specific river flow problem, two fundamental questions must be answered to guide the selection of an appropriate hydromechanical model. (1) What level of detail and sophistication is appropriate for modeling the turbulence effects on the flow? (2)What degree of dimensionality and therefore what specific terms in the conservation law system are significant to the analysis? The answers to these two questions are often closely linked and require an assessment of whether "far-field" or "near-field" effects (or a combination of both) are to be simulated. For example, Rodi ${ }^{6}$ notes that for certain flows the inertial terms $(\partial \rho U / \partial t, \nabla \cdot \rho U \otimes U)$ in the momentum equations are balanced by the pressure gradient and body-force terms $(\nabla p, B)$, even when the flow is turbulent (e.g., predominantly horizontal 2D flows in large shallow lakes). The selection of the turbulence model is, therefore, unimportant (because turbulence mixing is ineffective) for conservation of momentum, and 2D potential flow solutions provide acceptable accuracy for predicting a mass-conserving velocity field. However, in the absence of large source terms, the energy [Eq. (3)] and species-transport [Eq. (4)], equations have only the turbulence terms $(\rho \overline{u h}, \rho \overline{u \Phi})$ to balance the inertial terms $(\partial \rho H / \partial t, \nabla \cdot \rho U H, \partial \rho \Phi / \partial t, \nabla \cdot \rho U \Phi)$; therefore, careful modeling of the turbulent fluxes is always necessary to obtain realistic temperature and species-transport distributions. 


\subsection{FAR-FIELD MODELING}

Far-field modeling involves simulations of large bodies of water where the mesh discretizations are of necessity coarse, and special techniques must be employed to characterize relevant physical phenomena at the subgrid level. Refined modeling is typically not warranted for calculating horizontal turbulent transport where the use of empirical eddy diffusivities may be more appropriate.

Harper and $\mathrm{Vadnal}^{7}$ describe a far-field contaminant transport model for the CR in which the general $3 D$ velocity field is approximated by a uniform flow field with a constant velocity $V$ in the flow direction. With this approximation, the eddy diffusivities in the species transport equation are replaced by empirical dispersion coefficients which include the effects of the actual nonuniform mean velocity distribution as well as turbulent mixing. Assuming molecular diffusion to be negligible for the length and time scales of the model, contaminant transport is described by a linear advection-diffusion equation of the form

$$
\frac{\partial \Phi}{\partial t}+V \frac{\partial \Phi}{\partial x}-\left(E_{x} \frac{\partial^{2} \Phi}{\partial x^{2}}+E_{y} \frac{\partial^{2} \Phi}{\partial y^{2}}+E_{z} \frac{\partial^{2} \Phi}{\partial z^{2}}\right)+K \Phi=0
$$

where the contaminant concentration, $\Phi$, is assumed to be nonconservative and to be decaying by a first-order reaction with constant rate, $K$. The longitudinal $\left(E_{\gamma}\right)$, lateral $\left(E_{y}\right)$, and vertical $\left(E_{z}\right)$ dispersion coefficients can be estimated from empirical correlations. Rodi ${ }^{6}$ does not consider this type of approximation (even though appropriate for many cases) to represent a true turbulence model, since the application of the dispersion coefficients is restricted to the experimental conditions for which they were determined. A true turbulence model should allow some extrapolation of the experimental data employed in developing the model.

Far-field modeling does not necessarily imply the use of one-dimensional flow fields. Oey and Mellor ${ }^{8}$ developed a 3D, time-dependent, numerical model of the Hudson-Raritan Estuary. The narrow waterways connected to the estuary (specifically, the Hudson, Hackensack, Passaic, and Raritan rivers) were modeled by width-averaged equations as a subset of the full 3D equation set. Sufficiently fine grid sizes were employed to account for horizontal dispersion processes due to small-scale advection and vertical mixing. Assuming the effects of turbulence to be negligible on horizontal mixing, the horizontal diffusion coefficients were set to zero. Vertical turbulence diffusion coefficients, however, were calculated with a second-moment submodel without any calibration of the model constants.

Galperin and Mellor ${ }^{9,10}$ present a 3D, time-dependent numerical model that simulates the Delaware Bay, River, and adjacent continental shelf as a coupled hydrodynamic and thermodynamic system. The conservation law system included the conservation of mass, momentum, energy, and salinity; and the 3D equation set was formulated to provide free-surface predictions with a bottom-following $\sigma$-coordinate system. Horizontal diffusion coefficients were calculated using a simple empirical relation, and vertical Reynolds stresses, turbulent heat, and salt fluxes were evaluated with a second-moment closure model. Forcing variables included surface wind stress, surface heat flux, and freshwater runoff. This full 3D model reduced the phase error observed in surface-elevation predictions of an earlier depth-averaged, 2D model and accurately reproduced the observed amplification of high-frequency tidal components from the mouth of Delaware Bay to near the head of the Delaware River at Trenton, New Jersey, a distance of approximately $210 \mathrm{~km}$ (130 miles).

In Northern Europe, there is continuing interest in multidimensional modeling of contaminant dispersion in the North Sea with an emphasis on subgrid modeling and particle simulations using scaled random walk 
methods. ${ }^{11}$ Spanhoff and de Kok ${ }^{12}$ describe the development of a 3D model of silt transport for the Dutch Coastal Zone of the North Sea near the mouth of the Rhine River. Due to the relatively large freshwater outflow of the Rhine, significant vertical and horizontal density gradients exist in the mouth region of the coast that require 3D modeling to resolve. The hydrodynamic calculations are based upon a 3D model by Leendertse et al., ${ }^{13}$ to which a vertical coordinate transformation was added. Vertical gradients are accounted for by using five layers in the model, the lower three having a constant thickness of $1 \mathrm{~m}$ to ensure sufficient resolution near the bottom. Extensive use of a second-moment model allows calculation of sediment dispersion on subgrid scales much smaller than the $1 \times 1 \mathrm{~km}^{2}$ horizontal grid scale.

\subsection{NEAR-FIELD MODELING}

In near-field modeling, all of the terms in the momentum equations [Eq. (2)], may be important; and, in particular, turbulent mixing can be a significant mode for momentum transport. When mean-flow quantities are relatively constant over the vertical direction, $2 \mathrm{D}$ forms of the conservation law system can be derived. If free-surface tracking is required, the $3 \mathrm{D}$ equations can be integrated over the vertical direction (assuming a hydrostatic pressure distribution) to produce the hyperbolic depth-averaged (or shallow-water) equation set. ${ }^{6,14}$ The state variables resulting from depth averaging are the depth-averaged horizontal velocities, the depthaveraged temperature and species concentration, and the water depth. Bottom- and surface-shear stresses along with surface heat fluxes are applied to the model as gradient boundary conditions. The task of the turbulence model is to determine the depth-averaged turbulent Reynolds stresses and fluxes and the turbulence-induced bottom shear stress. Additional modeling is required to calculate dispersion terms that are due to vertical nonuniformities of the mean-flow quantities; however, these models are not turbulence models: Depthaveraged forms of the two-equation $k-\epsilon$ model (to be discussed) have been developed for shallow-water applications. ${ }^{6}$

For more complex hydraulic flows where vertical gradients of the mean flow variables need to be resolved, full 3D simulations may be appropriate. For a buoyant discharge of a contaminated water stream into a river, strongly $3 \mathrm{D}$ flow and temperature/species-concentration distributions can develop in the near field. A 1975 survey study by Dunn et al. ${ }^{15}$ found that 3D numerical simulations of buoyant side discharges into flowing channels using constant eddy viscosities and eddy diffusivities produced poor agreement with experimental results. More sophisticated turbulence models are required to resolve the 3D near-field phenomena. McGuirk and Spalding ${ }^{16}$ present 3D calculations of the coaxial discharge of heated water from a round pipe into a straight rectangular channel. Using a standard two-equation $\kappa-\epsilon$ turbulence model, comparison of the complex 3D CFD-predicted temperature contours at various cross sections showed good agreement with experimental measurements. Rastogi and Rodi ${ }^{17}$ performed similar calculations for a verticalslot discharge (at the center of the channel). As predicted by the model and confirmed by experimental measurements, the warm discharge stream rises to the surface, where it is deflected laterally and forms a buoyancy-induced secondary motion in the cross-flow plane. The SSIM code ${ }^{18,19}$ has recently been developed for $3 D$ simulations of sediment flow in rivers using the standard two-equation $k-\epsilon$ turbulence model. Solving the 3D Reynolds-averaged Navier-Stokes equations using the finite-volume SIMPLE algorithm, the calculated flow field is then applied to simulations of the advection-diffusion transport equations for different sediment sizes. 


\subsection{TURBULENCE MODELS AVALABLE IN CFDS-FLOW3D}

From dimensional arguments, turbulence models based on the Boussinesq approximation, [Eq. (5)] assume that the eddy viscosity is proportional to the product of length and velocity scales that are characteristic of the turbulence. The two-equation $\kappa-\epsilon$ model (where $\kappa$ is the turbulent kinetic energy and $\epsilon$ is the isotropic turbulence dissipation rate) uses the Prandtl-Kolmogorov equation,

$$
\mu_{T}=C_{\mu} \rho \frac{\kappa^{2}}{\epsilon}
$$

where $C_{\mu}$ is an empirically derived constant, to relate $\kappa$ and $\epsilon$ to the eddy viscosity, $\mu_{T}$. The velocity scale is $\sqrt{\kappa}$, and the characteristic length scale is $\kappa^{3 / 2} / \epsilon$. Two transport equations must be solved to complete the approximate turbulence closure. For $\kappa$, one solves

$$
\frac{\partial \rho \kappa}{\partial t}+\nabla \cdot(\rho U \kappa)-\nabla \cdot\left[\left(\mu+\frac{\mu_{T}}{\sigma_{\kappa}}\right) \nabla \kappa\right]-P-G+\rho \epsilon=0,
$$

and for $\epsilon$, one solves

$$
\frac{\partial \rho \epsilon}{\partial t}+\nabla \cdot(\rho U \epsilon)-\nabla \cdot\left[\left(\mu+\frac{\mu_{T}}{\sigma_{\epsilon}}\right) \nabla \epsilon\right]-C_{1} \frac{\epsilon}{\kappa}\left[P+C_{3} \max (G, 0)\right]+C_{2} \rho \frac{\epsilon^{2}}{\kappa}=0,
$$

where $P$ is the shear production rate defined by

$$
P \equiv\left(\mu+\mu_{T}\right) \nabla \boldsymbol{U} \cdot\left[\nabla \boldsymbol{U}+(\nabla \boldsymbol{U})^{T}\right]-\frac{2}{3} \nabla \cdot\left[\left(\mu+\mu_{T}\right) \nabla \cdot \boldsymbol{U}+\rho \kappa\right],
$$

and $G$ is the production rate due to any body forces. For a buoyancy body force,

$$
G=-\left(\frac{\mu+\mu_{T}}{\rho \sigma_{T}}\right) g \cdot \nabla \rho,
$$

where $g$ is the gravitational acceleration vector. Equations (10)-(11) represent the standard high-Reynolds number $\kappa-\epsilon$ model in which the computational domain does not extend all the way to solid walls. So-called wall functions, derived from the logarithmic "law-of-the-wall" velocity profile, are employed to simulate the effect of the no-slip wall boundary condition on the flow field adjacent to the wall. 
Two modified forms of the standard $k-\epsilon$ turbulence model are available in CFDS-FLOW3D. The lowReynolds number model was developed to allow calculation of turbulent flows at low Reynolds numbers, typically in the range of 5,000 to 30,000. This model uses wall-proximity functions to damp the eddy viscosity when the local Reynolds number is low. The RNG $k-\epsilon$ model, derived from an RNG analysis of the NavierStokes equations, differs from the standard model only through a modification to the equation for $\epsilon$ and the use of a different set of constants.

The Boussinesq approximation for the eddy viscosity assumes that the Reynolds stress tensor is isotropic, i.e., the normal Reynolds stresses are equal, $\rho \overline{u_{1} u_{1}}=\rho \overline{u_{2} u_{2}}=\rho \overline{u_{3} u_{3}}$. This assumption prevents the eddyviscosity turbulence models from predicting certain turbulence-induced secondary flows that result from a nonisotropic Reynolds stress. In the more sophisticated (and compute-intensive) DSM and algebraic Reynolds stress (ASM) models, the eddy-viscosity approximation is not made. Instead, equations are solved for the individual components of the Reynolds stress tensor. In the ASM, these equations are solved algebraically. Differential transport equations for the stress components and an $\epsilon$-transport equation are solved in the DSM. A differential Reynolds flux model (DFM) is also available in CFDS-FLOW3D which solves the same differential stress-component transport and $\epsilon$ equations as the DSM; however, the DFM solves an additional

transport equation for one of the Reynolds fluxes, $\rho \bar{u} \bar{\theta}$, the correlation between the velocity fluctuations and one other variable, $\theta$. For flows with heat transfer, the variable is the static enthalpy, $h$. For isothermal flows, $\theta$ is the species concentration, $\phi$.

\subsection{PREVIOUS CLINCH RIVER HYDRODYNAMIC MODELING}

The capability to simulate contaminant mixing has been developed by TVA ${ }^{7}$ and applied to the $\mathrm{CR}$ dispersion problem. Three sequential computer model components were used to (1) simulate one-dimensional hydrodynamics, (2) track the streamwise movement of the contaminant plume, and (3) estimate the spreading (cross-stream) movement of the plume. Results have been obtained for validation against the 1987 dye study. Maximum concentrations are predicted satisfactorily, but the timing of the contaminant transport is off significantly. This discrepancy was attributed to the cross-stream variations in the flow field that were neglected in the TVA models but that are accounted for in the present work.

To predict long-term environmental impact in the CR due to ORNL wastes in the WOC watershed, onedimensional sediment-transport models, ${ }^{20}$ developed at ORNL, have been used. These models were intended to represent complex phenomena that are not addressed in the present analysis but are important mechanisms in contaminant-fate analysis, including sedimentation, resuspension, and radioactive decay of contaminants. Emphasis is placed on determining the contaminant distribution within the sediment layers constituting the CR bed.

For these one-dimensional models, the $\mathrm{CR}$ hydrodynamics are treated using calibrated one-dimensional modules that cannot resolve details of cross-stream dispersion of contaminant. Such modules are not adequate for the analysis of short-term near-field surface-water effects. Dispersion coefficients are calculated based on available field data (such as that obtained during the 1987 dye study) and used to represent the turbulent dispersion of contaminant in the river. The use of such a calibrated model has the advantage of producing very accurate predictions for flow conditions that are near the calibrated state. However, in moving away from the conditions at which the model was calibrated, the error in the numerical extrapolations could grow at a. very large rate. Although these models have been successfully applied in the past with confidence, the short-term assessment of contaminant dispersion was not very important. 
The first advantage to using CFD to simulate the dispersion/dilution process is that the computed solution is not dependent upon any "tuned" parameters; i.e., the turbulence models are considered general purpose and are capable of extrapolating the data on which they are based. The same turbulence models are applied for the CR dispersion problem that are commonly used for a large range of turbulent flows in research and industrial applications. Separate values for turbulent kinetic energy and eddy dissipation are calculated for each of the tens of thousands of control volumes used to discretize the computational domain. However, once the comparison is made and the differences between computed results and measured data are quantified, it may be advantageous to take advantage of the data and calibrate certain quantities such as the turbulent Schmidt number [Eq. (7)] to provide better accuracy in future use of the model.

The second advantage to using a multidimensional CFD code for this analysis is that the capability exists to predict multidimensional contaminant distributions. Consider the $1987 \mathrm{CR}$ dye study case. Because the dye was injected near the river bank, the velocity at the point of injection was less than the average free-stream velocity. As was discovered in the comparison of TVA predictions to dye study measurements, this local variation in the flow field caused the dye transport time to be significantly underpredicted. Necessarily, the multidimensional analysis also requires much more detailed geometric information, as will be discussed.

\subsection{CLINCH RIVER MEASURED DATA}

Flow rate data and temperature data are continuously measured in the CR near Melton Hill Dam and in WOC near White Oak Creek Dam. The Environmental Restoration Program at ORNL issues annual summaries of hydrologic data for the WOC watershed (see Borders et al. ${ }^{21}$ for 1992) including daily stream flow data.

River depth contours are presented by Struxness et al. ${ }^{22}$ for CRMs 19.1 and 19.6. At both locations, a

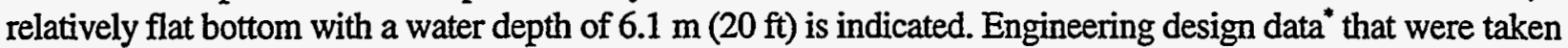
just before the construction of theWOC SRS are shown in Fig. 3. Figure 4 shows data that were collected by TVA Engineering Laboratory ${ }^{23}$ at five transects along the CR in 1993. These data indicate that the crosssection of the river has approximately the same regular (nearly rectangular shape) at each of the transects, although the channel gets deeper and wider in the downstream direction. The summer pool elevation in the CR is 226 $\mathrm{m}(741 \mathrm{ft})$, so that the river depth increases from $6.1 \mathrm{~m}$ (20 ft) to $12.2 \mathrm{~m}$ (40 ft) over the $28.8 \mathrm{~km}$ (17.9 miles) (0.02\% grade).

The dye study, documented by Vadnal and Beard, ${ }^{4}$ includes some information on the river depth, flow rates, and velocities measured on May 7, 1987. The depth information is given at the WOC/CR confluence (CRM 20.8), just downstream of Jones Island (CRM 19.6), just downstream of Grubb Islands (CRM 18.0), and at CRMs 16.5 and 14.5. Also depth information is provided at the mouth of WOC, just downstream of the SRS. On the day of the dye study, the flow through Melton Hill Dam was held constant at $283 \mathrm{~m}^{3} / \mathrm{s}$ $(10,000 \mathrm{cfs})$, which produced an average velocity of $0.257 \mathrm{~m} / \mathrm{s}(0.843 \mathrm{ft} / \mathrm{s})$ at $\mathrm{CR}$ mile 20.8 .

Recently a hydro-acoustic field study was performed by the Waterways Experiment Station of the U.S. Army Corps of Engineers measuring the CR depth along three streamwise lines at intervals of less than $5 \mathrm{~m}$. Data from this study, which included soundings from 6589 different locations in the river, were combined with the previous measurements and then fitted and smoothed by Hargrove, Hoffman, and Levine ${ }^{3}$ of ORNL to

"Unpublished data collected by the Army Corp of Engineergs in 1990, plotted by Adams Craft Herz Walker under contract wiht Martin Marietta Energy System, Inc., personal communication from C. J. Ford, Oak Ridge National Laboratory, to M. W. Wendel, Oak Ridge National Laboratory, October 1994. 
produce a finely resolved bathymetric field. It is these data that were used to generate the discretization of the 3D model presented here.

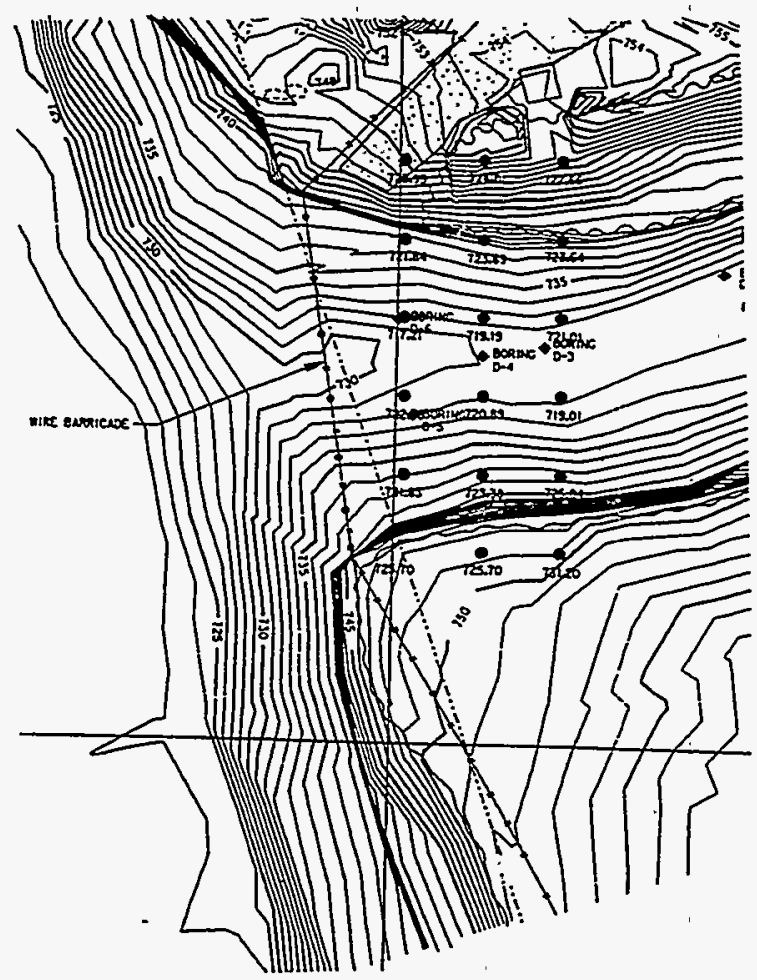

Fig. 3. Depth contours measured near the mouth of White Oak Creek in December 1990 as part of the design work for the sediment retention structure.

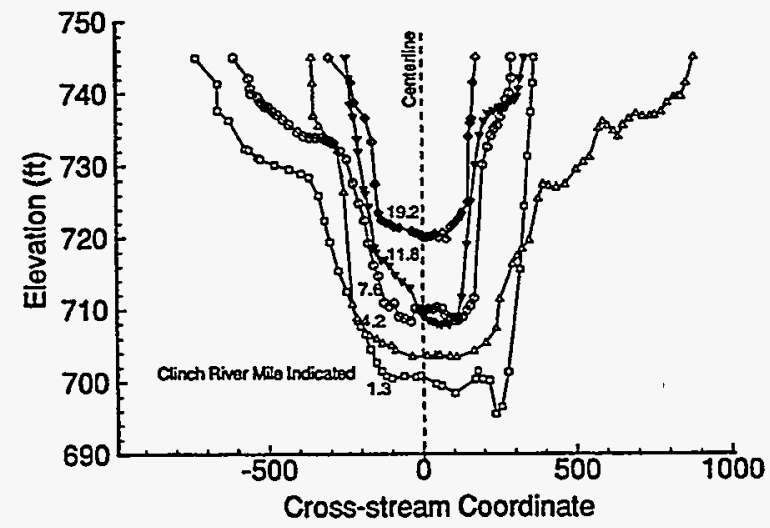

Fig. 4. Transects of the Clinch River between Melton Hill Dam and the mouth. 


\section{MULTIDIMENSIONAL CFD REPRESENTATION}

\subsection{TWO-DIMENSIONAL REPRESENTATION}

Before proceeding with a large fully $3 \mathrm{D}$ application, a more simplified approach was taken as an intermediate step. A 2D (horizontal) domain was defined that would be useful for studying the effects of discretization, finding a workable convergence scheme, and performing various parametric studies with such variables as molecular diffusivity, turbulence models, and assumed inlet turbulence at Melton Hill Dam. Because this preliminary application is $2 \mathrm{D}$ and isothermal, it requires significantly less computational effort (for a given reach of the river) to arrive at a converged solution when compared with computations in a full 3D domain.

\subsubsection{Assumptions and Limitations}

The 2D CFDS-FLOW3D CR representation assumes a top layer of water that remains isolated from the deeper portion of the river (Fig. 5). The top and bottom surfaces of the layer are assumed to be free from stress in the tangential direction. The stress-free boundary conditions are implemented by defining these surfaces to be "free-slip", or symmetry, surfaces in the CFDS-FLOW3D input. For this assumption to be physically relevant, the layer must be thin compared with the depth. (For one particular case of turbulent open channel flow, Rodi ${ }^{6}$ shows that there is very little depthwise gradient through the top $10 \%$ of the depth.) Hence, only part of the uncontaminated CR water would be available for mixing with the contaminated WOC water.

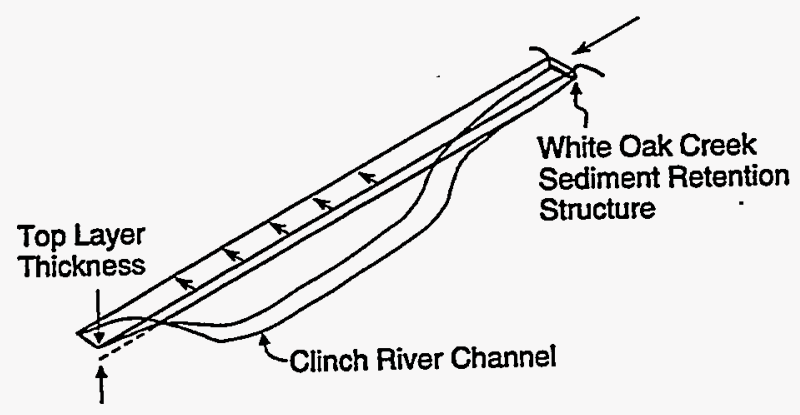

Fig. 5. Schematic of free-slip top layer assumed for the 2D model.

For 2D open-channel flow simulations that do not use depth-averaging, a free-slip boundary condition on the sidewall (bank) gives a more accurate horizontal velocity distribution in the developed open channel than a no-slip boundary with the standard law of the wall applied. This fact is demonstrated by Rodi ${ }^{6}$ for an open rectangular channel with width-to-depth ratio of 30 . Hence, the free-slip boundary was also assumed for the river banks. Although no sedimentation, resuspension, or radioactive decay of the contaminants was assumed, if necessary, representations of these phenomena could be added to the existing model.

The depth of the $\mathrm{CR}$ is assumed to remain constant throughout the computational domain. As previously noted, cross-stream depth measurements ${ }^{1}$ have shown the river channel to be quite regular and only slightly sloped. However, there are localized areas along the river channel that significantly deviate from the 
general trend of the river bed contour. One important example of local variation is the significant difference in depth on the north and south sides of Jones Island. The amount of variation in average depth at each streamwise location produces a variation in the velocity (based on mass conservation) that is not accounted for in the $2 D$ simulations.

The main use of this application is for parametric studies. Because the third dimension is not discretized, fewer nodes are required, leading to much shorter run times and making it much more feasible to run a series of simulations investigating the sensitivity of certain aspects of the model.

\subsubsection{Discretization}

The discretization and computational domain containing 55,300 cells are shown in Fig. 6 . A small extension was added to the computational domain upstream of Melton Hill Dam to implement the CR inlet condition. The CR boundary was imported from the S-16A base map database from the Arc/Info Geographic Information System. A line source of length $28.38 \mathrm{~m}(76.7 \mathrm{ft})$ connecting two points on the opposite banks of the WOC near its mouth emptying into the CR was assumed for injection of the contaminant.

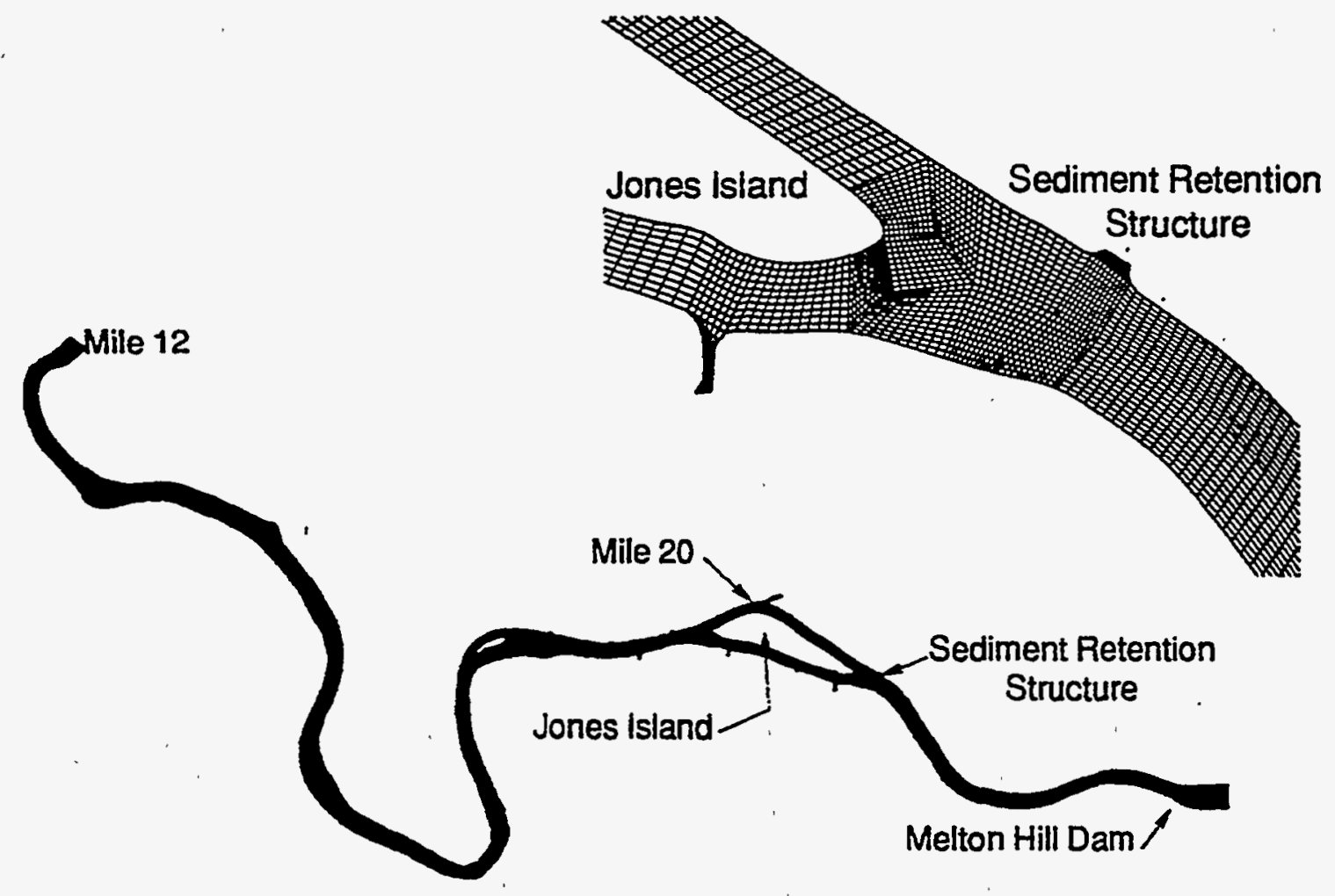

Fig. 6. Two-dimensional discretization developed for the Clinch River CFD simulation. 


\subsection{THREE-DIMENSIONAL REPRESENTATION}

The 2D computational domain representing the river surface was extended depth wise to produce a fully 3D domain. The 3D flow domain was limited to the 13.7- $\mathrm{km}$ (8.5-mile) stretch of the CR between Melton Hill Dam (CRM 23) and the pumping station located in Bear Creek Valley (CRM 14.5).

\subsubsection{Geometry}

The 3D computational domain is based on the detailed field measurements discussed previously for the river bottom topology. The domain includes Jones and Grubb islands, which introduce significant complexities to the discretization.

CFDS-FLOW3D uses a multiblock discretization technique, where the computational domain is divided into six-sided regions, each of which must contain a structured mesh (i.e. rows, columns, and levels of computational cells arranged in a rectangular logical space. By piecing together these structured blocks, the exact geometry can be closely approximated. The surface elevation was assumed to be at the summer pool level of $226 \mathrm{~m}$ (741 ft). The river geometry was first defined by specifying a 2D block structure shown in Fig. 7 and then extruding that structure in the vertical direction, constraining the geometry with the bathymetric data. Depth contours at 2, 4,6 and $8 \mathrm{~m}$ after extrusion are shown in Fig. 8. The coordinates on Fig. 8 indicate meters, with the origin located at the confluence of WOC and CR. A close-up of the 3D geometry near the WOC confluence is shown in Fig. 9.

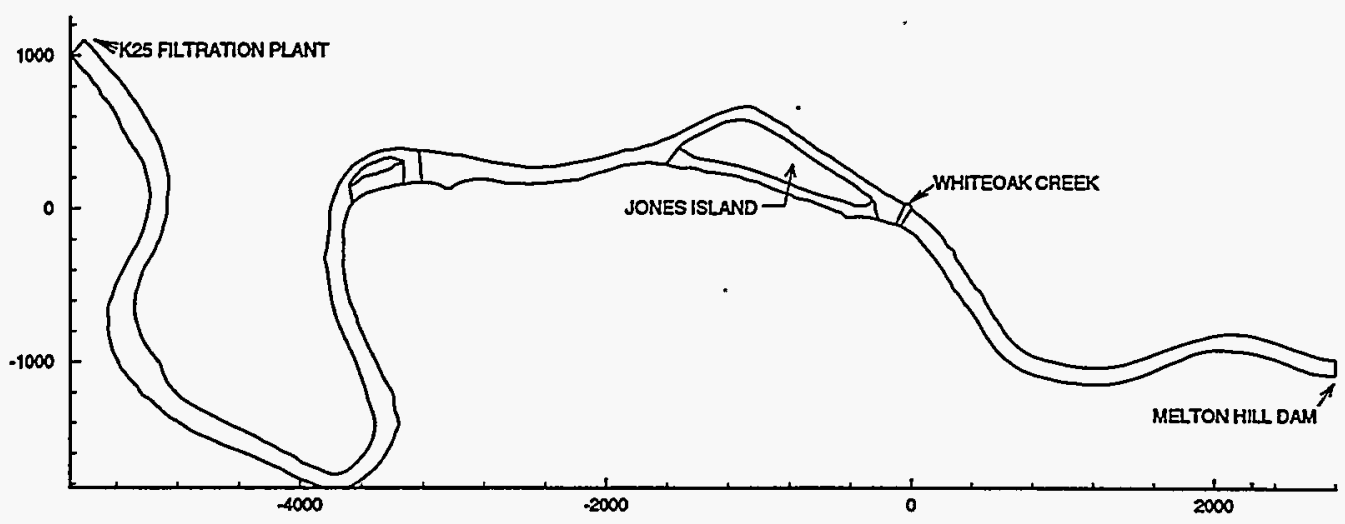

Fig. 7. Block structure used to define the surface of the Clinch River used in the 3D model.

\subsubsection{Discretization}

Whether a discretization is appropriate for a given simulation of a spill depends upon the flow conditions in the $\mathrm{CR}$ and the portion of the river through which the plume passes. In general, it is desirable 
to have a mesh that is characterized by nearly orthogonal control volumes (cells) and relatively equal cell spacing. Transitions in control volume size through the mesh should occur as gradually as possible so as to minimize numerical truncation error that is brought on by approximating the differentials with finite
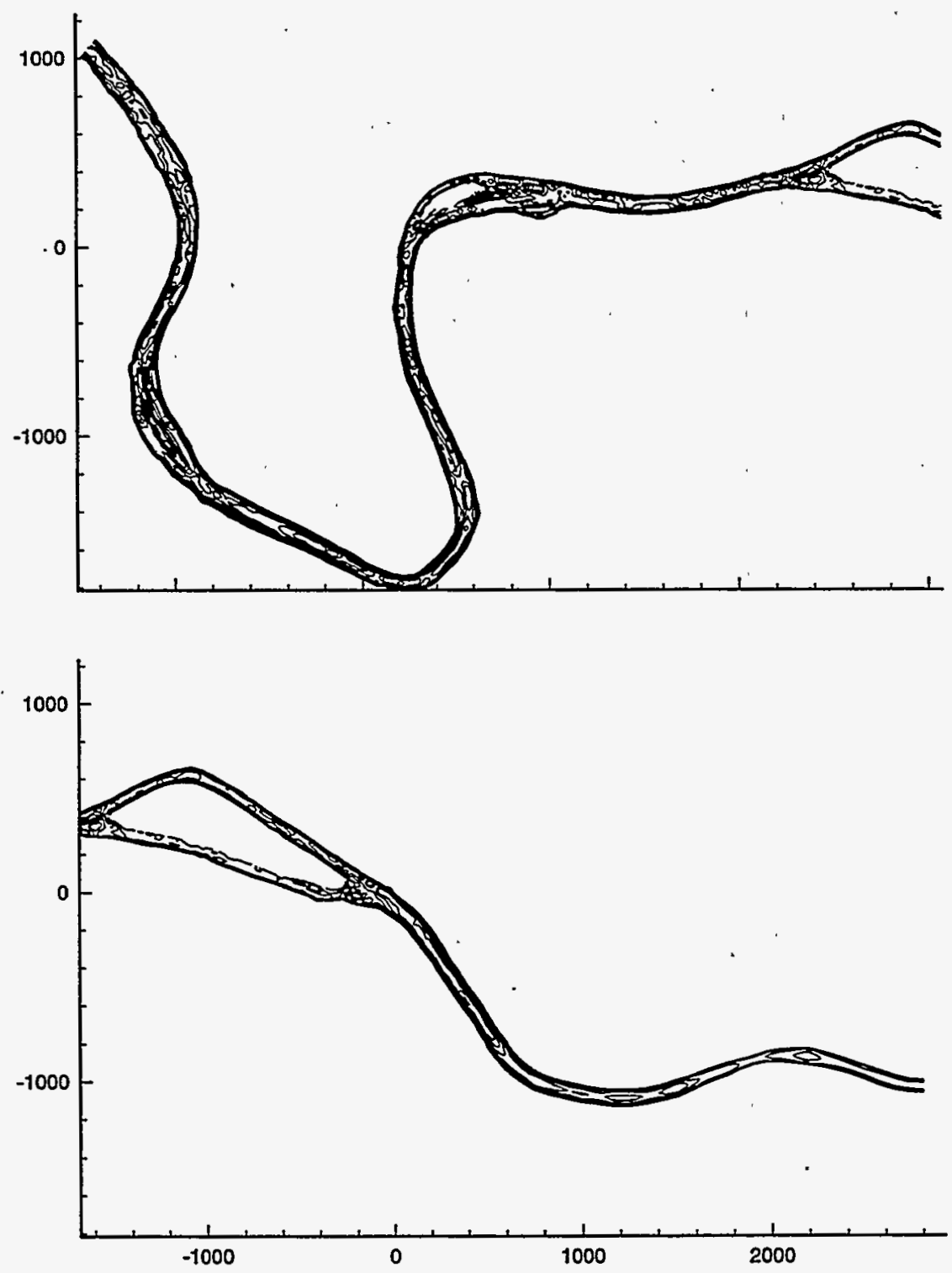

Fig. 8. River bottom topology used in the 3D model. 
differences. Skewed and elongated control volumes are necessary because of practical limitations on the total number of volumes allowed and the desire to closely represent the true geometry, but with significant effort these effects can be minimized and localized.

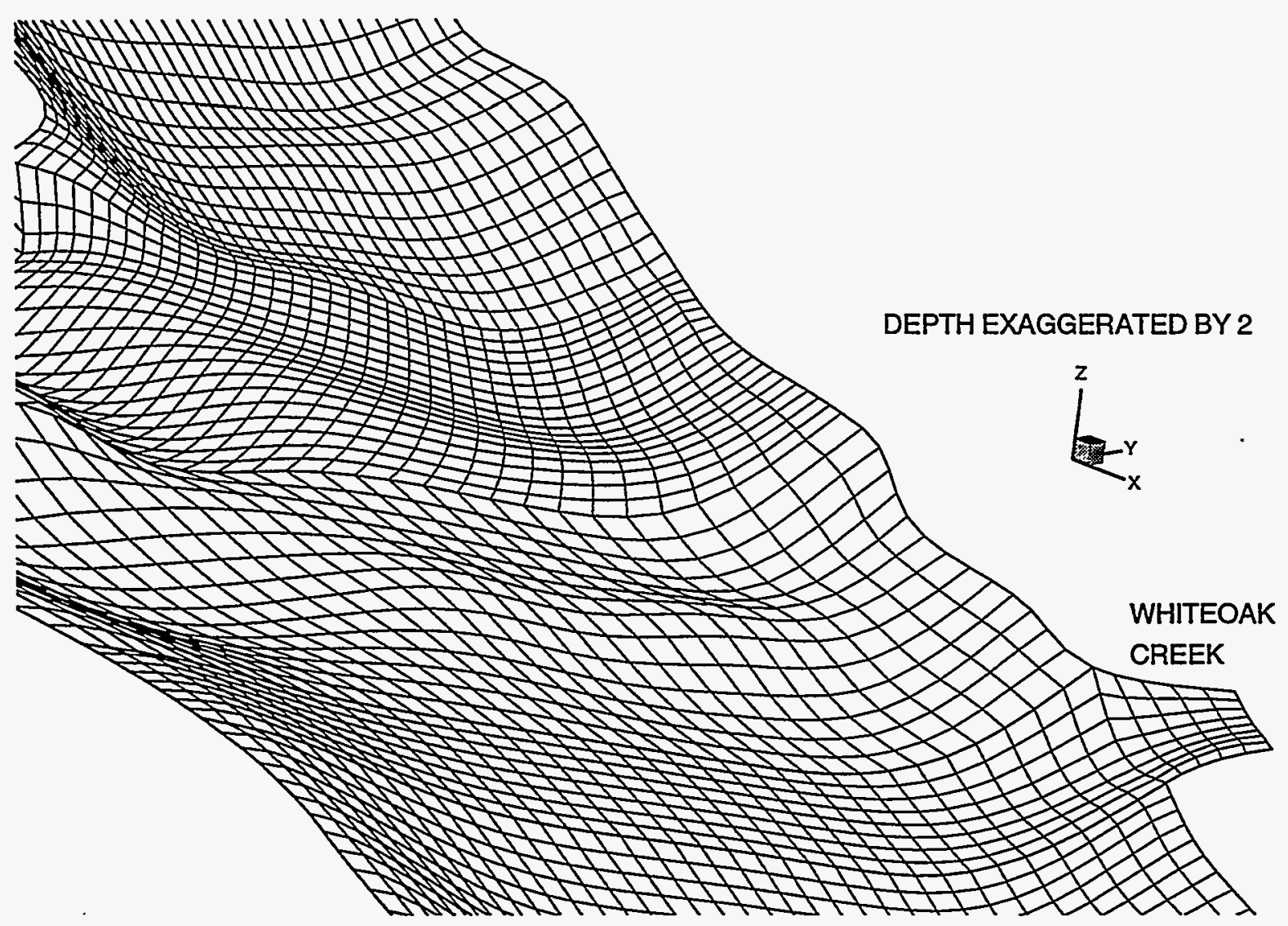

Fig. 9. Geometry of the 3D CR river boundary near WOC.

The discretization that will be discussed here was that used in the simulation presented in Chap. 4 for the purposes of validation. Other discretizations were also used in the dye-study simulation to determine the level of dependency that the solution had upon the mesh; however, only the "baseline" discretization is presented here. In Figs. 10-12, the baseline discretization of the river surface is shown moving from upstream to downstream. Figure 13 shows a close-up of the discretization near Grubb Islands. Again, the coordinates shown are in meters from the confluence of WOC and CR. This mesh contains 107,744 control volumes. It is six cells deep, with equal cell spacing in the vertical direction. 

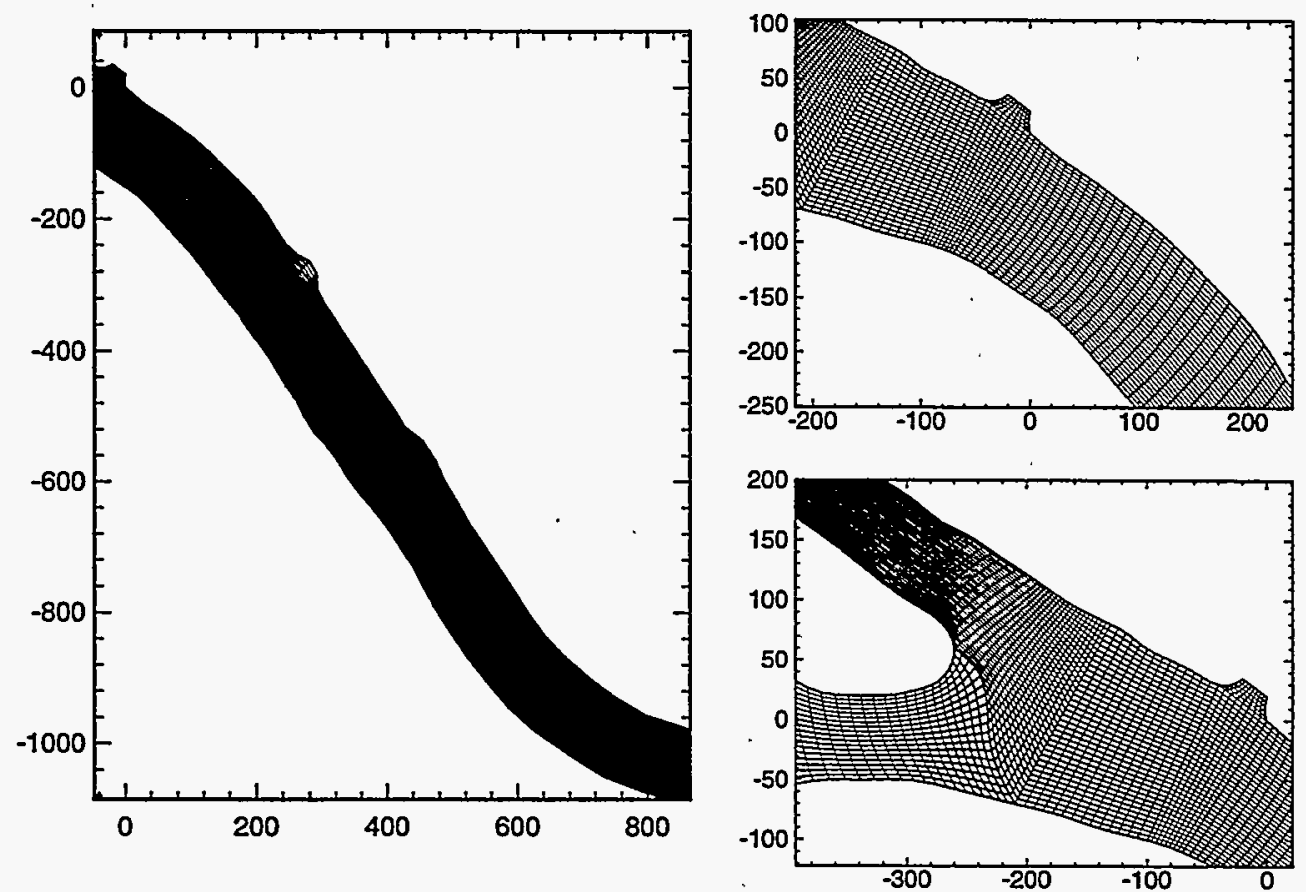

Fig. 10. Baseline discretization of river surface for the 3D model near White Oak Creek confluence.
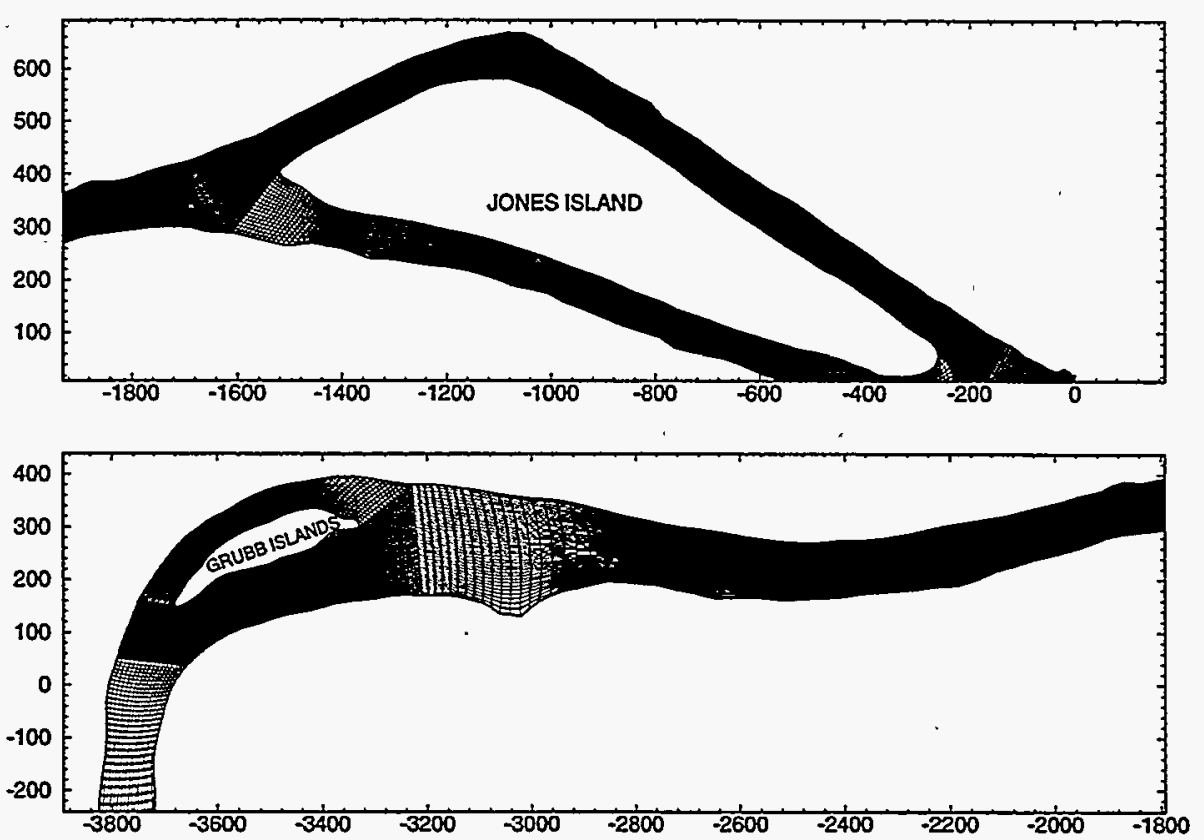

Fig. 11. Baseline discretization of river surface for the 3D model between Jones and Grubb islands. 


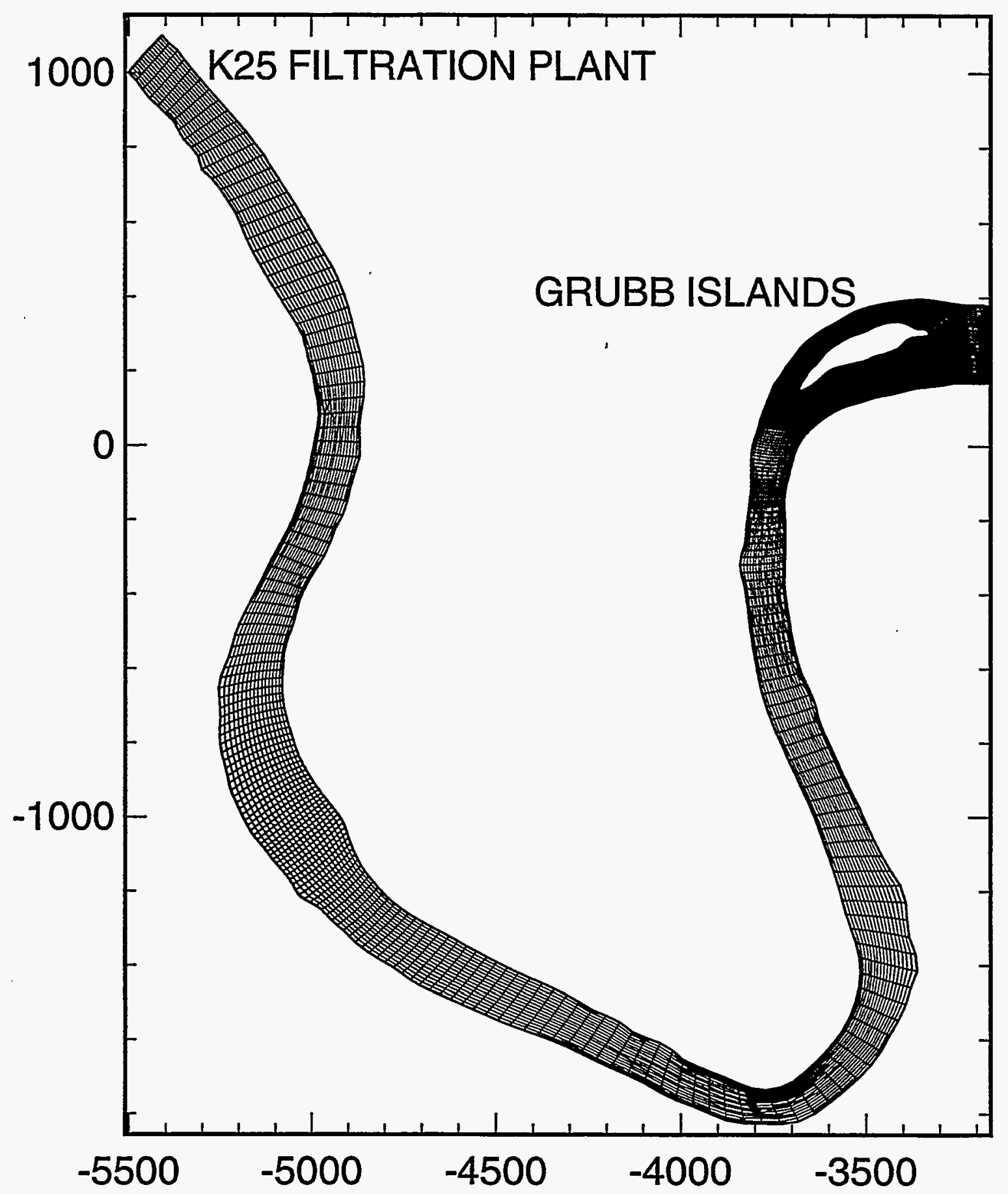

Fig. 12. Baseline discretization of river surface for the 3D model between Grubb Islands and the K-25 Filtration Plant. 


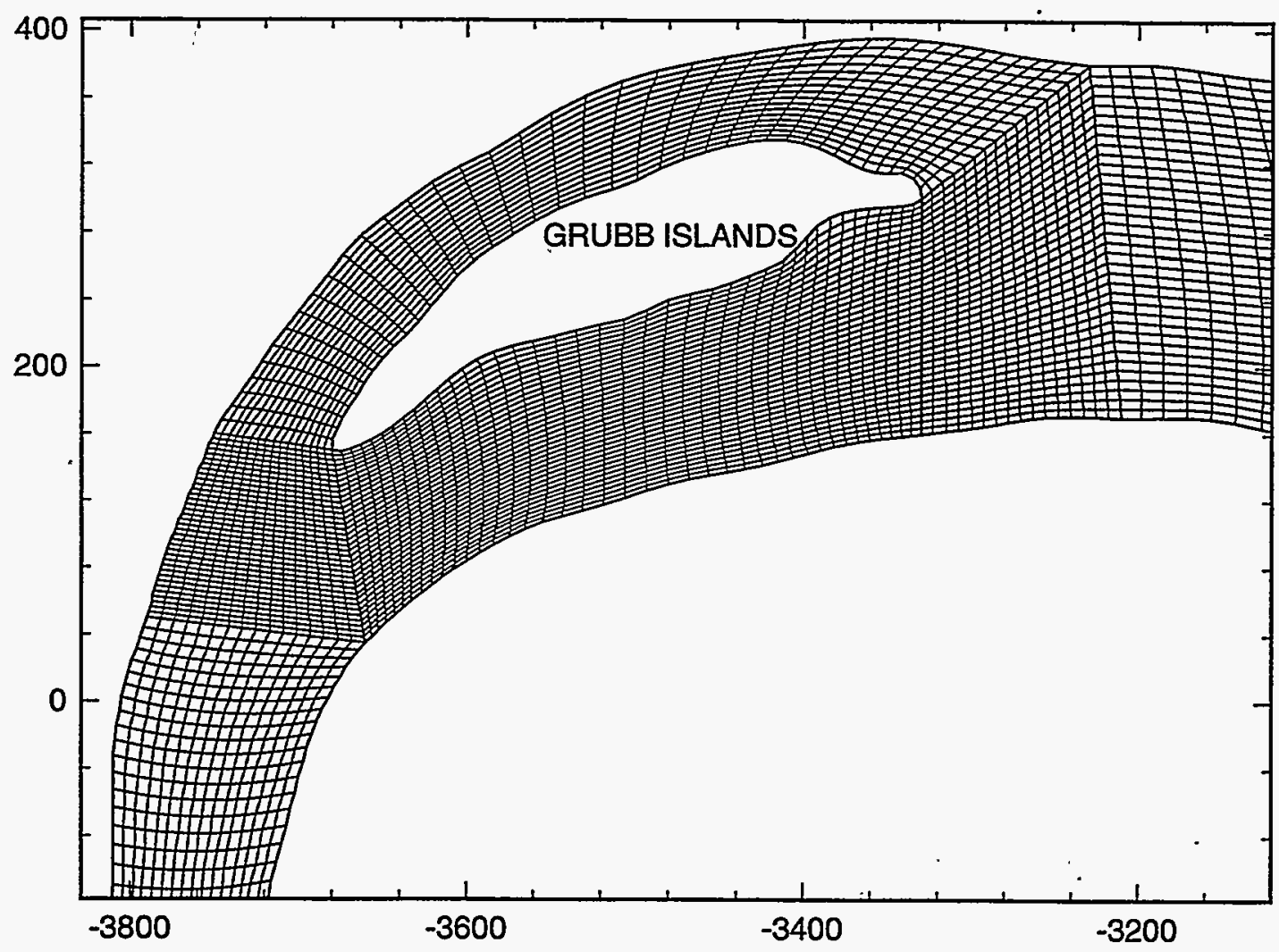

Fig. 13. Baseline discretization of river surface for the 3D model near Grubb Islands.

\subsubsection{Boundary Conditions}

The surface of the water was assumed to be a rigid lid with free-slip boundary (zero shear-stress condition). The vertical surfaces at the SRS and Melton Hill Dam were defined as inlet boundaries with specified velocity. The vertical exit plane of the CR flow domain was defined as a "mass-flow" boundary where the total flow leaving the computational domain is constrained to be equal to the net inflow. Early simulations with the 2D representation showed that when this type of boundary condition is used, the solution upstream is independent of how far downstream the exit plane is located. The remaining boundaries representing the river bottom were all defined as no-slip boundaries, where drag is calculated automatically by the CFDS-FLOW3D turbulence-equation wall functions. Since the flow rate is specified to the model, the shear stress at the river bottom is important only in how it influences the velocity field and the turbulent kinetic energy distribution. The inlet velocities to the river and to WOC are applied uniformly across the face of the inlet boundary. The turbulence energy and eddy dissipation at the inlet are specified as a function of the inlet velocity, although parametric cases with the $2 \mathrm{D}$ model revealed that the Melton Hill boundary is far enough upstream as to make the results downstream of WOC relatively independent of the inlet turbulence.

\subsubsection{Limitations}

Two important limitations must be considered before applying this model. First, the specified WOC flow rate is assumed to be uniform across the vertical frontal area of the SRS adjacent to the river. The flow 
from WOC is assumed to have negligible momentum so that the inlet velocity distribution is unimportant, although the total contaminant level dumped into the CR is very important. Also, because it is known that a strong recirculation eddy exists in the CR immediately below the SRS, it is likely that the flow through the SRS will be higher on the upstream end due to a lower CR pressure. If details of the flow very near the SRS are important, the uniform-flow assumption may not be valid. It may in the future be desirable to treat the SRS as a porous medium, impose a pressure distribution on the upstream side of the SRS, and allow CFDSFLOW3D to calculate the flow distribution across the frontal area. This technique may actually result in backflow at some positions along the front surface of the SRS.

The second limitation is the assumption of a rigid (shear-stress-free) lid. Although CFDS-FLOW3D has the capability to simulate free-surface flows, the present assumptions are for a fixed river geometry, so that surface waves cannot be represented. This approximation is reasonable if the flow rate is constant, or the opening (or closing) of the dam occurs slowly compared to the time for surface wave propagation. However, if the surface-wave phenomenon is determined to be important for some analysis, calculations can be performed by extending the present application to include a region of air above the river and allowing the freesurface model in CFDS-FLOW3D to calculate the variation in water level.

\subsubsection{Description of Input File}

Once the grid is generated, a simulation of a flow problem requires that an input file be assembled to define such things as the relevant physics, numerical convergence parameters, boundary conditions, and print controls. Figure 14 shows the command file that was used to run the steady-state simulation that represents the river condition during the dye study. Within the input, some of the characters are set apart between the symbols $I^{*}$ and $* /$, meaning that the text is merely a comment.

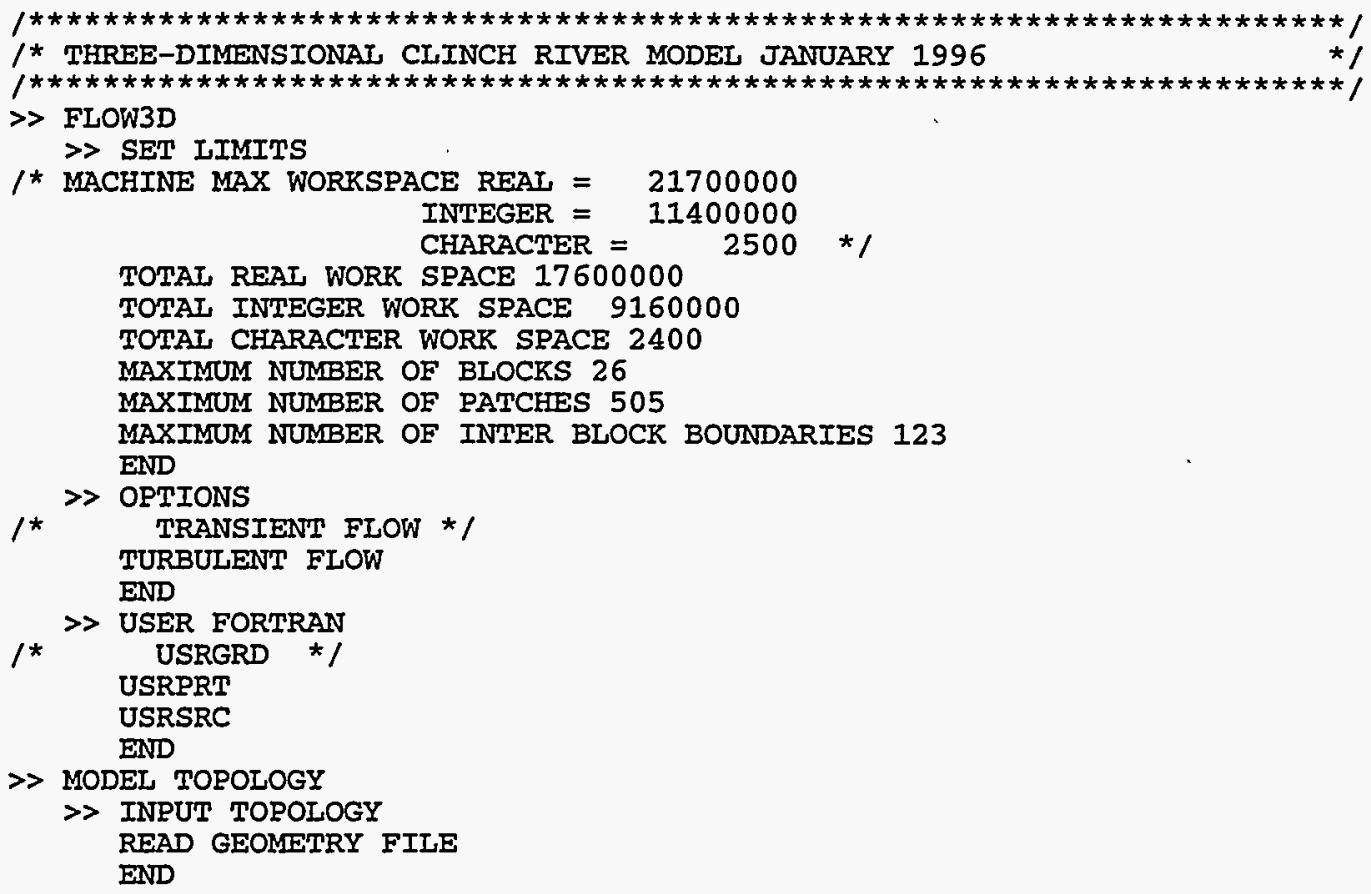

Fig. 14. CFDS-FLOW3D input file for initial steady-state dye-study case. 


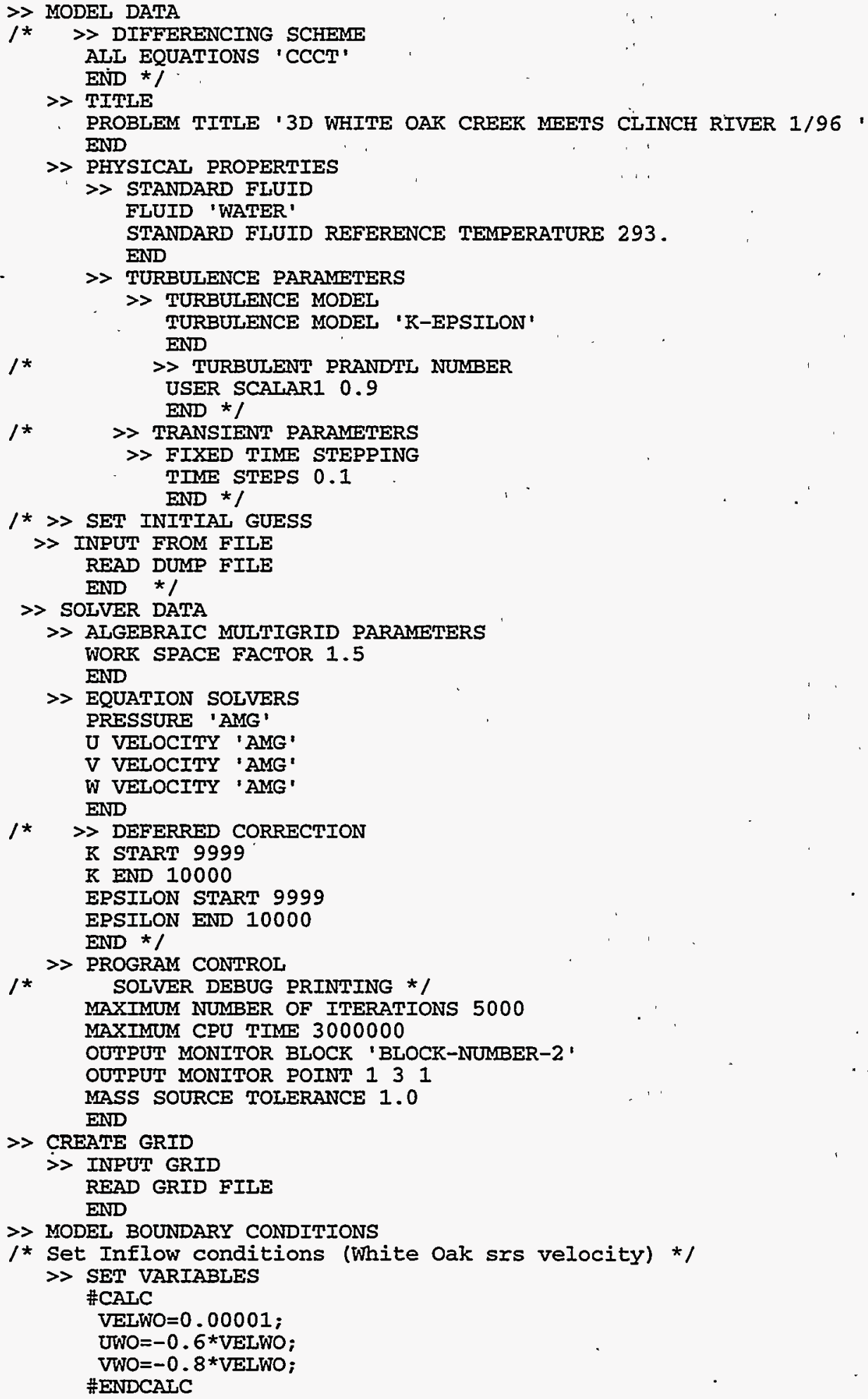

Fig. 14. (continued) 


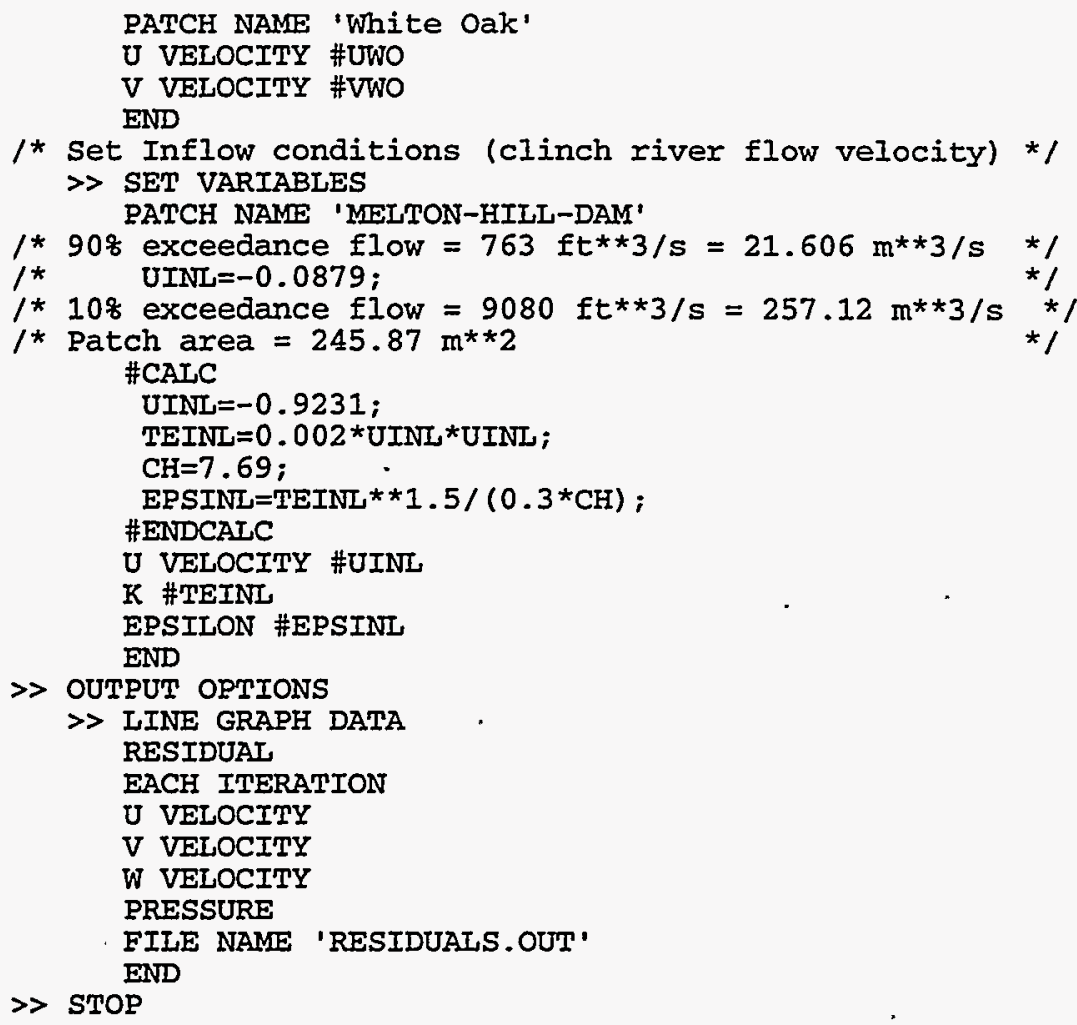

Fig. 14. (continued)

The SET LIMITS command defines the computational work space (memory) needed to perform the simulation. The OPTIONS command identifies the problem as turbulent. It also specifies whether the gravitational forces are important and whether the energy equation is to be solved. Also in these data the request is made to solve a user scalar transport equation. The USER FORTRAN command stipulates that a user-supplied subroutine USRSRC will be supplied to the simulation. For the dye study, this subroutine was used to introduce the dye into the appropriate location of the flow domain and to calculate average velocities at important streamwise locations. The MODEL TOPOLOGY indicates that the block structure has been developed using the preprocessor and is supplied in a separate data file.

The MODEL DATA sets the ambient value of the dye concentration (USER SCALAR1) to be 0.0 so that fluid entering the domain at Melton Hill Dam is assumed to be clean. Also, the differencing scheme is identified. The default hybrid differencing scheme which uses upwinding is applied here, although other differencing schemes such as CONDIF and CCCT (shown commented out in the input) were exercised. The problem title and physical properties are defined. CFDS-FLOW3D has its own library of material properties that includes those for water viscosity, conductivity, specific heat, density, Prandtl number, and coefficient of thermal expansion. The selection of the turbulence model is also made under MODEL DATA using the TURBULENCE PARAMETERS subcommand. In this case the standard $\mathrm{k}-\epsilon$ model is invoked. The molecular diffusivity of the user scalar (contaminant or dye) is defined to be small enough that it does not impact the solution. The eddy (turbulence-induced) diffusivity is much larger than the molecular value unless the flow is stagnant. The direction and magnitude of gravity and the reference temperature used in buoyant flows are the last two parameters defined under MODEL DATA.

The SET INITIAL GUESS command identifies the source for the initial condition. In this case, the initial condition is read from the results of a previous simulation. 
The SOLVER DATA includes information that defines the method of solution for the linearized difference equations. The pressure and momentum equations are solved here using the algebraic multigrid solver, which was determined to give the most efficient performance. Similarly, the line solver was used for the user scalar equation. It was found that using any of the other solvers for the user scalar equation led to very slow (often impossible) convergence. The underrelaxation factors, reduction factors, and number of sweeps are also important in obtaining rapid convergence. The reduction factor determines how much accuracy is required on the linearized equation before the next nonlinear step is taken.

Under PROGRAM CONTROL the overall convergence of the nonlinear equations is controlled by specifying how many linearized steps to take (MAXMMUM NUMBER OF ITERATIONS) and how low the residual must be before the solution is considered to be converged (MASS SOURCE TOLERANCE).

The CREATE GRID subcommand indicates that the discretization is supplied in a separate data file. This data file is output by the grid generator.

The MODEL BOUNDARY CONDITION information specifies a uniform velocity across part of the external surface of the computational domain. The turbulent kinetic energy and eddy dissipation at the inlet near Melton Hill Dam are specified in the standard way, with the turbulent kinetic energy equal to $0.2 \%$ of the free-stream velocity squared. Based on parametric tests with the $2 \mathrm{D}$ model, significantly increasing the level of inlet turbulence does not affect the solution downstream of WOC because the "entrance length" between Melton Hill Dam and WOC is sufficient to allow the flow to be independent of the inlet turbulence. The inflow is defined in the negative $x$ direction with a magnitude that will produce the correct velocity near the WOC confluence.

Finally, the OUTPUT options are specified so that the residuals are printed to a separate file to keep track of convergence on each iteration. 


\section{VALIDATION OF THREE-DIMENSIONAL CFD APPLICATION}

\subsection{DESCRIPTION OF THE DYE STUDY}

On May 5-7 1987, two field surveys were performed by the TVA Engineering Laboratory in collaboration with ORNL to quantify the mixing and transport characteristics for a typical CR flow in the reach of the river below the confluence with WOC. The first field survey was a plane source release of Rhodamine WT dye at CRM 14.5 to quantify longitudinal dispersion characteristics. The second survey, performed on May 7, involved a vertical-line source release of Rhodamine WT dye at the confluence between WOC and the $\mathrm{CR}$. The plume generated downstream of the line source release was tracked at discrete points throughout the day, by recording measurements of dye concentration as a function of time, depth, streamwise location, and transverse location (distance from the right bank). Here the right bank refers to the WOC side of the river, i.e. on the right when facing downstream. It is this second survey that provides appropriate data to validate the 3D application of the CFDS-FLOW3D model.

The May 7 field survey began at 9:00 a.m. EDT when $0.394 \mathrm{~m}^{3}$ (104 gal) of dye solution were pumped at a rate of $2.62 \mathrm{~m}^{3} / \mathrm{s}(4.16 \mathrm{gpm})$ through a manifold placed vertically in the river at a location (20 ft) off of the right bank just downstream of the WOC SRS. The initial concentration of the dye was $4.808 \times 10^{7} \mathrm{ppb}$. The flow rates at White Oak, Melton Hill, Fort Loudon, and Watts Bar dams were held constant as shown in Table 1 during the field survey. Flow velocities and dye concentration measurements were taken within the extent of the plume as it moved downstream. Based on the measurements, average velocities were calculated at various streamwise locations. The average velocity calculated for the cross section at CRM 20.8 was 0.257 $\mathrm{m} / \mathrm{s}(0.843 \mathrm{ft} / \mathrm{s})$. At CRMs 19.6 and 18.0, the average velocities were $0.301 \mathrm{~m} / \mathrm{s}$ and $0.287 \mathrm{~m} / \mathrm{s}(0.99$ and 0.942 $\mathrm{ft} / \mathrm{s})$, respectively.

Table 1. Important flow rates during the Clinch River dye study of May 7, 1987

\begin{tabular}{ccc}
\hline \multirow{2}{*}{ Location } & \multicolumn{2}{c}{ Flow rate } \\
\cline { 2 - 3 } & $\mathrm{ft}^{3} / \mathrm{s}$ & $\mathrm{m}^{3} / \mathrm{s}$ \\
\hline White Oak Dam & $30-35$ & $0.85-0.99$ \\
Melton Hill Dam & 8,000 & 227. \\
Fort Loudon Dam & 20,000 & 566 \\
Watts Bar Dam & 30,200 & 855 \\
\hline
\end{tabular}

${ }^{a}$ During dye injection

The measured dye concentrations at CRM 19.6 (just downstream of Jones Island), CRM 18.0 (just downstream of Grubb Islands), CRM 16.5, and CRM 14.5 (K-25 Filtration Plant) are shown in Figs. 15-18.

\subsection{SIMULATION OF THE DYE STUDY}

The results of the 1987 dye study were used to validate the accuracy of the 3D CR model. This validation was accomplished by first solving the steady-state flow field before the dye injection, and then fixing the hydrodynamic field and solving the time-dependent dye transport problem. All simulations were performed on an IBM RISC System (RS) 6000 Model 580 Workstation. 


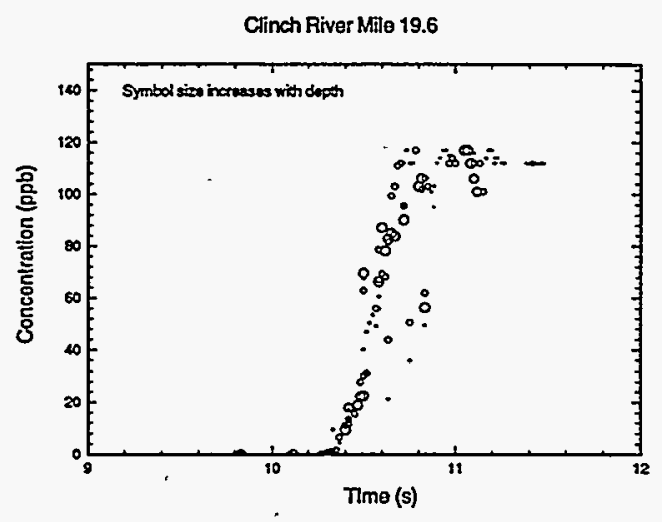

Fig. 15. Dye concentration measurements taken on May 7, 1987, at CRM 19.6.

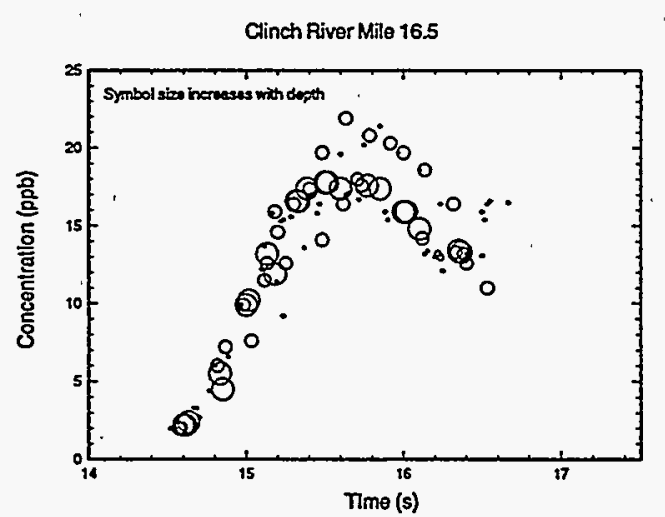

Fig. 17. Dye concentration measurements taken on May 7, 1987, at CRM 16.5.

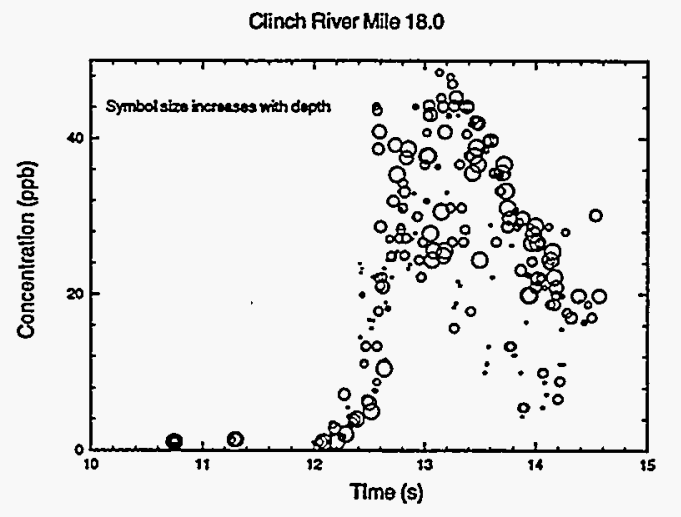

Fig. 16. Dye concentration measurements taken on May 7, 1987, at CRM 18.0.

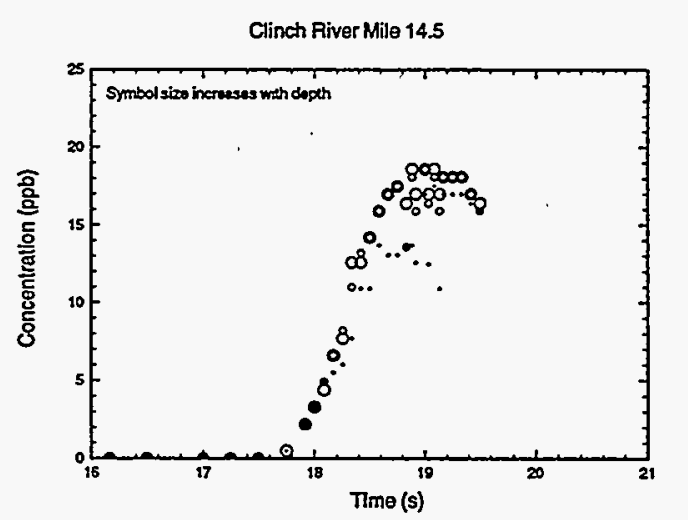

Fig. 18. Dye concentration measurements taken on May 7, 1987, at CRM 14.5.

To determine whether the solution was dependent upon the selected grid, more than one discretization was used. The baseline discretization has already been described in Chap. 3. Also, for the transient, care was taken to select a time step small enough that the solution was virtually insensitive to further reductions.

\subsubsection{Steady-State Simulation}

The inlet velocity at the Melton Hill Dam boundary was set such that the resulting average velocity at CRM 20.8 was $0.257 \mathrm{~m} / \mathrm{s}$ as measured on May 7, 1987. The resulting computed flow rate of $208 \mathrm{~m}^{3} / \mathrm{s}$ is $8.5 \%$ lower than the indicated measured flow at Melton Hill Dam (see Table 1). This discrepancy is probably due to the inaccuracy of the Melton Hill Dam flow-rate measurement, although some inaccuracy also exists in the river cross-sectional area that is based on discrete depth measurements taken during the 1987 field survey. It is important that the average measured velocity be used as the flow rate constraint in the simulation rather than the Melton Hill Dam measured flow rate because it is the local velocity distribution that dictates the magnitude of the turbulent kinetic energy production and, hence, the rate of contaminant transport in the river.

The input file presented in Chap. 3 was used for performing steady-state simulations. A steady-state solution was obtained by iterating on the finite-difference equations until the residuals for all equations were as low as possible. The residual indicate how close the solution approximates conservation of mass and momentum. After a certain point, the numerical precision and/or errors introduced due to the finite differences 
limits any further reduction in the residuals. Using the default (hybrid) differencing scheme, the mass residual was lowered to $3700 \mathrm{~kg} / \mathrm{s}$, which is $1.6 \%$ of the river flow rate $(226,500 \mathrm{~kg} / \mathrm{s})$. With other, less diffusive, differencing schemes, it was not possible to get the residuals down to a reasonable level.

The resulting computed speed on the water surface is shown in Fig. 19. Figure 20 shows surface stream lines near the WOC confluence. The velocity distribution shows recirculation patterns at the WOC confluence on either side of the river.This feature in the flow field is consistent with the field observations that have been made when Melton Hill Dam is operating.

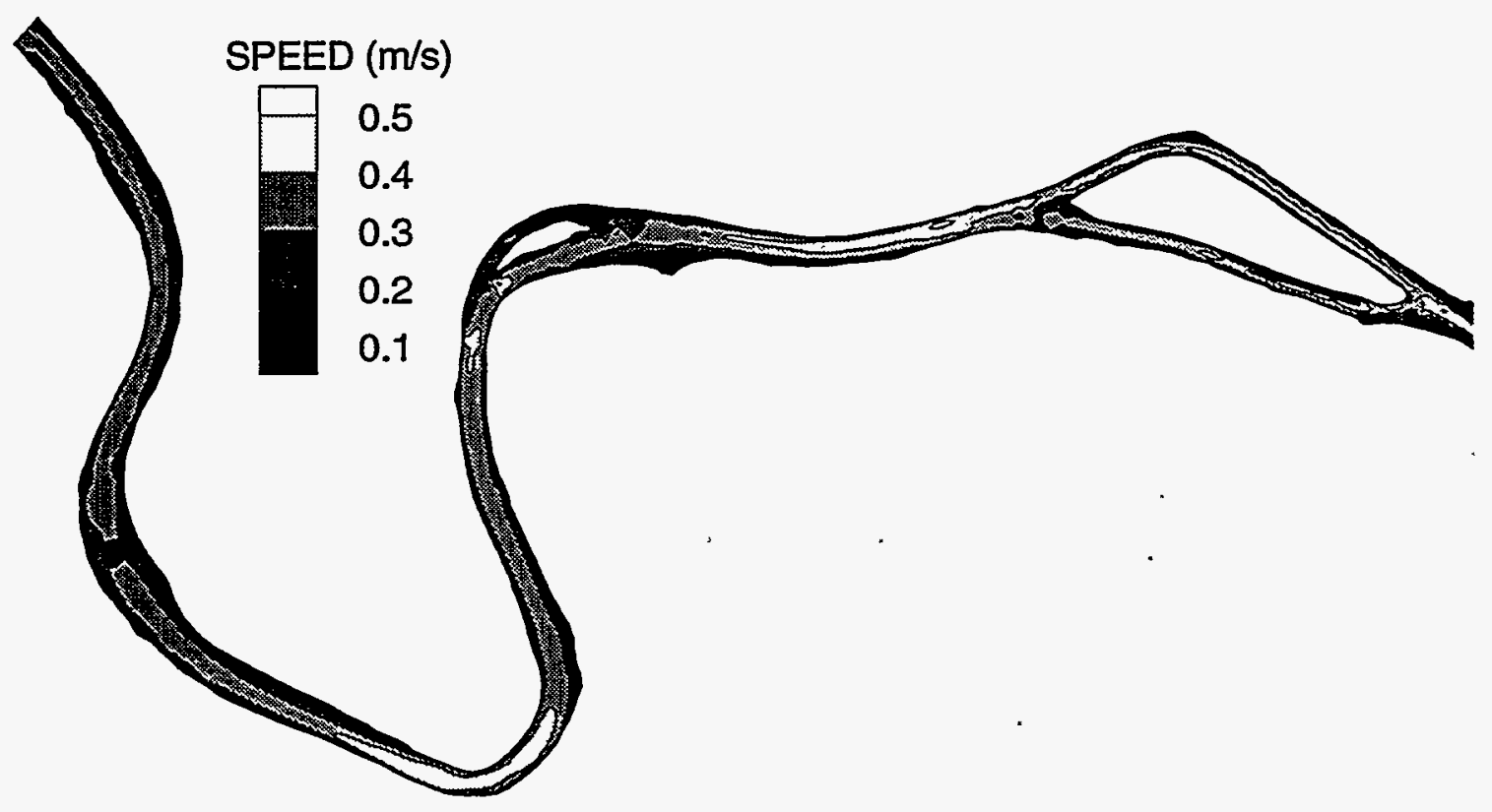

Fig. 19. Speed on the surface of the Clinch River computed with the three-dimensional model for the dye study calculation. 


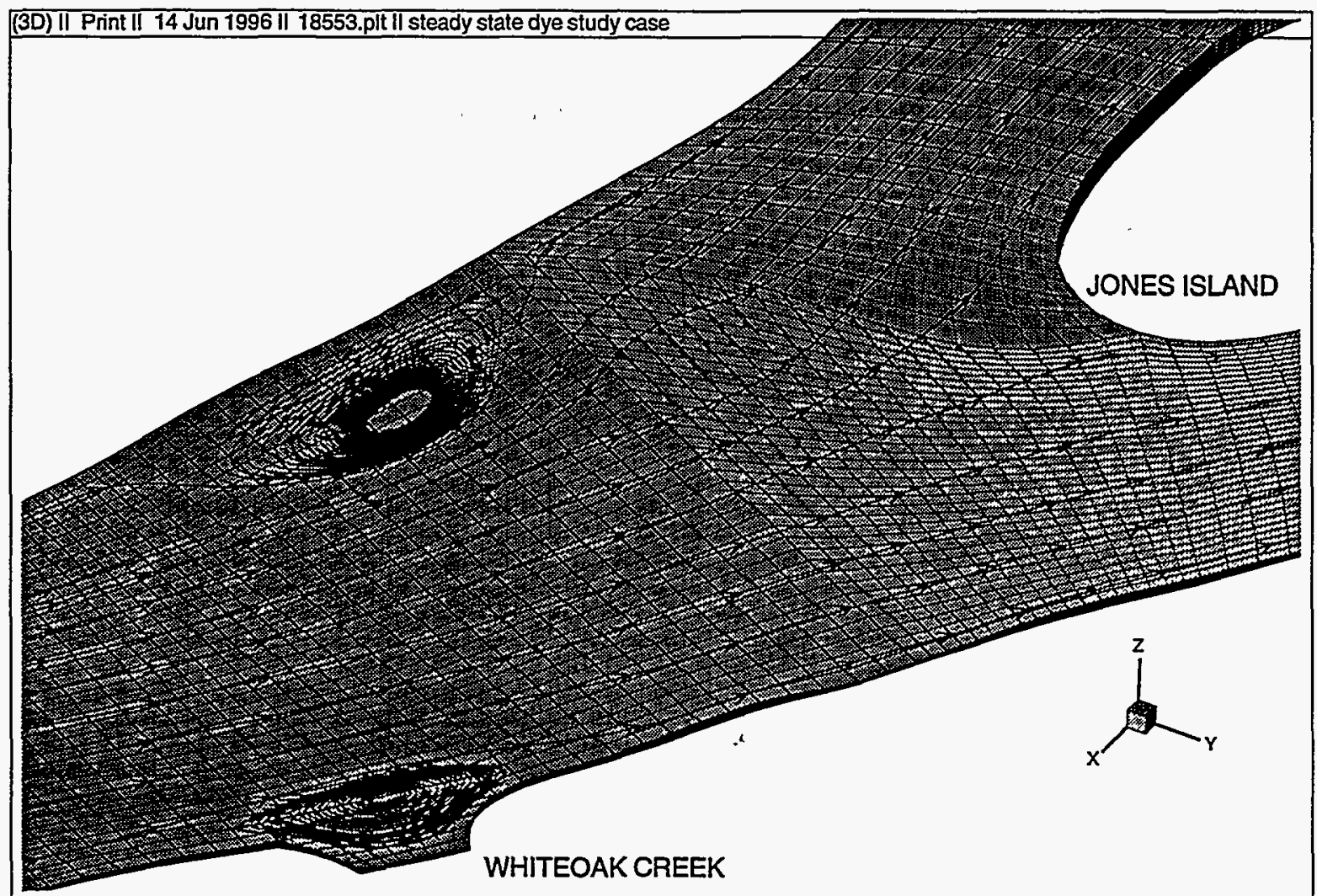

Fig. 20. Computed flow pattern near the WOC/CR confluence.

\subsubsection{Transient Simulation}

The 3D velocity-vector field was fixed at the calculated steady-state solution, and a transient simulation of the dye dispersion through the steady flow field was run until the dye plume passed out of the computational domain. The advection and diffusion of the dye was modeled with a user-defined scalar equation. The injection of the dye was represented by introducing a mass source into the user scalar equation lasting the first $25 \mathrm{~min}$ of simulated time. The subroutine USRSRC included in Appendix A contains the FORTRAN that was written to accomplish this purpose. USRPRT (also shown in Appendix A) was used to calculate maximum dye concentrations at each cross section and to obtain some extra output.

The transient simulation was run for 39,600 s (from 9:00 a.m. until 8:00 p.m.), requiring 20 hours of CPU time on the RS6000 Model 580. The dye was injected, as specified in the dye study report, just off the right bank of the river near the WOC SRS, as shown in Fig. 21.

The dye concentration is shown in Fig. 22 at 11:22 a.m., the time at which the maximum dye concentration at CRM 19.6 was calculated. Three concentration contour levels are shown in Fig. 22: the black represents concentration greater than $100 \mathrm{ppb}$ the darker gray represents concentrations between 10 and 100 $\mathrm{ppb}$; the lighter gray represents concentrations between 1 and $10 \mathrm{ppb}$ and the white represents concentrations less than $1 \mathrm{ppb}$. The entire plume stays to the north of Jones Island in the main river channel. The computational results showed that the dye spreads in the cross-stream direction across the river bottom faster than along the surface. This is because turbulence energy is generated near the river bottom and the turbulent diffusion is therefore greater near the bottom. 


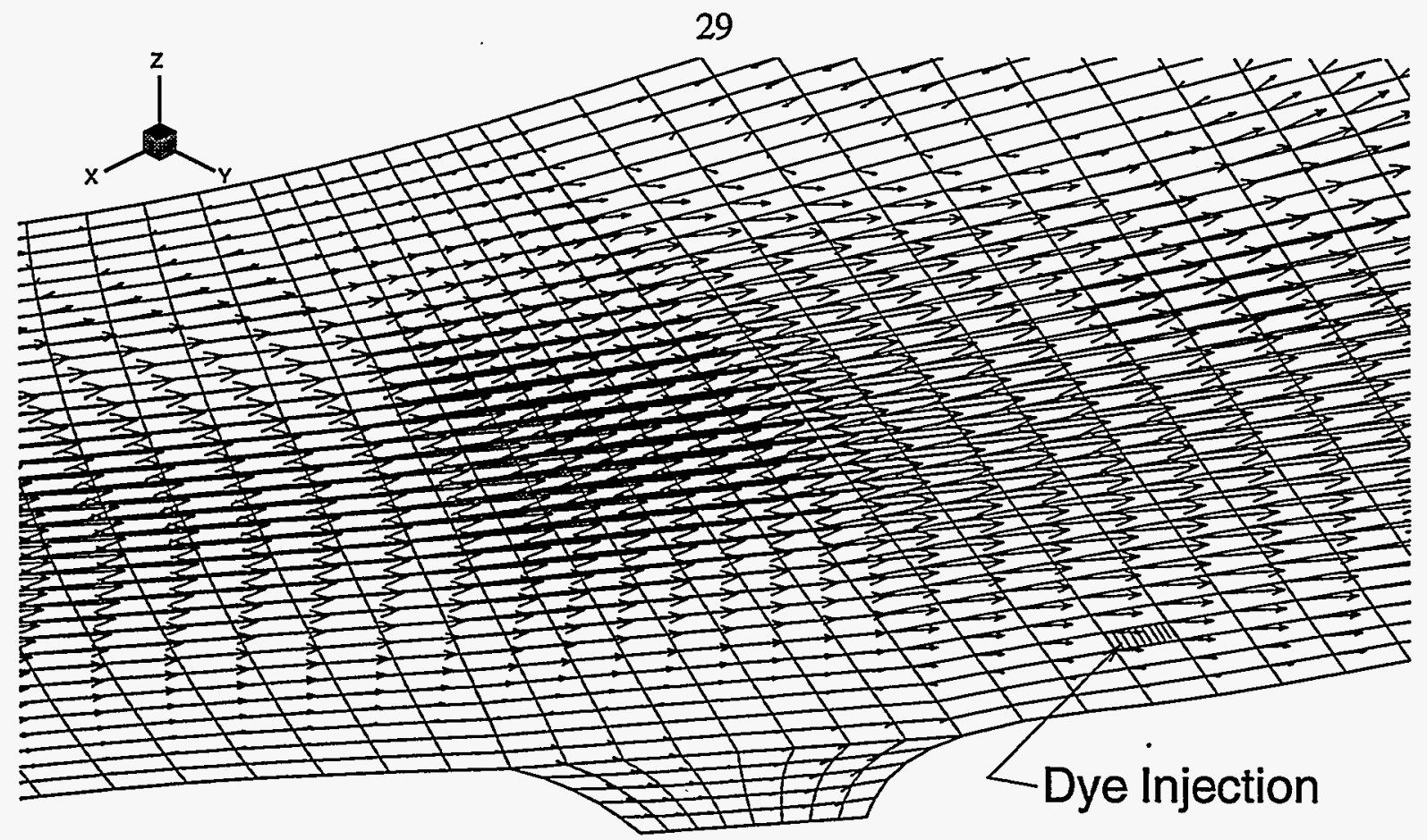

Fig. 21. Isometric of computational domain near WOC SRS showing computed steady-state surface velocities and control volumes used for simulating dye injection.

Figure 23 shows the dye concentration in the river at 1:38 p.m. when the peak concentration is calculated at CRM 18.0. Some of the dye passes to the south of Grubb Island, but most remains on the north side nearer the right bank. The tendency for the dye to spread faster along the river bottom is evident in the cross-stream profiles shown in Fig. 23.

Figures 24 and 25 show the dye concentration at 3:18 p.m. and 6:02 p.m. when the peak values are calculated at CRMs 16.5 and 14.5 , respectively. 


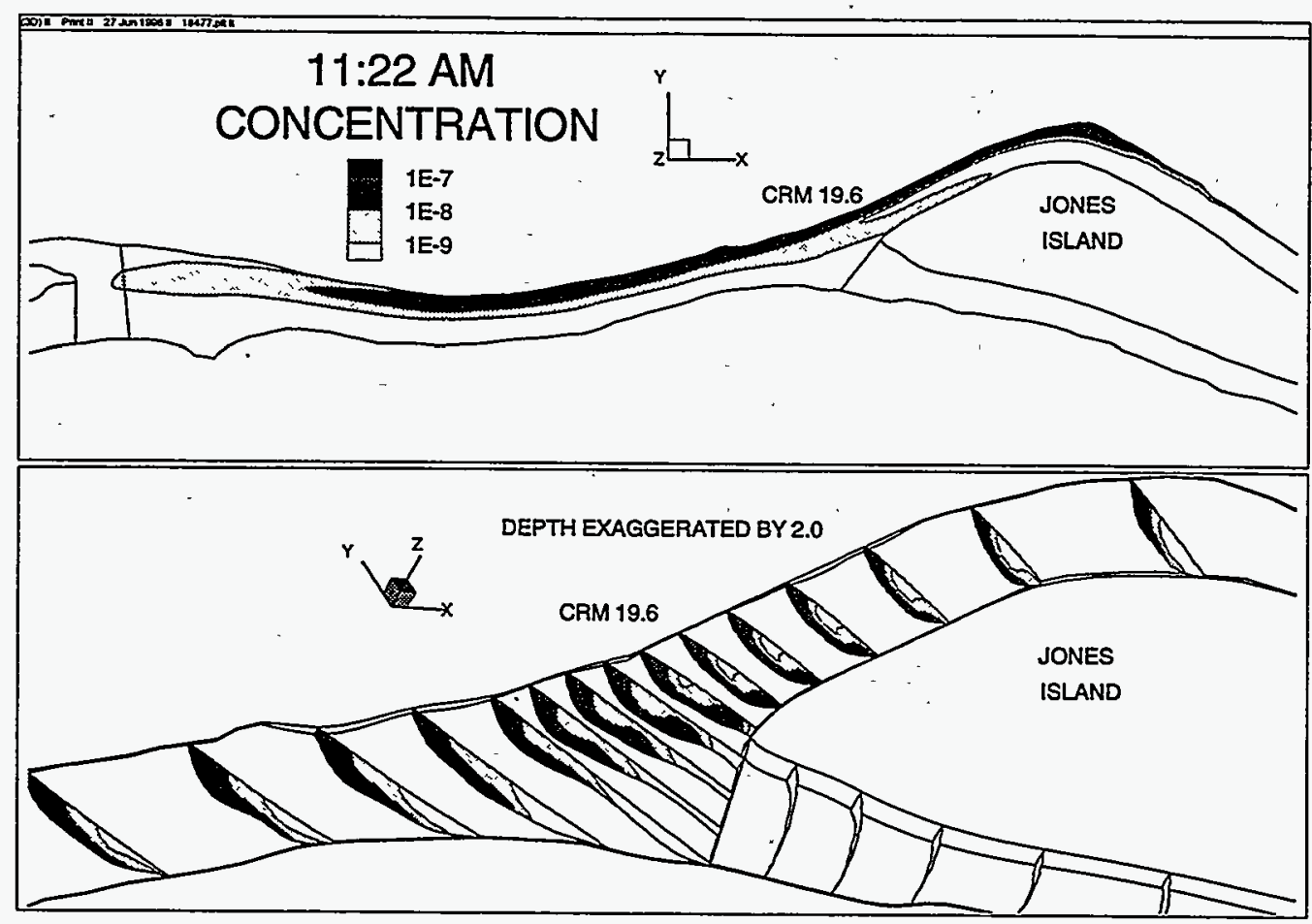

Fig. 22. Clinch River dye concentration at 11:22 a.m. when maximum concentration is calculated at CRM 19.6.

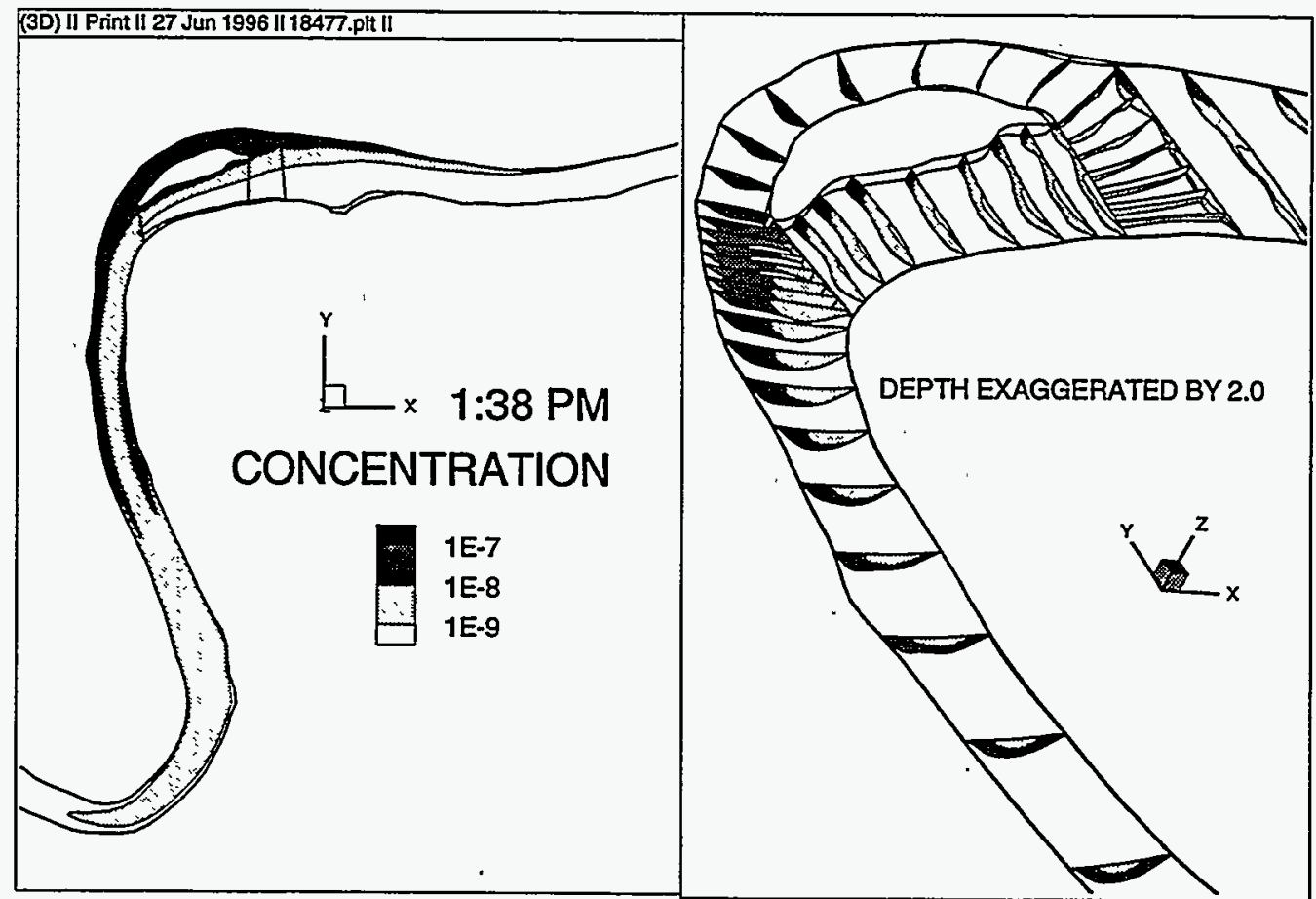

Fig. 23. Clinch River dye concentration at 1:38 p.m., when maximum concentration is calculated at CRM 18.0. 


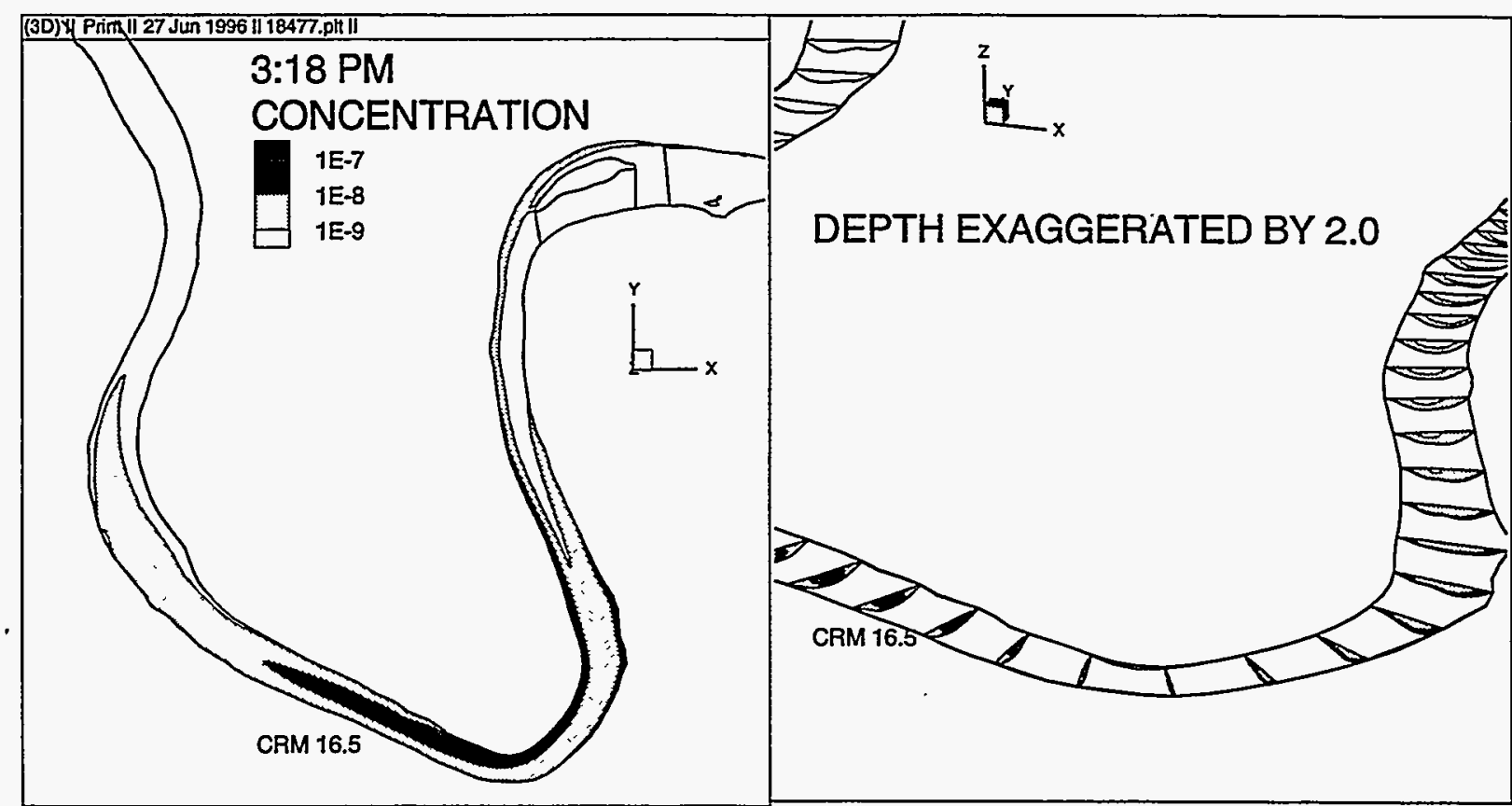

Fig. 24. Clinch River dye concentration at 3:18 p.m., when maximum concentration is calculated at CRM 16.5.

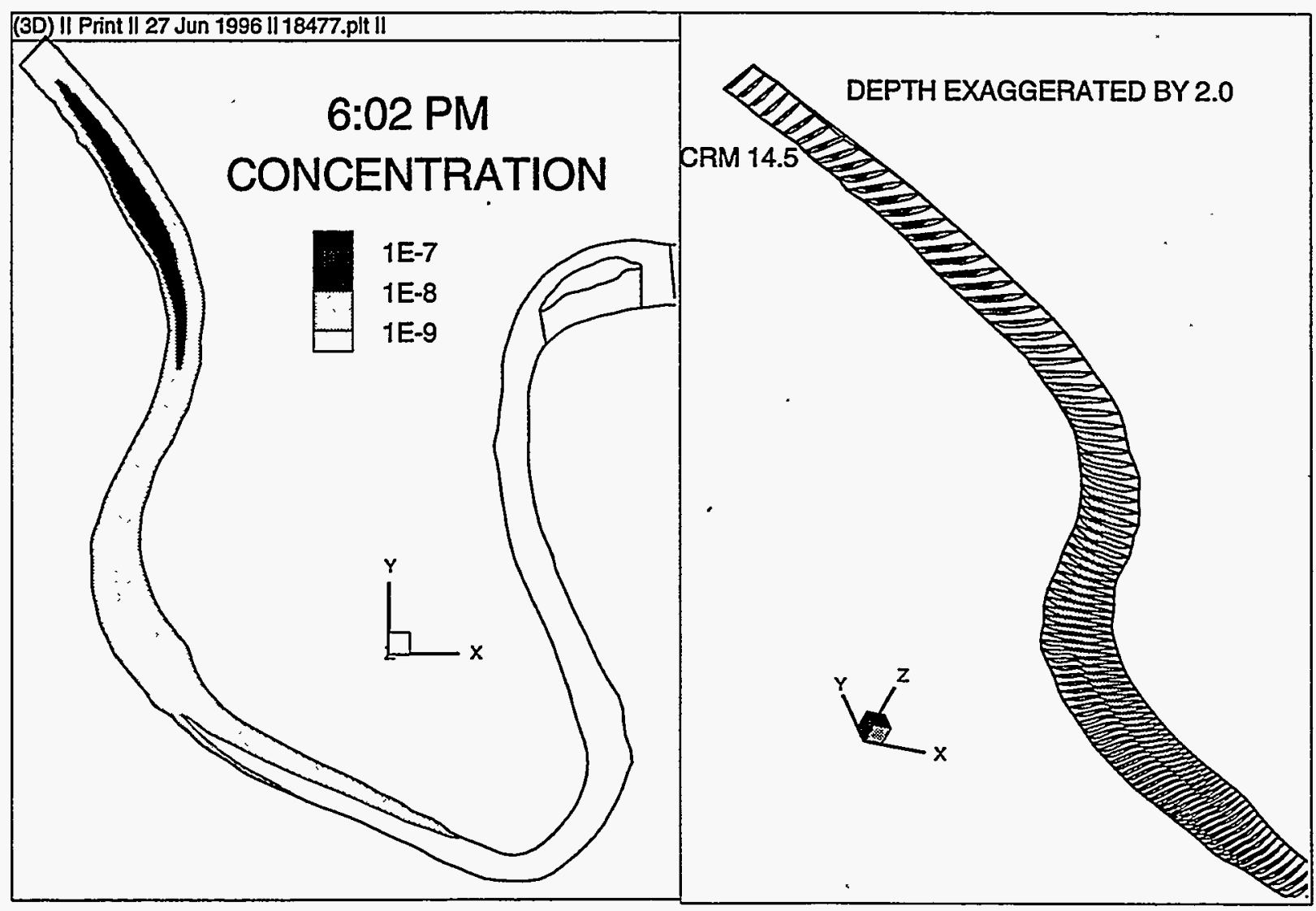

Fig. 25. Clinch River dye concentration at 6:02 p.m., when slug approaches CRM 14.5. 
The first location for which data are available downstream of the dye injection point is CRM 19.6. A comparison of the simulated and measured dye concentrations at this location is given in Fig. 26 at the six cross-stream locations for which data were collected. Similar comparisons are shown at CRMs 18.0, 16.5, and 14.5 in Figs. 27-29 respectively. The continuous curves in the figures show the computed results at six depth levels equally spaced through the river depth at that location. The curve at the shallowest location is labelled as "SURFACE," and the curve for the deepest level is labelled as "BOTTOM." The circular symbols show the measured data with symbol size proportional to the depth at which the measurement was taken. The distance from the right bank for each cross-stream location is indicated in the upper right corner of the plot.

At CRM 19.6 (Fig. 26) the computed concentrations are consistent with the measured data, although the computations indicate that perhaps the maximum concentration was missed during the field study since only a few measurements were taken at the 40 -ft cross-stream location (see the first plot in Fig. 26). At the 80$\mathrm{ft}$ location, enough data were collected to indicate that the computed maximum concentration is only $8 \%$ lower than the measured maximum. None of the other locations have enough data to distinguish a maximum. The simulation indicates that the concentration is much higher near the river bottom than at the surface, but the measurements do not show this dispersion of the dye. Also, the effect of side streams flowing into the CR, in particular those on the right bank, would be to increase transverse mixing. These streams have been neglected although given appropriate flow rate data (not specified in the dye-study report), they could easily be included in the analysis.

At CRM 18.0 (Fig. 27), the computed maximum concentrations at cross-stream distances of 75,150 , and $262 \mathrm{ft}$ are lower than the measurements by $26 \%, 32 \%$, and $40 \%$, respectively. However, the distribution with the depth appears to match the data with higher concentrations being detected at greater depths. The time at which the plume arrives and passes appears virtually the same for measurement and simulation at a crossstream distance of $150 \mathrm{ft}$, although for two other cross-stream locations (75 and $262 \mathrm{ft}$ ) the experimental data indicate an earlier arrival (by about an hour) than that predicted by the model.

At CRM 16.5 (Fig. 28), the simulation once again predicts lower concentrations, this time 26-59\% lower than the measured maxima. The time at which the peak concentration is reached at CRM 16.5 is well predicted by the simulation (within less than 20 minutes). However, the simulated dye slug has clearly been spread out in the streamwise direction significantly more than measurements indicate the actual slug spread. This overestimate of streamwise dispersion accounts for the lower peak concentrations predicted by the simulation. 

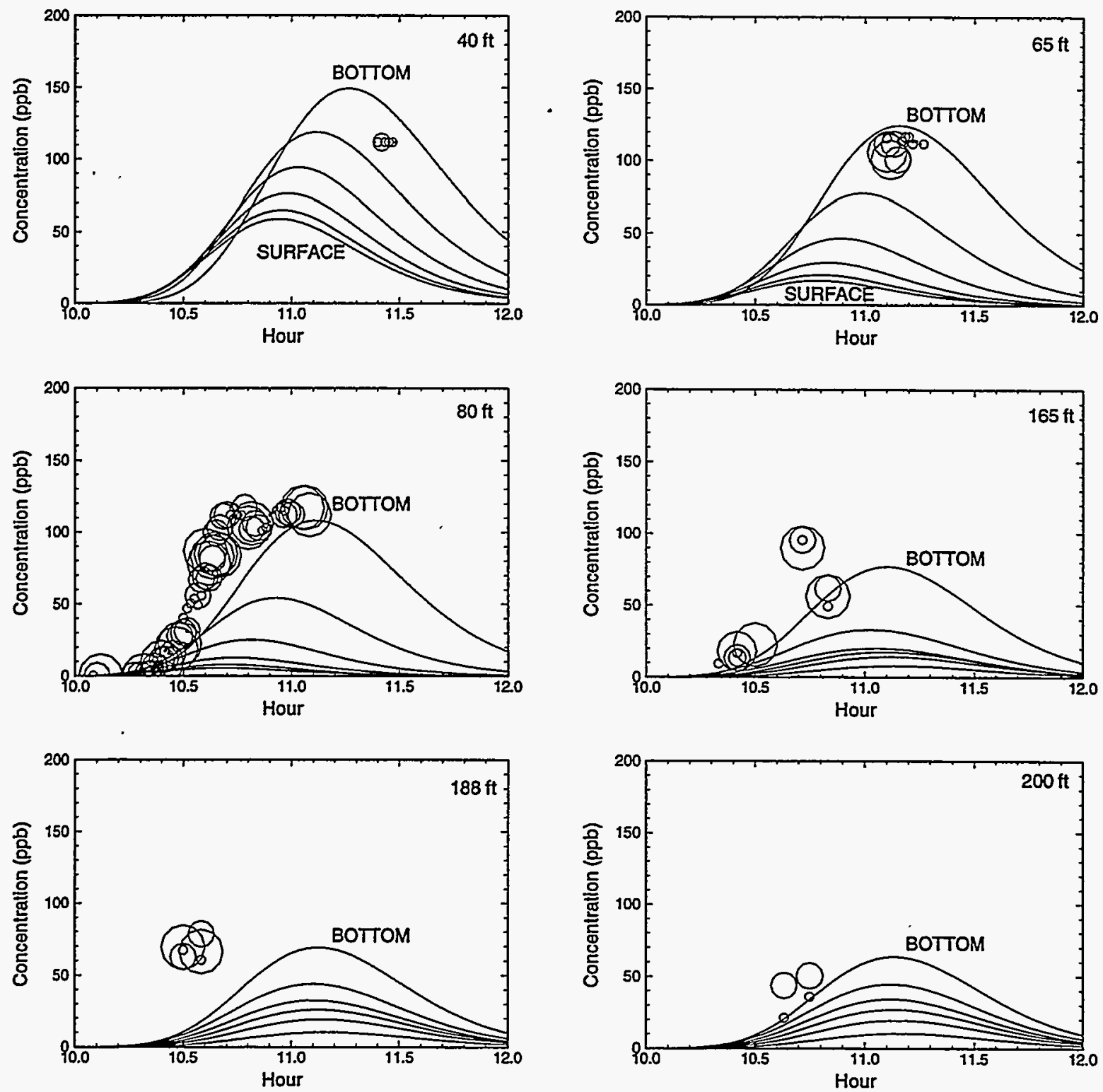

Fig. 26. Comparison of computed and measured dye concentration at CRM 19.6 for baseline case. 

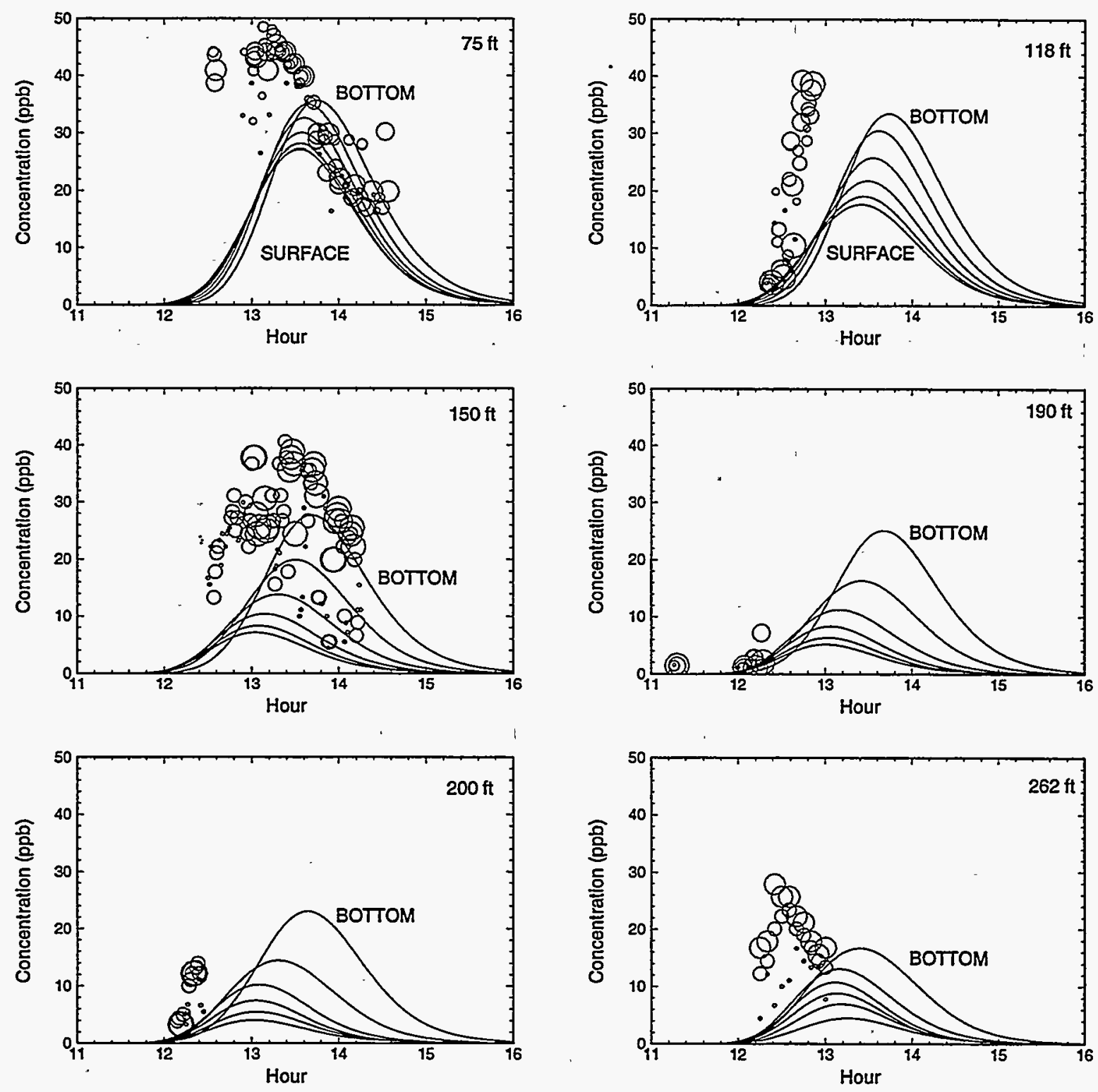

Fig. 27. Comparison of computed and measured dye concentration at CRM 18.0 for baseline case. 
At the K-25 pumping station near CRM 14.5 (Fig. 29), the trend in the simulation to overpredict the streamwise dispersion of the dye slug is again evident. This time, the peak concentration is underpredicted by $42 \%$ for the cross-stream location of $220 \mathrm{ft}$. Both the data and the simulation indicate that there is very little variation in concentration in the depthwise direction.
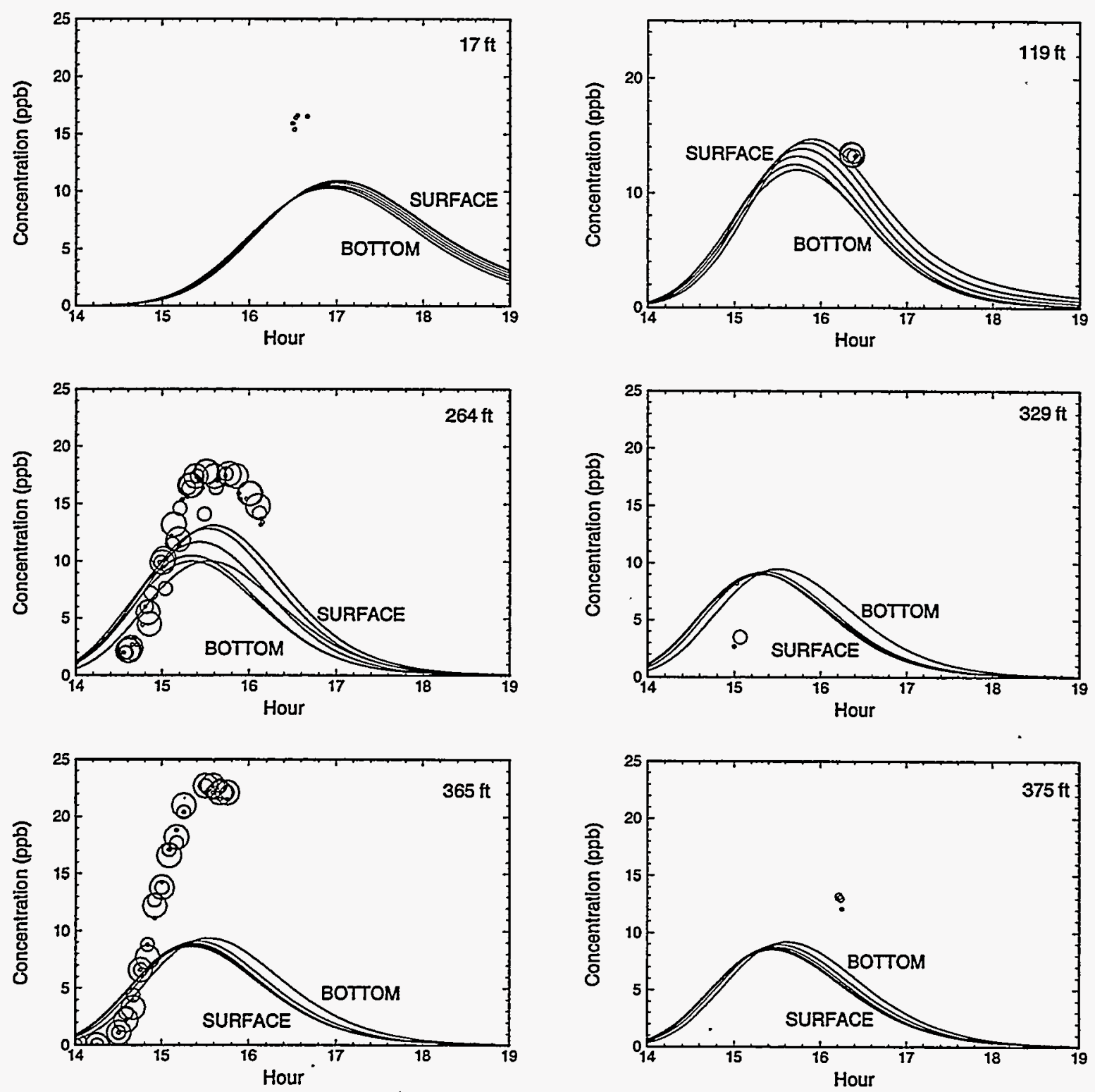

Fig. 28. Comparison of computed and measured dye concentration at CRM 16.5 for baseline case. 

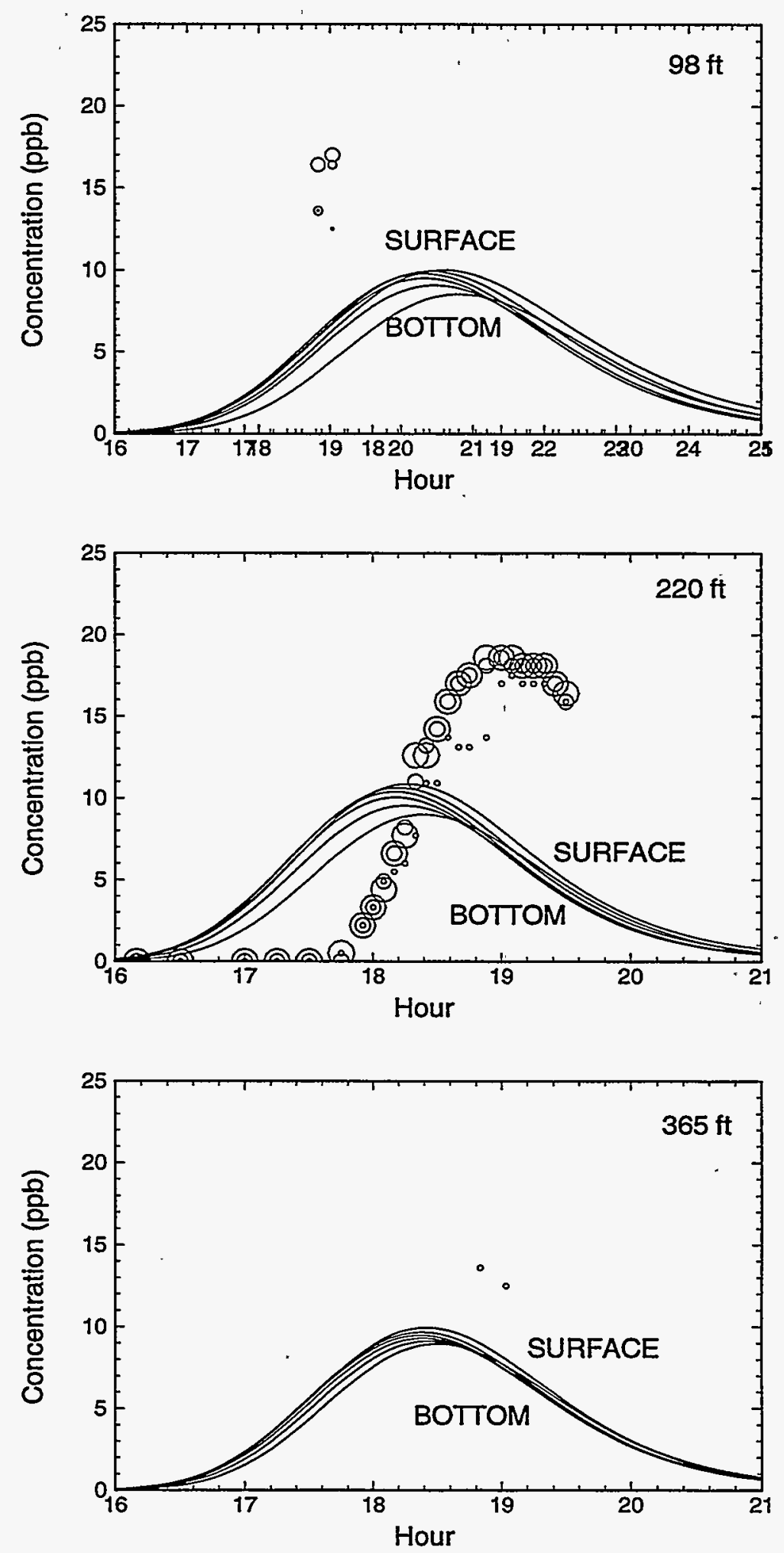

Fig. 29. Comparison of computed and measured dye concentration at CRM 14.5 for baseline case. 


\subsubsection{Sensitivity Studies}

To ensure that the computed results represent a meaningful solution to the conservation law system over the defined computational domain with applied boundary conditions, it must be shown that they are not highly distorted by numerical aspects of the model, specifically, time-step and mesh distribution. For this purpose additional simulations were used to investigate the sensitivity of the computed results to these aspects. Table 2 shows the resulting maximum concentrations for all of the cases including sensitivity studies. The case numbers are indexed to match computer tape backup information. The "baseline" case presented in detail in the previous section is case number 18477 .

Table 2. Maximum concentrations of dye for all dye-study simulation cases

\begin{tabular}{cccccc}
\hline \multirow{2}{*}{ Case number } & Time step & $\begin{array}{c}\text { Number of control } \\
\text { volumes }\end{array}$ & \multicolumn{3}{c}{ Maximum dye concentrations } \\
\cline { 4 - 6 } & $(\mathrm{s})$ & 108,744 & 31.7 & 12.7 & 10.0 \\
\hline 26427 & 50 & 108,744 & 41.0 & 15.8 & 10.9 \\
18477 & 20 & 108,744 & 41.7 & 16.1 & 11.1 \\
33693 & 10 & 108,744 & 36.6 & 14.0 & 9.6 \\
13651 & 50 & 106,576 & 35.3 & 13.2 & 9.2 \\
33198 & 50 & 51,102 & 33.5 & 13.9 & 10.0 \\
29287 & 50 & 186,040 & 41.8 & 17.2 & 11.4 \\
30094 & 50 & & & & CRM 14.5 \\
\hline
\end{tabular}

Sensitivity to the time step was first addressed. The results that were presented in detail in Sects. 4.2.1 and 4.2.2 were produced by a simulation that assumed a time step of $20 \mathrm{~s}$. Two additional simulations were performed to determine the sensitivity of the results with respect to time step. The results for maximum concentration at CRMs 18.0, 16.5, and 14.5 are presented in Fig. 30. These results show that increasing the time step to $50 \mathrm{~s}$ (case 26427) results in decreases in contaminant concentration of $24 \%$ at CRM 18.0, 22\% at CRM 16.5, and 10\% at CRM 14.5. However, when the time step is reduced to $10 \mathrm{~s}$ (case 33693), there is less than a $2 \%$ change in concentration at all locations. Therefore, the 20 -s time step is adequately small at this or lower flow rates. 


\section{TIME STEP SENSITIVITY FOR DYE STUDY CASE}

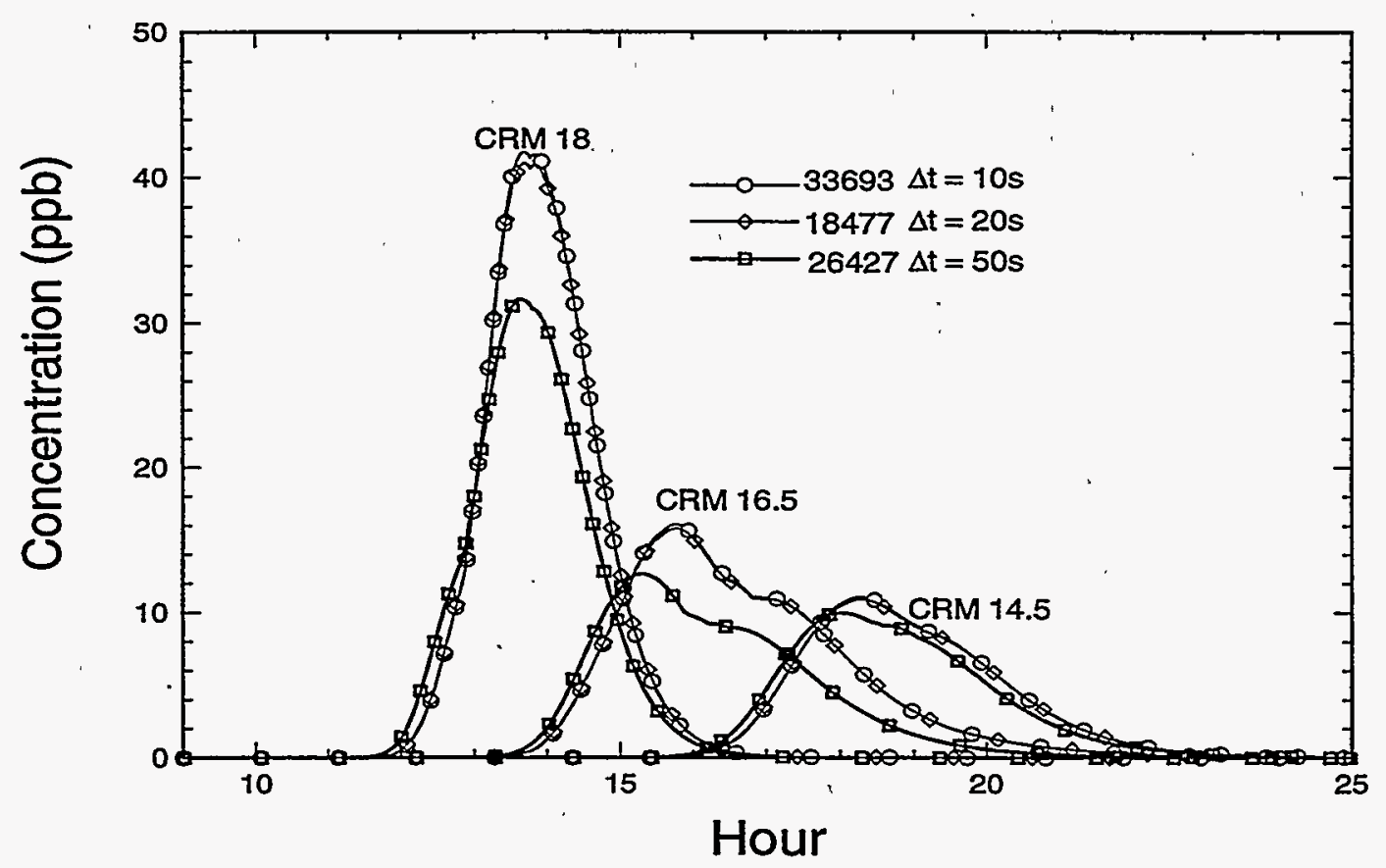

Fig. 30. Comparison of maximum dye concentration for time-step sensitivity study.

The sensitivity of the dye study simulation results to discretization was also investigated. The depth-wise node distribution in the baseline discretization is equally spaced throughout the depth with only six control volumes used. The first refinement (case 13651) left the number of nodes through the depth at six, but the distribution of control volume size was set to grow progressively smaller towards the river bottom. A geometric progression factor (ratio of adjacent control volume heights) of 0.7 was applied. The second refinement (case 33198) used eight cells through the depth, again with a geometric progression factor of 0.7 , and fewer nodes in the horizontal plane, keeping the total number of nodes nearly unchanged.

Another discretization (case 29287) with fewer subdivisions on the horizontal plane was generated. The number of subdivisions for each block was decreased by $20 \%$ in both horizontal dimensions, and the depth wise refinement was maintained at six subdivisions. This coarser mesh had 51,102 control volumes.

A final discretization (case 30094), much refined (by about a factor of 2) in the horizontal direction and with six nodes deep, was produced. Results using this discretization showed higher dye concentration levels, with a $10 \%$ increase at CRM 14.5 compared to all of the other discretizations. This refinement shows some improvement in the comparison with the data.

The resulting maximum concentrations at CRMs 18.0, 16.5, and 14.5 are shown in Fig. 31 as a function of time for the discretization study. This comparison shows that the peak concentrations at CRM 14.5 are all within $10 \%$; hence, the solution is relatively grid-independent. 


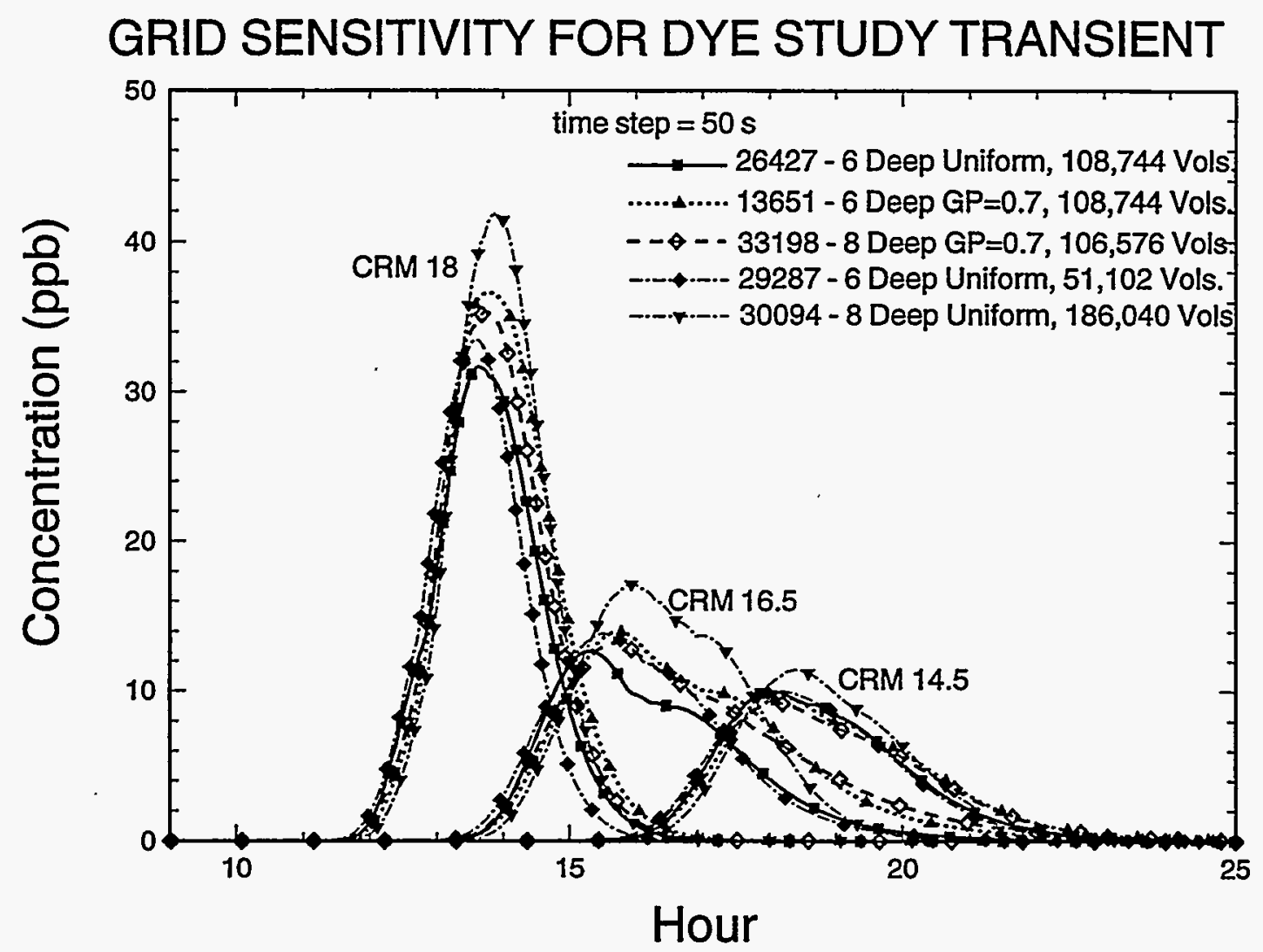

Fig. 31. Comparison of maximum dye concentrations for grid-resolution sensitivity study. 


\section{CONCLUSIONS}

A CFD model has been built for use in simulating dispersion of suspended WOC contaminants within the, $\mathrm{CR}$. The model consists of: (1) a detailed 3D discretization of the river geometry; (2) FORTRAN prepared to represent injection of contaminant sources and monitoring of dye concentration; and (3) physical properties and solution control information. The solution of the conservation equations is obtained over the defined flow domain using CFDS-FLOW3D, a commercial CFD code.

Validation has been performed against transient multidimensional field data collected during a 1987 dye study. The comparisons show that differences between the 3D model predictions and the measured dye concentration are within a factor of 2 , five miles downstream of the dye injection point. The predicted steadystate velocity field shows the recirculation pattern that can be readily observed at the confluence with WOC when Melton Hill Dam is operating. The solution to the dye study problem has been shown to be relatively insensitive to refinement of the grid and time step.

The tendency for the model to spread the dye out in the axial direction can be attributed to numerical diffusion and to the inapplicability of the general purpose turbulence model. Numerical diffusion is a problem with using a heavily upwinded differencing scheme, as the solution is only first-order accurate. Attempts to use a higher-order differencing scheme led to problems with convergence of the solution (numerical instability). The best way to reduce the numerical diffusion is through additional mesh refinement.

To use the present 3D application of the CFDS-FLOW3D model, the following restrictions apply:

(1) The flow rates at Melton Hill Dam, WOC SRS, and all side streams must be known or assumed.

(2) The CR flow rate cannot vary rapidly unless the application of CFDS-FLOW3D is extended to include the free-surface capability or unless the flow rate changes uniformly with time in the vicinity of the contaminant. All other side-stream flow rates can vary at any rate as long as surface wave effects are not expected to be important.

(3) The sediment is assumed to be suspended or in solution with no radioactive decay. The application can be extended to include sedimentation and radioactive decay models if desired. 


\section{ACKNOWLEDGMENTS}

- Antoinette Brenkert, Steve Bao, and Clell Ford of Environmental Sciences Division were generous with their consultations and accelerated the model development by providing data, access to the WOC SRS site, and referrals to important documentation. John Vadnal of Duke Power and Vahid Alavian and Gary Hauser of the TVA Engineering Laboratory at Norris, Tennessee, were very helpful with their answers to questions about the $C R$ dye study and with their very useful comments regarding the CFD model. The support staff of AEA Technology Engineering Software in Pittsburgh, Pennsylvania, provided numerous problemsolving consultations that accelerated the model-building process. Fred Latham of the Oak Ridge Environmental Restoration Program exported the river boundary data from the Arc/Info Geographic Information System. Antoinette Brenkert, Jack Dixon, and James Clinton were quite helpful in their reviews of this document. 



\section{REFERENCES}

1. R. J. Morton (ed.) et al., Status Report No. 4 on Clinch River Study, Clinch River Study Steering Committee, ORNL-3049, Union Carbide Corp., Oak Ridge Natl. Lab., September 1963.

2. R. O. Johnson, The Development of an Aquatic Spill Model for the White Oak Creek Watershed, ORNL/TM-13181, Lockheed Martin Energy Systems, Inc., Oak Ridge Natl. Lab., May 1996.

3. W. W. Hargrove, F. M. Hoffman, and D. A. Levine, "Interpolation of Bottom Bathymetry and Potential Erosion in a Large Tennessee Reservoir System Using GRASS," pp. 552-57 in Proc. Ninth Annual Symposium on Geographic Information Systems in Natural Resources Management, Vancouver, British Columbia, Canada, March 27-30, 1995, Vol. 2.

4. J. L. Vadnal and L. M. Beard, Mixing and Transport Caracteristics of the Clinch River, WR28-1-530111, Tennessee Valley Authority Office of Natural Resources and Economic Development, June 1988. (NEED location of publisher)

5. CFDS-FLOW3D Release 3.2: User Manual, AEA Industrial Technology, Harwell Laboratory, Oxfordshire, United Kingdom, 1992.

6. W. Rodi, Turbulence Models and their Application in Hydraulics-A State of the Art Review, 2d ed., Institut für Hydromechanik, University of Karlsruhe, Karlsruhe, Federal Republic of Germany, 1984.

7. W. L. Harper and J. L. Vadnal, Description of the Contaminant Mixing and Transport Models Developed at the TVA Engineering Laboratory for the Clinch River, WR28-1-530-115, Tennessee Valley Authority Engineering Laboratory, Norris, Tennessee, April 1991.

8. L.-Y Oey and G. L. Mellor, "A Three-Dimensional Simulation of the Hudson-Raritan Estuary, Part I: Description of the Model and Model Simulations," J. Phys. Oceanogr. 15, 1676-92 (1985).

9. B. Galperin and G. L. Mellor, "A Time-Dependent, Three-Dimensional Model of the Delaware Bay and River System, Part 1: Description of the Model and Tidal Analysis," Estuarine, Coastal and Shelf Sci 31, 231-53, (1990).

10. B. Galperin and G. L. Mellor, "A Time-Dependent, Three-Dimensional Model of the Delaware Bay and River System, Part 2: Three-Dimensional Flow Fields and Residual Circulation," Estuarine, Coastal and Shelf Sci. 31, 255-81 (1990).

11. G. C. van Dam, "Two-and Three-Dimensional Models of Dispersion Based Upon Measurements in the North Sea," Wat. Sci. Tech. 24(10), 45-53 (1991).

12. R. Spanhoff and J. M. de Kok, "3-D Model and Field Studies of Silt Transport in the Dutch Coastal Zone of the North Sea with Emphasis on Dump Sites," Wat. Sci. Tech. 24(10), 39-43 (1991).

13. J. J. Leendertse, R. C. Alexander, and S. K. Liu, A Three-Dimensional Model for Estuaries and Coastal Seas, R-1417-OWRR, Vol. 1, The Rand Corporation, Santa Monica, Calif. 1973. 


\section{REFERENCES (cont)}

14. P. D. Bates and M. G. Anderson, "A Two-Dimensional Finite-Element Model for River Flow Inundation," Proc. R. Soc. Lond. A 440, 481-91 (1993).

15. W. E. Dunn, A. J. Policastro, and R. A. Paddock, Surface Thermal Plumes; Evaluation of Mathematical Models for the Near and Complete Field, ANL/WR-75-3, Argonne National Laboratory, Chicago, 1975.

16. J. J. McGuirk and D. B. Spalding, "Mathematical Modeling of Thermal Pollution in Rivers," in Proc. Int. Conf. on Math. Models for Environmental Problems, Southampton, United Kingdom, September 1975.

17. A. K. Rastogi and W. Rodi, "Predictions of Heat and Mass Transfer in Open Channels," J. of the Hydraul. Div., ASCE, No. HY3, 397-420 (1978).

18. N. R. B. Olsen, "SSIM-A Three-Dimensional Numerical Model for Simulation of Water and Sediment Flow," presented at HYDROSOFT-94, Port Carras, Greece, September 1994.

19. N. R. B. Olsen and S. M. Stokseth, "Three-Dimensional Modeling of Hydraulic Habitat in Rivers with Large Bed Toughness," presented at IAHR Conference on Habitat Hydraulics, Trondheim, Norway, August 1994.

20. K. A. Rose et al., "Multiple Model Analysis of Sediment Transport and Contaminant Distribution in the Clinch River/Watts Bar Reservoir, Tennessee, USA," Wat. Sci. Tech. 28(8-9), 65-78 (1993).

21. D. M. Borders et al., Hydrologic Data Summary for the Shite Oak Creek Watershed at Oak Ridge National Laboratory, Oak Ridge, Tennessee (January-December 1992), ORNL/ER-166, Martin Marietta Energy Systems, Inc., Oak Ridge Natl. Lab., June 1993.

22. E. G. Struxness et al., Comprehensive Report of the Clinch River Study, ORNL-4035, Union Carbide Corp., Oak Ridge Natl. Lab., April 1967.

23. L. K. Ewing, "Suspension and Sedimentation Inflows to Watts Bar Reservoir," TVA Resource Group, Engineering Services, Hydraulic Engineering, [ NEED location of publisher], 1993.

24. L. K. Ewing, Suspended-Sediment Inflows to Watts Bar Reservoir, WR28-3-14-105, TVA Resource Group, Engineering Services, [location of publisher], 1993. 


\section{Appendix A. USER FORTRAN}

The following pages contain a FORTRAN listing of subroutined USRSRC and USRPRT that were supplied to CFDS-FLOW3D to simulate the dye study transient. Subroutine USRSRC is used to write out the hydraulic conditions at CRMs 20.8, 19.6, 18.0,16.5, and 14.5 and to introduce the dye as a source term into the user scalar equation during the first $1500 \mathrm{~s}(25 \mathrm{~min})$ of the simulation. Subroutine USRPRT outputs the dye concentrations at six cross-stream locations for CRMs 19.6, 18.0, 16.5, and 14.5, and at six axial depths for each cross-stream location to facilitate comparison against the measured data.

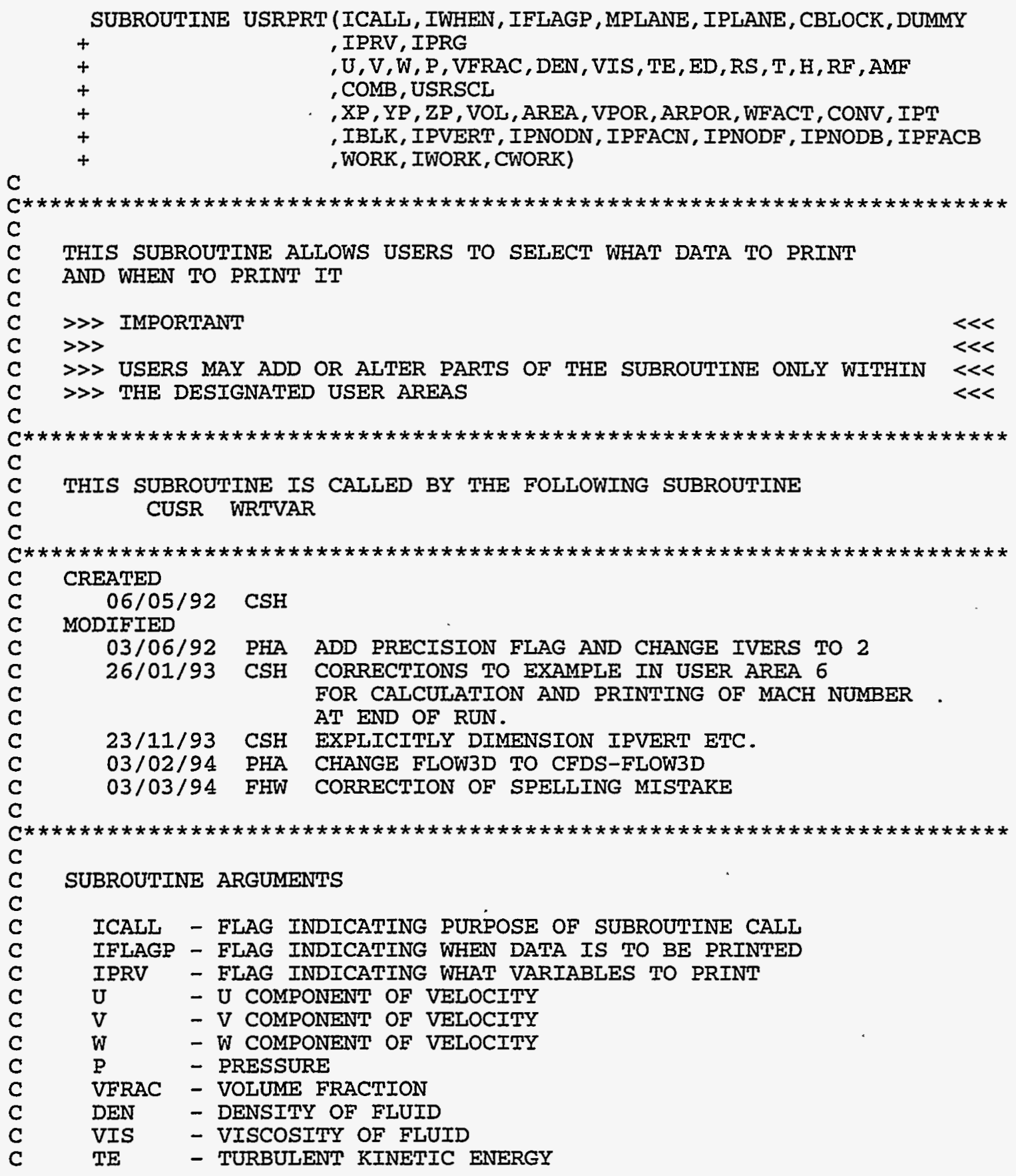









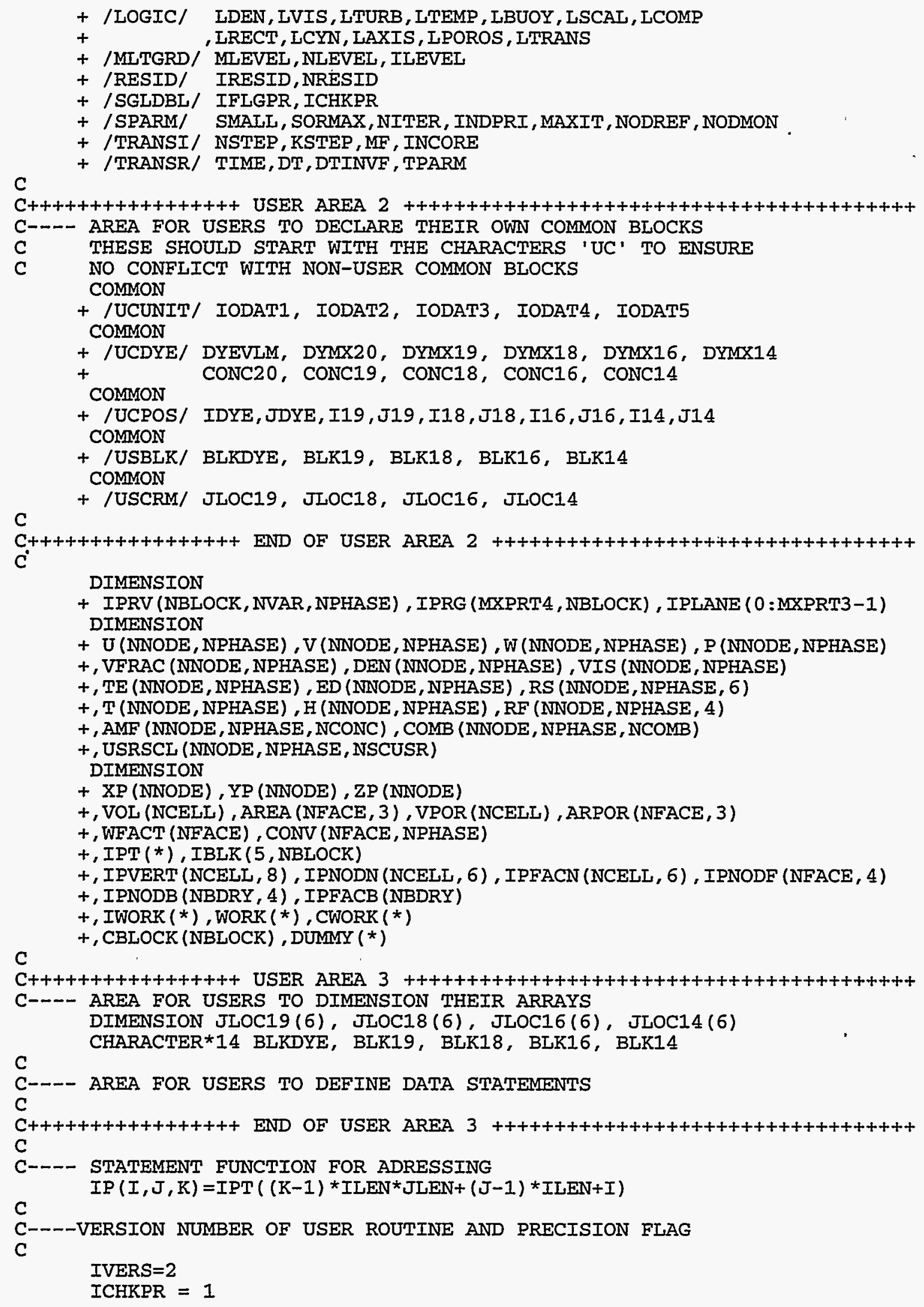


C

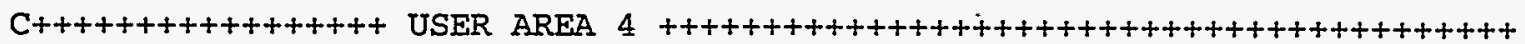
C---- TO USE THIS USER ROUTINE FIRST SET IUSED $=1$

C IUSED $=1$ IF (IUSED.EQ.0) RETURN

$\mathrm{C}$

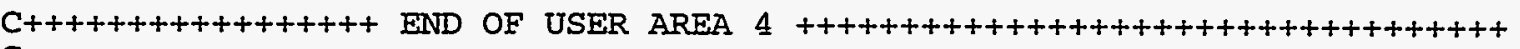
C

C---- FRONTEND CHECKING OF USER ROUTINE IF (IUCALI.EQ.0) RETURN

C IF (ICAII.EQ.1) THEN

C

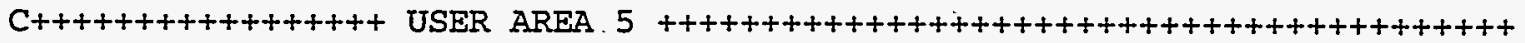

C

c

IWHEN

$=1$ INITIALISATION

$=2$ END OF ITERATION - NITER

IWHEN

IWHEN

$=3$ END OF TIME STEP - KSTEP

$=4$ END OF RUN

IFLAGP

$=1$ PRINT DATA ON THIS CALL

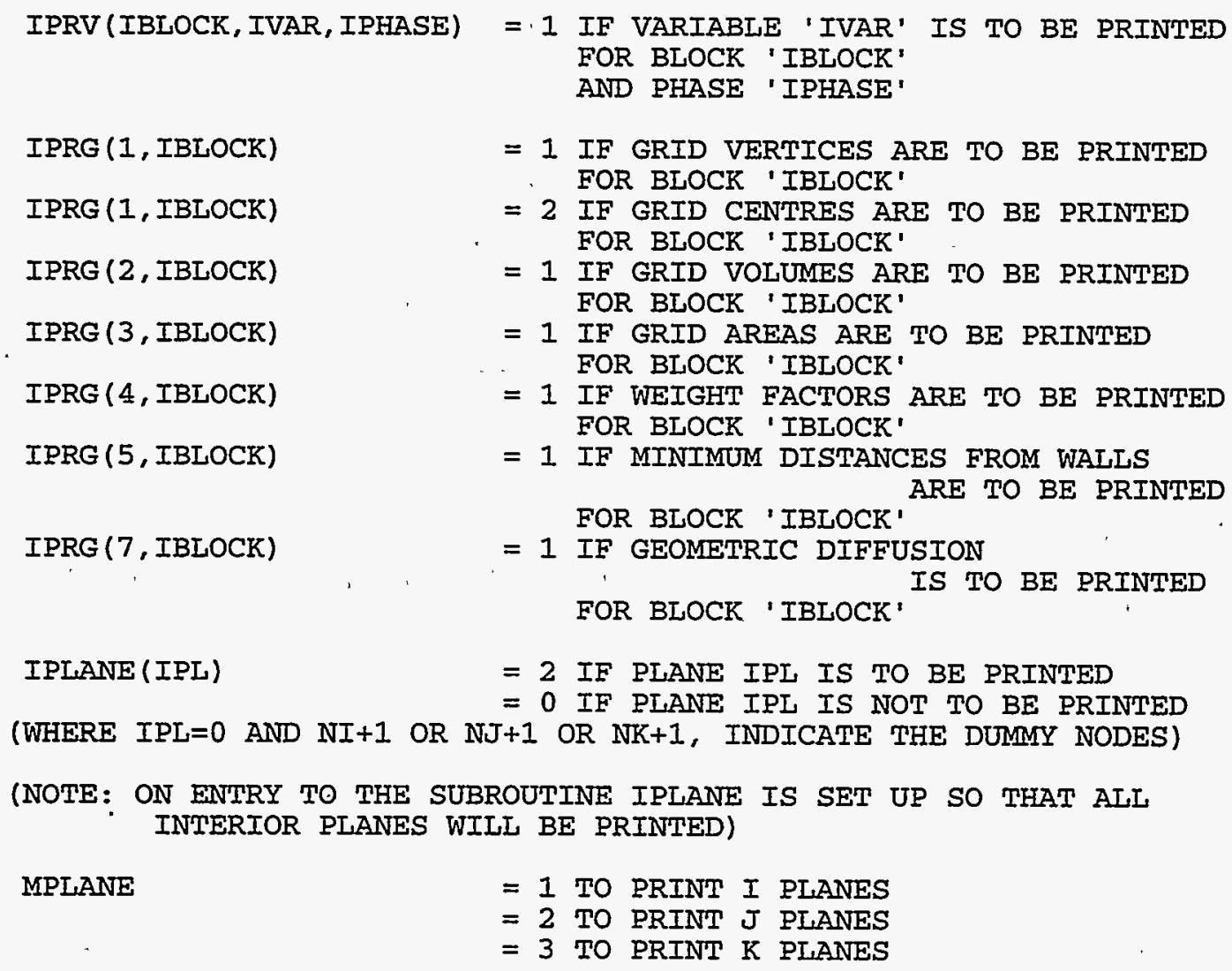

(NOTE: ON ENTRY TO THE SUBROUTINE MPLANE = 3 FOR DEFAULT PRINTING)

IF (IWHEN.EQ.3) THEN

CALI GETADD ('USRPRT', 'XNN ', 'XC ', ILEVEL, JXC)

CALL GETADD ('USRPRT', 'XNN ', 'YC ', ILEVEL, JYC) 


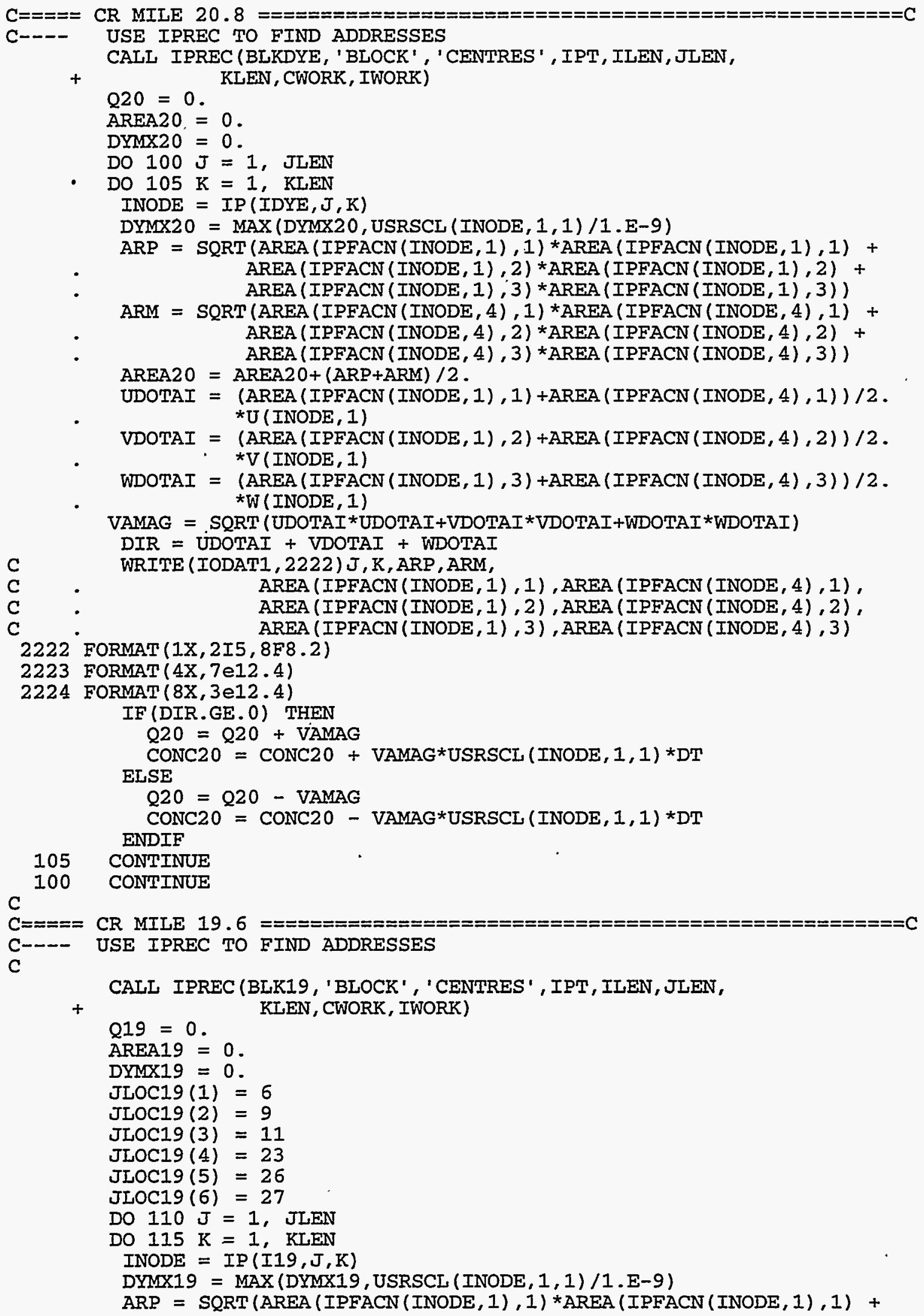




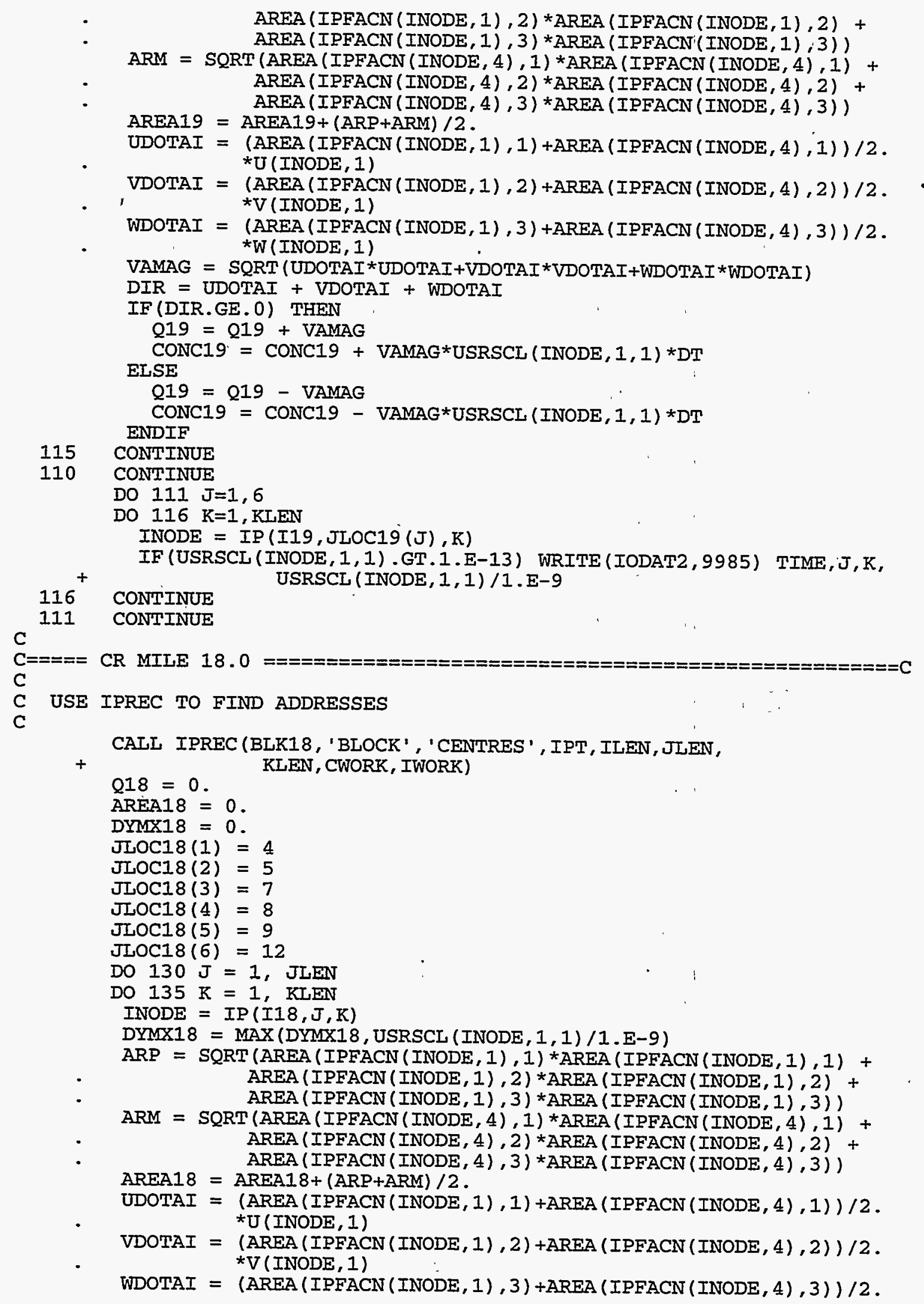




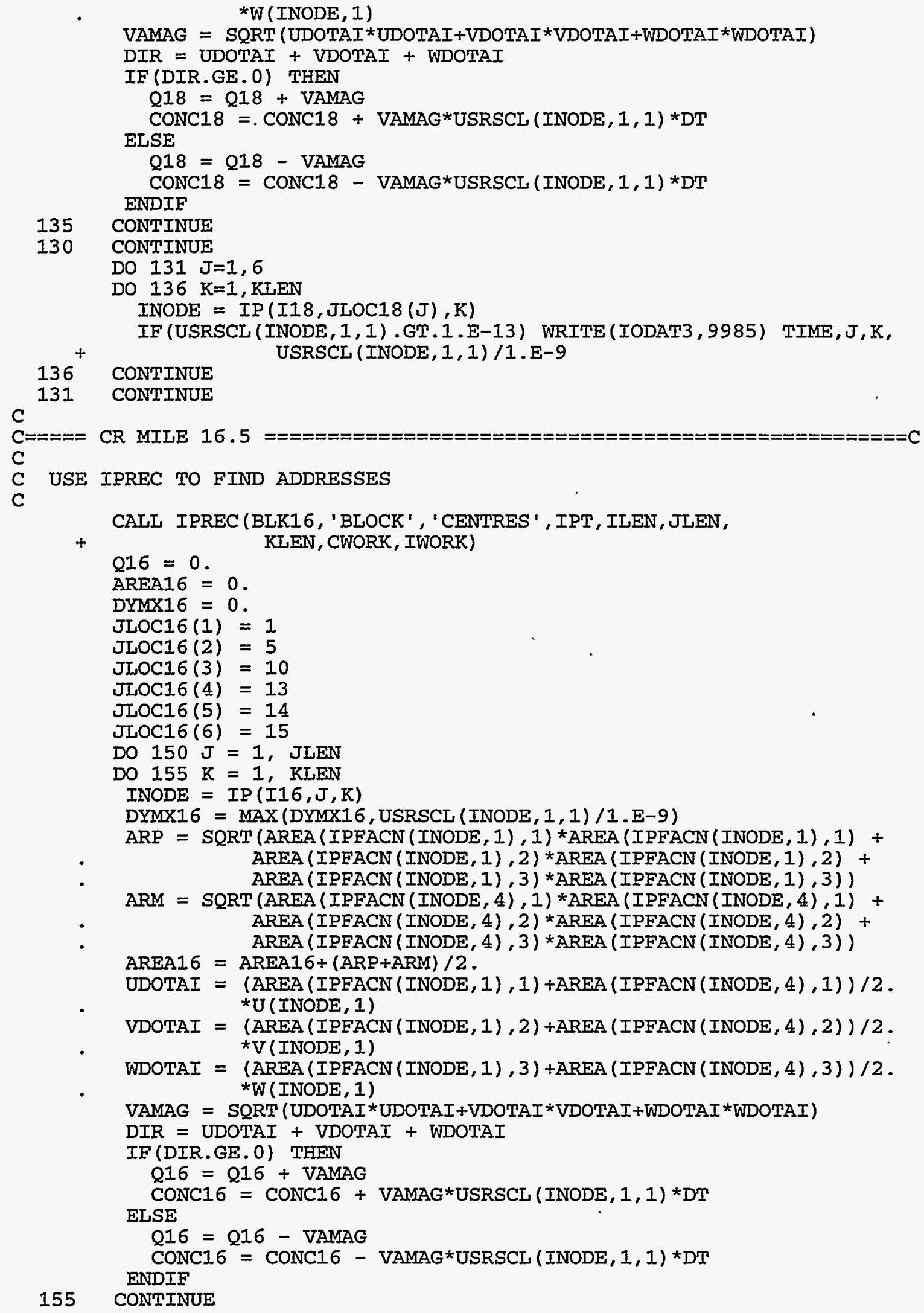




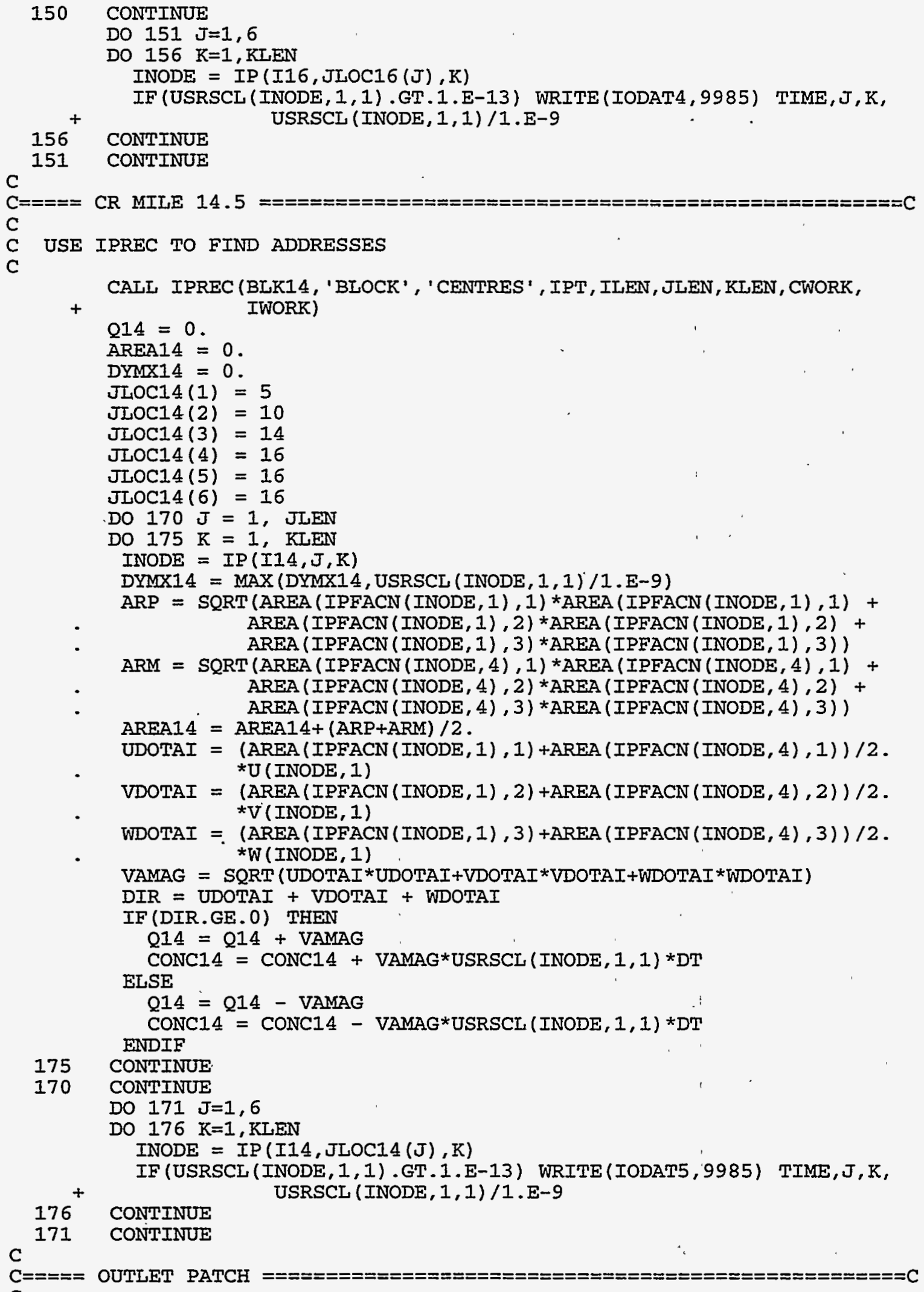




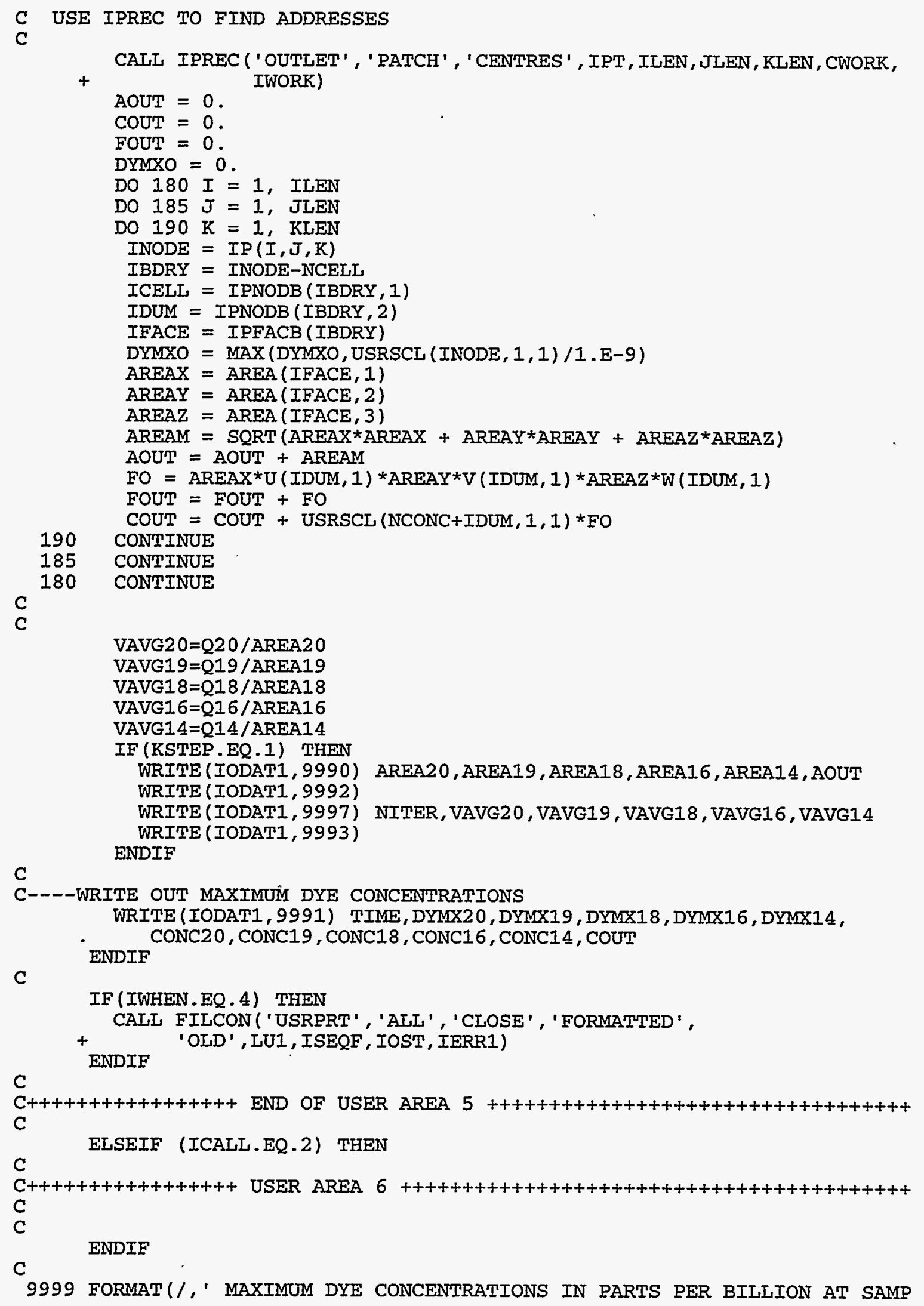




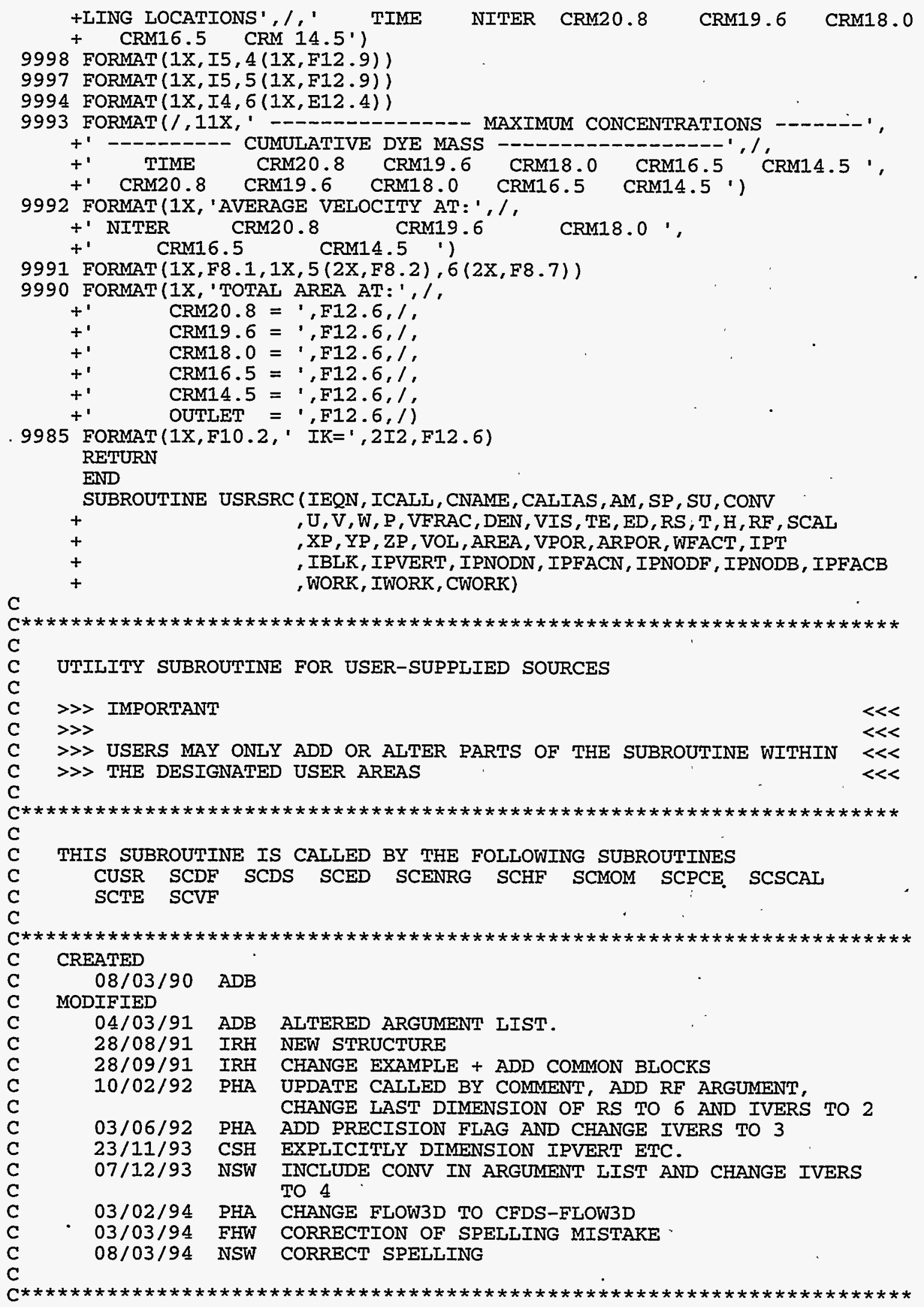




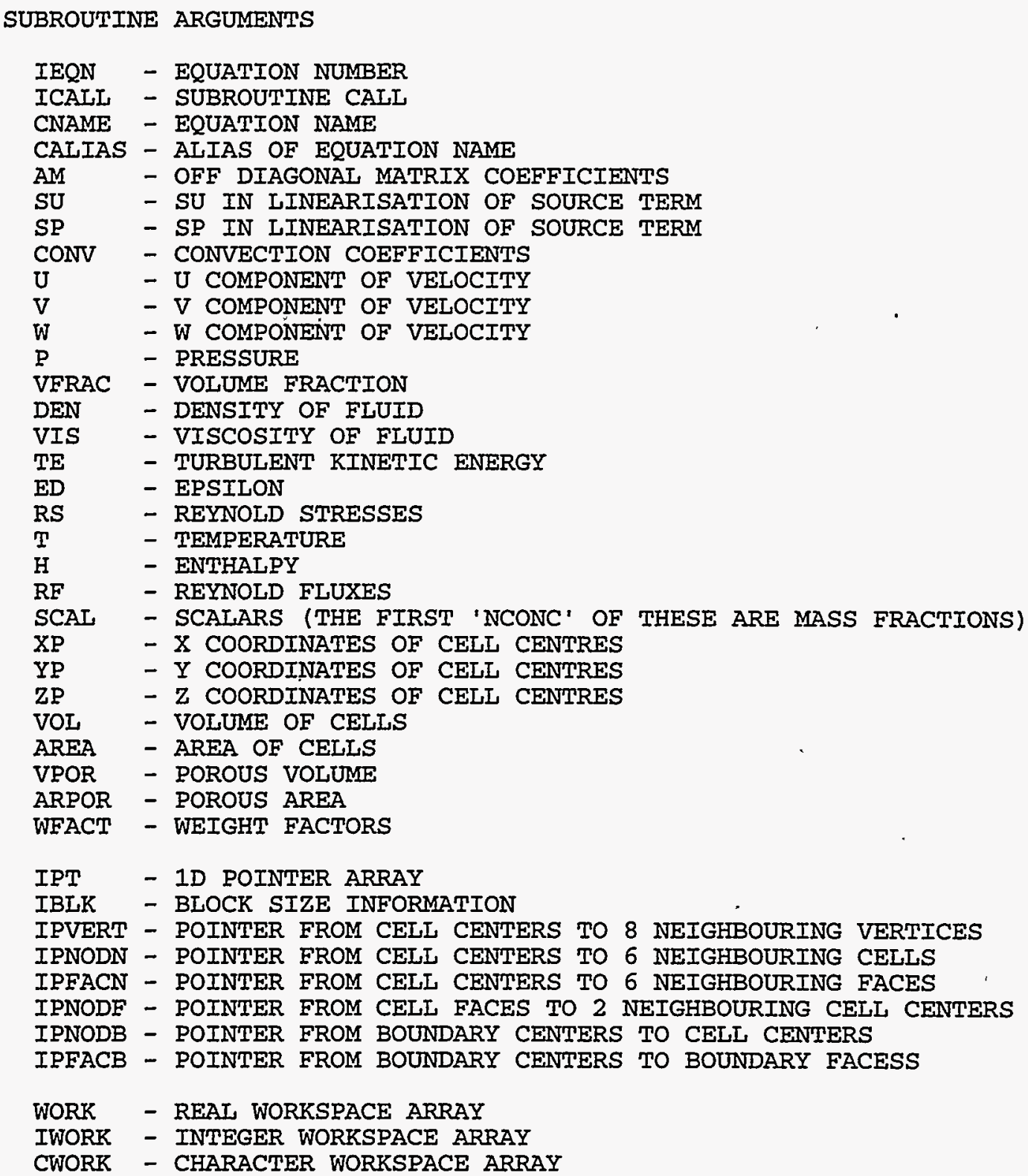




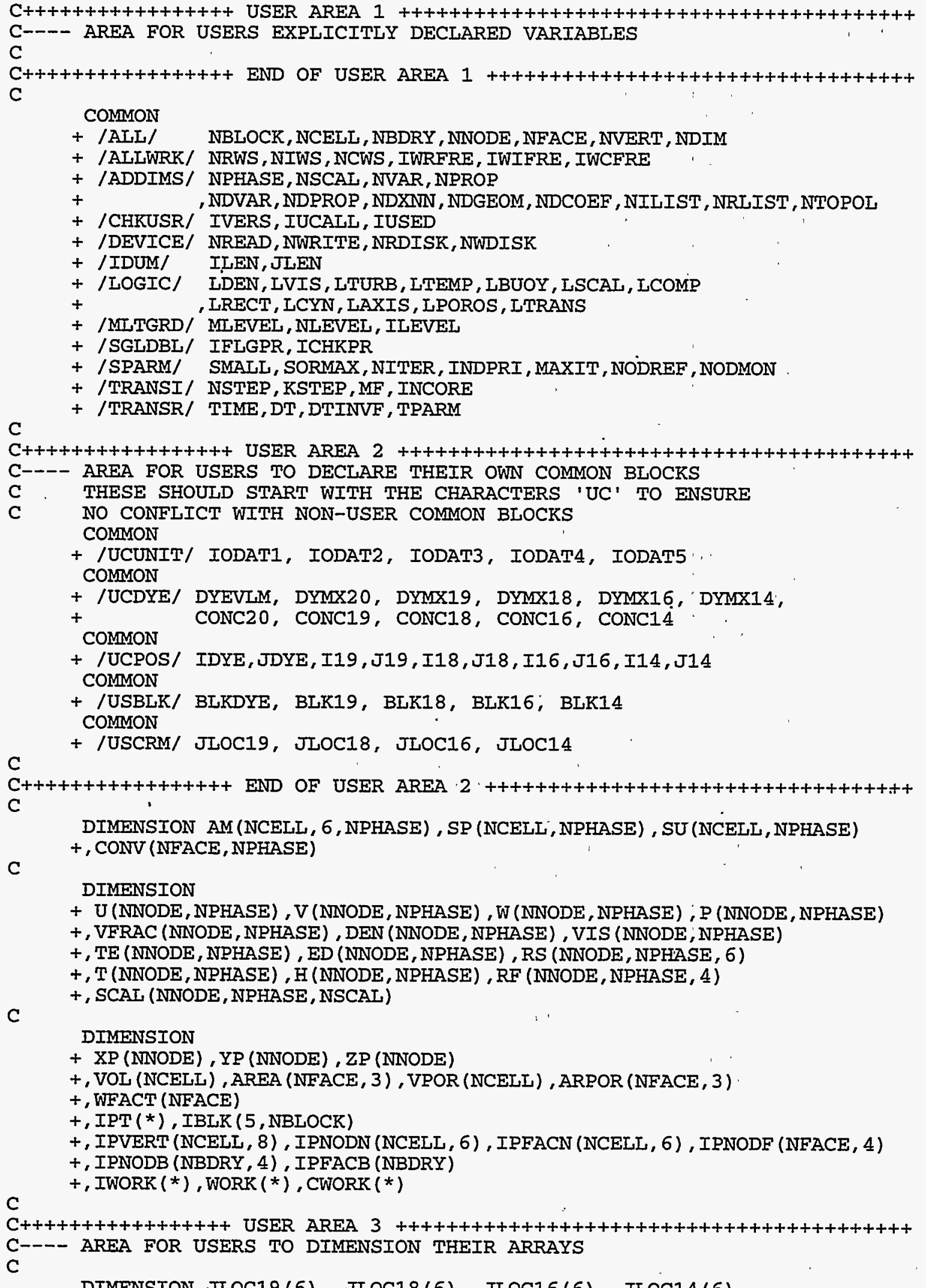
DIMENSION JLOC19(6), JLOC18(6), JLOC16(6), JLOC14(6) 


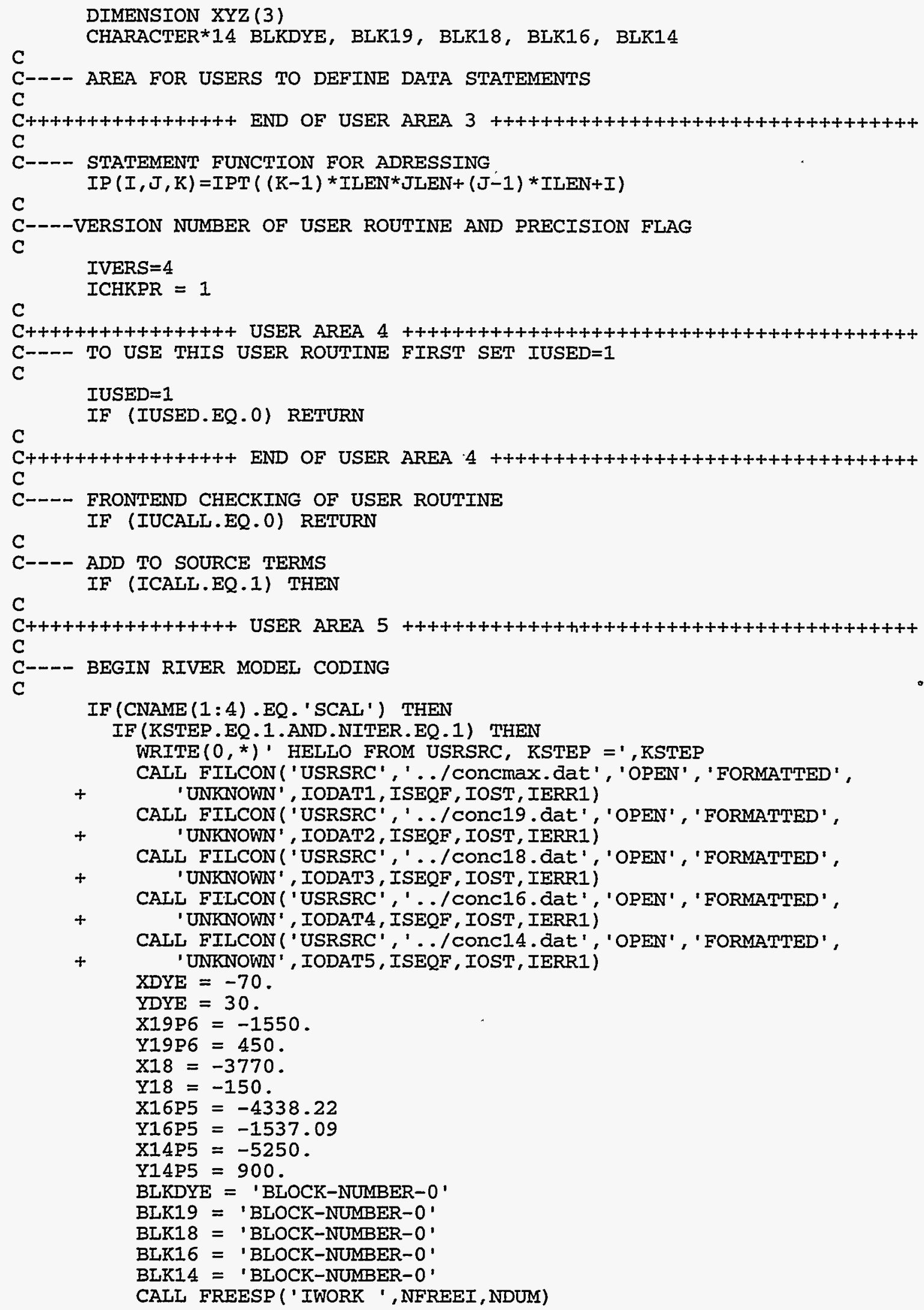


CALL FREESP ('WORK ' NFREER, NDUM)

ILIMI $=($ NFREEI - NVERT -I $) / 2$

ILIMR $=$ NFREER/24

MAXPOL = MIN (NCELI, ILIMI, ILIMR)

CALI SETWRK ('USRSRC', 'IWORK ','ISIDE ', NVERT, JSIDE)

CALL SETWRK ('USRSRC', 'IWORK ',' ICMAP ', MAXPOL, JCMAP)

CALL SETWRK ('USRSRC', 'IWORK ', 'NVRT ',MAXPOL+1, JNVRT)

CALI SETWRK ('USRSRC', 'WORK ', 'VERT ', 24 *MAXPOL, JVERT)

CALI GETADD ('USRSRC', 'ITOPOL', 'ISOLID', ILEVEL, JSOLID)

CALL GETADD ('USRSRC', 'ITOPOL', 'INDBLK' , ILEVEL, JNDBLK)

CALI GETBCS ('USRSRC', 'BLKBDY', ILEVEL, NDUM1, NDUM2, NCVBLK, ISTBDY)

CALL GETADD ('USRSRC', 'XNN ', 'XC ', ILEVEL, JXC)

CALL GETADD ('USRSRC', 'XNN ',' 'YC ', ILEVEL, JYC)

CALL GETADD ('USRSRC', ' XNNN ', ' ZC ' , ILEVEL, JZC)

CALL GETADD ('USRSRC', 'ITOPOL', 'IPVERT', ILEVEL', JPVERT)

C

$\mathrm{XYZ}(1)=\mathrm{XDYE}$

$\mathrm{XYZ}(2)=\mathrm{YDYE}$

$\mathrm{XYZ}(3)=-0.2$

CALL FXYZ (XYZ, WORK (JXC), WORK (JYC), WORK (JZC), IWORK (JPVERT) IWORK (JSIDE), IWORK (JCMAP), IWORK (JNVRT), WORK (JVERT', IWORK (JSOLID) , IWORK (JNDBLK) , NCVBLK, MAXPOL, INODE)

CALI BLKIJK (IBLK, INODE, NBLK, II, JI, KI)

NODDYE = INODE

IDYE $=I 1$

$\mathrm{JDYE}=\mathrm{J} 1$

WRITE $(0,9995)$

WRITE $(0,9996)$ 'CRM20.8', NBLK, IDYE, JDYE

WRITE (BLKDYE (14:14), 9997) NBLK

$\mathrm{XYZ}(1)=\mathrm{X} 19 \mathrm{P} 6$

$\mathrm{XYZ}(2)=\mathrm{Y} 19 \mathrm{P} 6$

$X Y Z(3)=-0.2$

CALL FXYZ (XYZ, WORK (JXC), WORK (JYC), WORK (JZC), IWORK (JPVERT), IWORK (JSIDE), IWORK (JCMAP), IWORK (JNVRT) ,WORK (JVERT), IWORK (JSOL ID), IWORK (JNDBLK), NCVBLK, MAXPOL, INODE)

CALL BLKIJK (IBLK, INODE, NBLK, I1, J1, KI)

NOD19 = INODE

$I I 9=I 1$

$\mathrm{J} 19=\mathrm{J} 1$

WRITE $(0,9996)$ 'CRM19.6', NBLK, I19, J19

WRITE (BLK19 (14:14), 9997) NBLK

$\mathrm{XYZ}(1)=\mathrm{X} 18$

$\mathrm{XYZ}(2)=\mathrm{Y} 18$

$X Y Z(3)=-0.2$

CALI FXYZ (XYZ, WORK (JXC), WORK (JYC), WORK (JZC), IWORK (JPVERT), IWORK (JSIDE), IWORK (JCMAP) , IWORK (JNVRT) , WORK (JVERT), IWORK (JSOLID), IWORK (JNDBLK), NCVBLK, MAXPOL, INODE)

CALI BLKIJK (IBLK, INODE, NBLK, I1, J1, K1)

NOD18 = INODE

$I 18=I 1$

$\mathrm{J} 18=\mathrm{J} 1$

WRITE $(0,9996)$ 'CRMI 8.0 ', NBLK, I18, J18

WRITE (BLK18 (14:14), 9997) NBLK

$\mathrm{XYZ}(1)=\mathrm{X} 16 \mathrm{P} 5$

$\mathrm{XYZ}(2)=\mathrm{Y} 16 \mathrm{P} 5$

$X Y Z(3)=-0.2$

CALI FXYZ ( $X Y Z$, WORK (JXC), WORK (JYC), WORK (JZC), IWORK (JPVERT) , IWORK (JSIDE) , IWORK (JCMAP) , IWORK (JNVRT), WORK (JVERT), CALI BLKIJK (IBLK, INODE, NBLK, I1, JI, KI)

NOD16 = INODE 


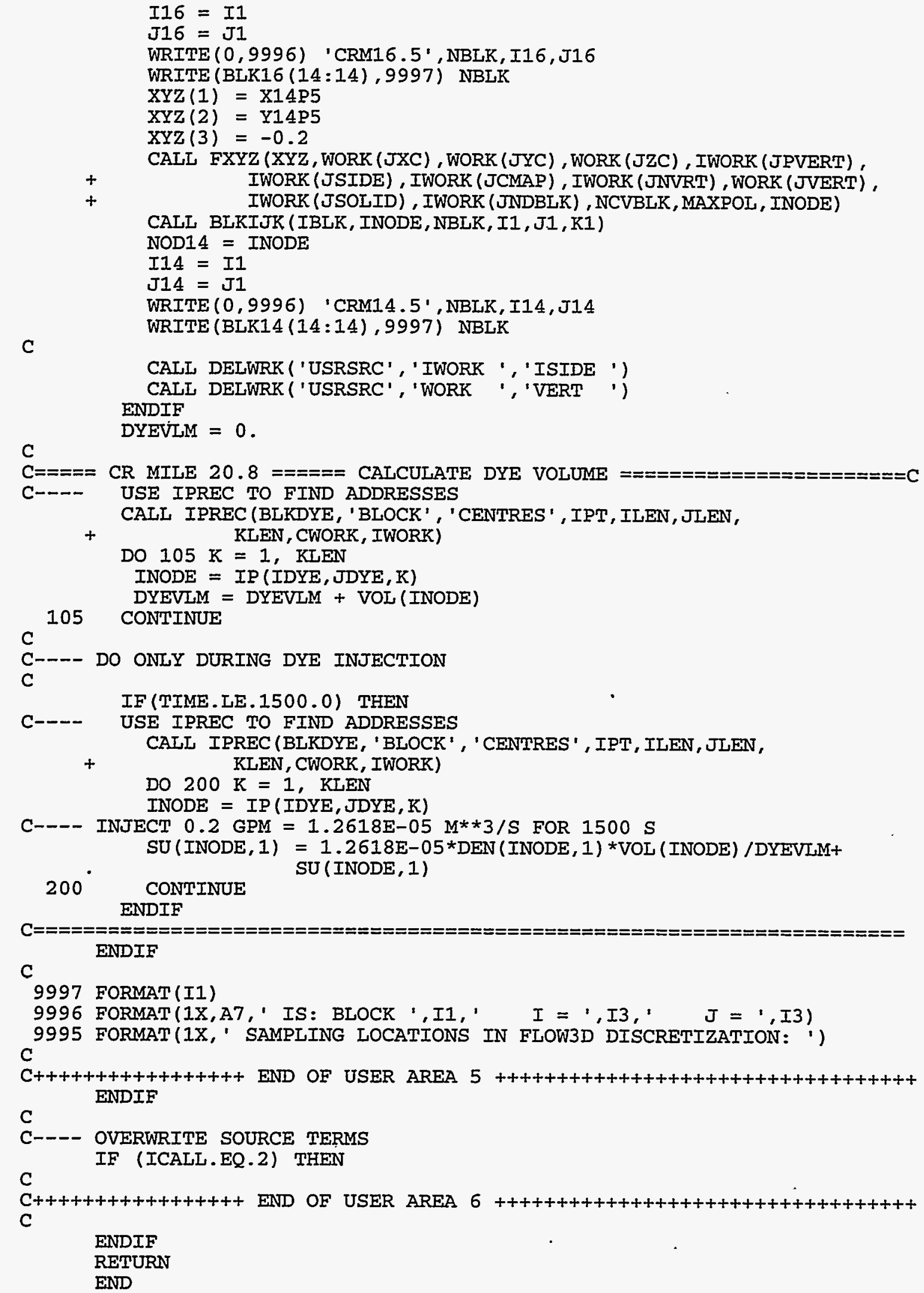

C DYEVIM $=0$.

$\mathrm{C}=====\mathrm{CR}$ MILE $20.8======$ CALCULATE DYE VOLUME $====================0$

C-- - USE IPREC TO FIND ADDRESSES

CALL IPREC (BLKDYE, 'BLOCK', ' CENTRES' , IPT, ILEN, JLEN,

$+\quad$ KLEN, CWORK, IWORK)

DO $105 K=1$, KLEN

INODE $=\operatorname{IP}($ IDYE, JDYE, K)

105 CONTINUE

DYEVLM = DYEVLM + VOL (INODE)

C

C---- DO ONLY DURING DYE INJECTION

IF (TIME.LE.1500.0) THEN

C--- USE IPREC TO FIND ADDRESSES

CALL IPREC (BLKDYE, 'BLOCK', 'CENTRES', IPT, ILEN, JLEN,

$+\quad$ KLEN, CWORK, IWORK)

DO $200 \mathrm{~K}=1$, KLEN

INODE = IP (IDYE, JDYE, K)

$\mathrm{C}----$ INJECT $0.2 \mathrm{GPM}=1.2618 \mathrm{E}-05 \mathrm{M} * * 3 / \mathrm{S}$ FOR $1500 \mathrm{~S}$

SU (INODE, 1) $=1.2618 \mathrm{E}-05 * \mathrm{DEN}$ (INODE, 1) *VOL (INODE) /DYEVLM+

$200^{\circ}$ CONTINUE

SU ( INODE, 1)

ENDIF

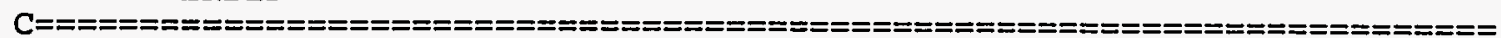
ENDIF

C

9997 FORMAT (I1)

9996 FORMAT (1X,A7,' IS: BLOCK ',II,' $I=$ ',I3,' $J='$, I3) C

9995 FORMAT (1X,' SAMPLING LOCATIONS IN FLOW3D DISCRETIZATION: ')

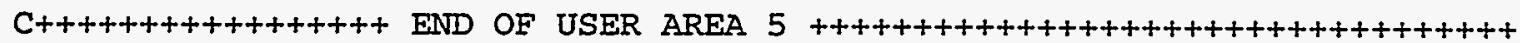
ENDIF

C---- OVERWRITE SOURCE TERMS

IF (ICALL.EQ.2) THEN

C

$\mathrm{C}+++++++++++++++++$ END OF USER AREA $6++++++++++++++++++++++++++++++++++$ C

ENDIF

RETURN

END 



\section{INTERNAL DISTRIBUTION}

\section{Y.S. Bao}

2. A. L. Brenkert

3. K. W. Childs

4. J. H. Clinton

5. R. B. Cook

6. W. K. Crowley

7. J. R. Dixon

8. D. M. Hetrick

9. J. A. Hoffmeister

10. M. A. Kuliasha

11. J. J. Maddox

12-16. J. H. Platfoot

17. M. J. Taylor

18-22. M. W. Wendel

23. P. T. Williams

24. Laboratory Records Department

25. Laboratory Records, ORNL-RC

26. Central Research Library

\section{EXTERNAL DISTRIBUTION}

27. Office of Scientific and Technical Information, P.O. Box 62, Oak Ridge, TN 37831. 